\title{
Unraveling postgraduate communication learning: from transfer to transformative learning
}

Citation for published version (APA):

van den Eertwegh, V. P. M. (2015). Unraveling postgraduate communication learning: from transfer to transformative learning. [Doctoral Thesis, Maastricht University]. Datawyse / Universitaire Pers Maastricht. https://doi.org/10.26481/dis.20151111ve

Document status and date:

Published: 01/01/2015

DOI:

10.26481/dis.20151111ve

Document Version:

Publisher's PDF, also known as Version of record

\section{Please check the document version of this publication:}

- A submitted manuscript is the version of the article upon submission and before peer-review. There can be important differences between the submitted version and the official published version of record.

People interested in the research are advised to contact the author for the final version of the publication, or visit the DOI to the publisher's website.

- The final author version and the galley proof are versions of the publication after peer review.

- The final published version features the final layout of the paper including the volume, issue and page numbers.

Link to publication

\footnotetext{
General rights rights.

- You may freely distribute the URL identifying the publication in the public portal. please follow below link for the End User Agreement:

www.umlib.nl/taverne-license

Take down policy

If you believe that this document breaches copyright please contact us at:

repository@maastrichtuniversity.nl

providing details and we will investigate your claim.
}

Copyright and moral rights for the publications made accessible in the public portal are retained by the authors and/or other copyright owners and it is a condition of accessing publications that users recognise and abide by the legal requirements associated with these

- Users may download and print one copy of any publication from the public portal for the purpose of private study or research.

- You may not further distribute the material or use it for any profit-making activity or commercial gain

If the publication is distributed under the terms of Article $25 \mathrm{fa}$ of the Dutch Copyright Act, indicated by the "Taverne" license above, 


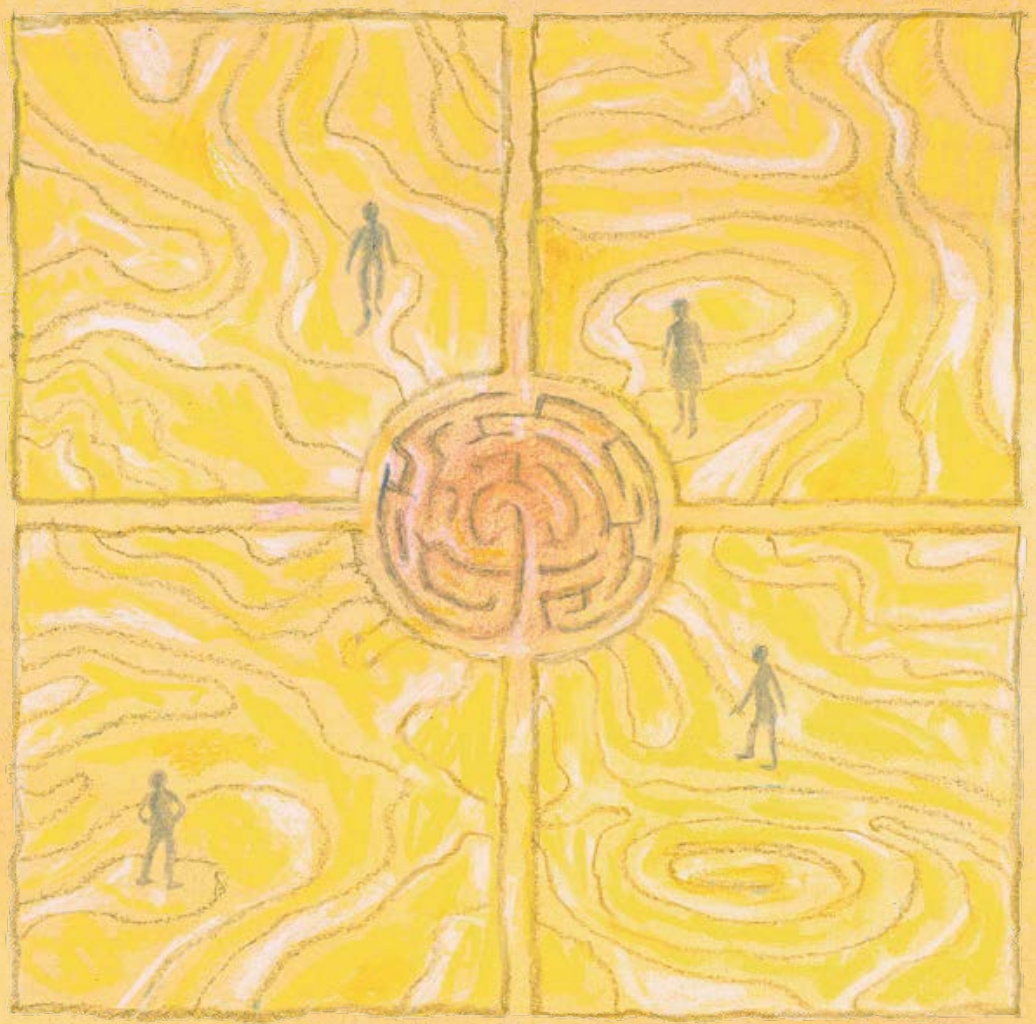

\title{
UNRAVELLING POSTGRADUATE COMMUNICATION LEARNING
}

from transfer to transformative learning

\author{
VALERIE VAN DEN EERTWEGH
}


The research reported here has been carried out at

14 Maastricht University in Leading inng!

In the School of Health Professions Education

C copyright V. van den Eertwegh, Maastricht 2015

Printing: Datawyse | Universitaire Pers Maastricht ISBN: 9789461594815 


\title{
Unravelling postgraduate communication learning: \\ From transfer to transformative learning
}

\author{
PROEFSCHRIFT \\ ter verkrijging van de graad van doctor \\ aan de Universiteit Maastricht \\ op gezag van Rector Magnificus Prof. Dr. L.L.G. Soete \\ volgens het besluit van het College van Decanen, \\ in het openbaar te verdedigen \\ op woensdag 11 november 2015, om 12.00 uur \\ door
}

Valerie Philomène Marie van den Eertwegh

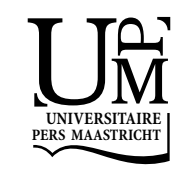




\section{Supervisor}

Prof. dr. A. Scherpbier

Prof. dr. C. van der Vleuten

Prof. dr. S. van Dulmen, Radboud Universiteit / Nivel Utrecht (co-supervisor)

dr. J. van Dalen

\section{Beoordelingscommissie}

Prof. dr. JJ Rethans (chairman)

Prof. dr. I. Heyligers

Prof. dr. R. Koopmans

dr. A. Kramer. Leids Universitair Medisch Centrum

dr. E. van Weel-Baumgarten, Radboud Nijmegen 
All learners construct knowledge from an inner scaffolding of their individual and social experiences, emotions, will, aptitudes, beliefs, values, self-awareness, purpose, and more.... If you are learning, what you understand is determined by how you understand things, who you are and what you already know.

Peter Senge (founder of Society for Organizational Learning, Massachusetts Institute of Technology). 



\section{Content}

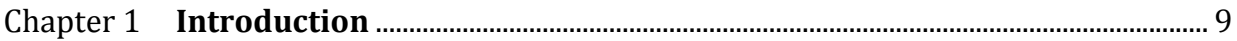

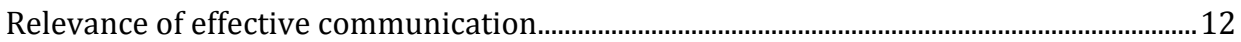

Challenges in medical communication skills training ...........................................................12

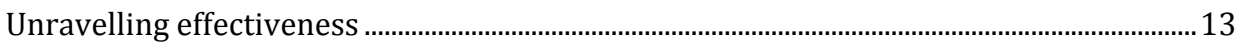

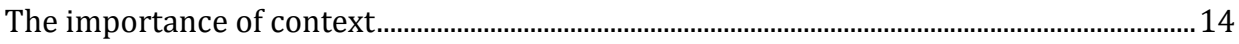

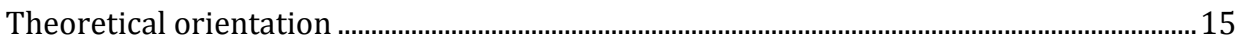

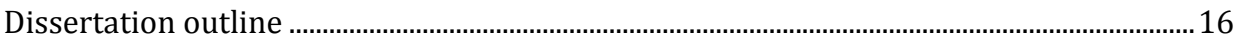

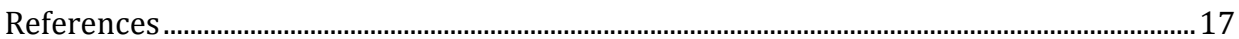

Chapter 2 Learning in context: Identifying gaps in research on the transfer of medical communication skills to the clinical workplace .................................21

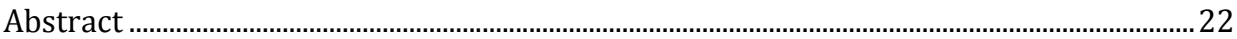

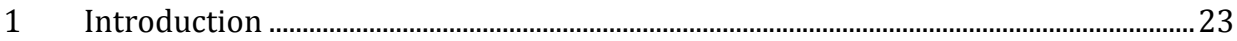

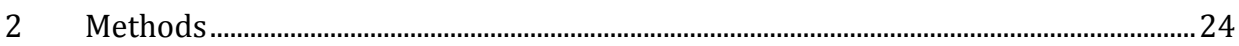

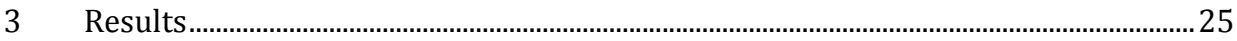

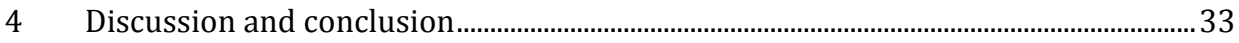

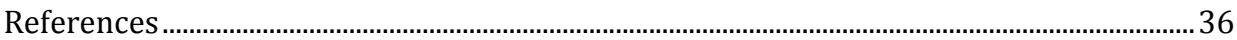

Chapter 3 Residents' perceived barriers to communication skills learning: comparing two medical work contexts in postgraduate training ...................39

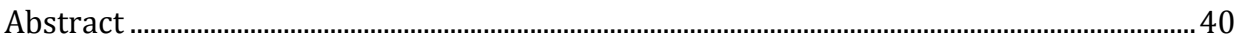

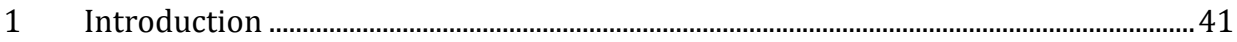

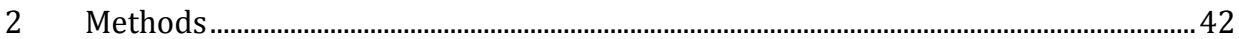

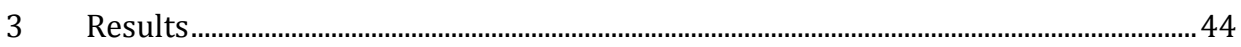

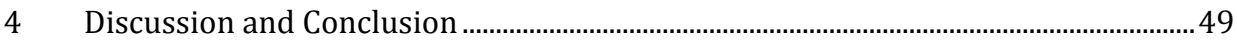

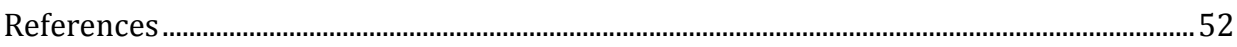

Chapter 4 Exploring residents' communication learning process in the workplace: A five-phase model ..........................................................................55

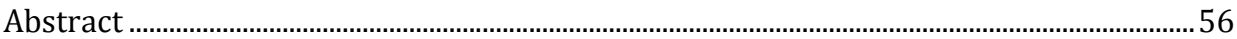

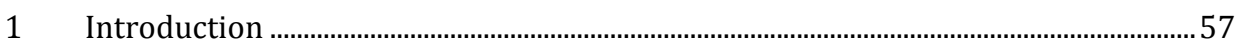

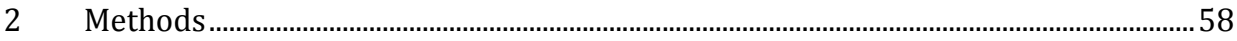

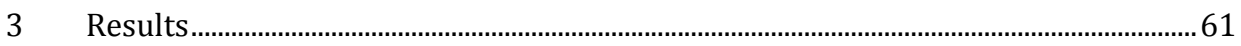

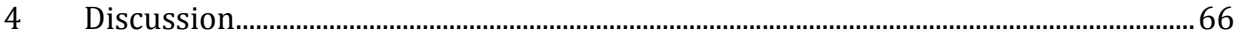

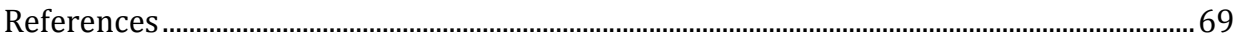

Chapter 5 Transformative learning in clinical communication:

Creating the opportunity to know thyself ............................................................73

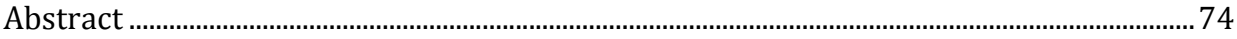

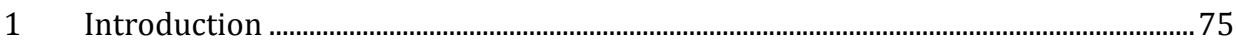

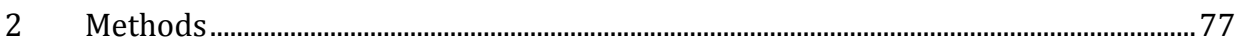




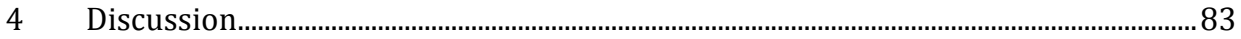

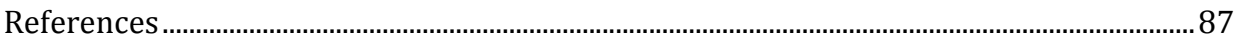

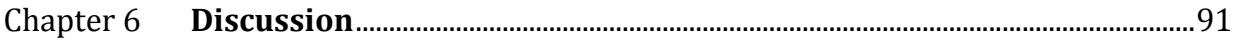

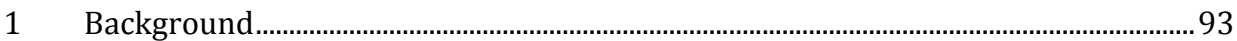

$2 \quad$ Main results in relation to existing research gaps...........................................................93

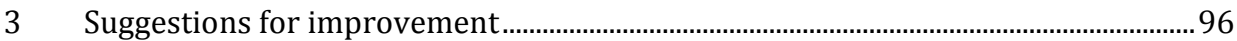

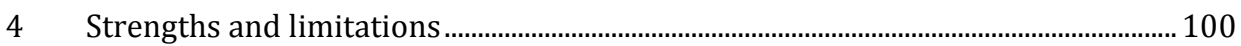

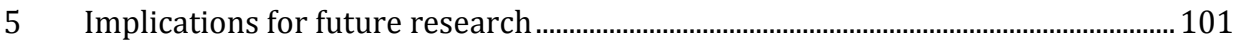

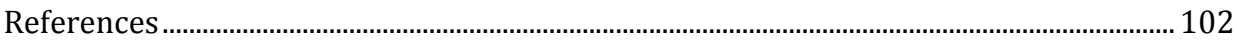

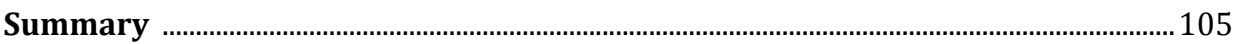

Chapter 1: Introduction ...................................................................................................... 107

Chapter 2: Learning in context - Identifying gaps in research on the transfer of medical communication skills to the clinical workplace.............................................. 107

Chapter 3: Residents' perceived barriers to communication skills learning Comparing two medical work contexts in postgraduate training ...

Chapter 4: Exploring residents' communication learning process in the workplace

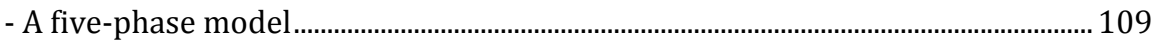

Chapter 5: Transformative learning in clinical communication - Creating the opportunity to know thyself...................................................................................... 110

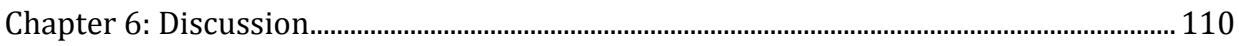

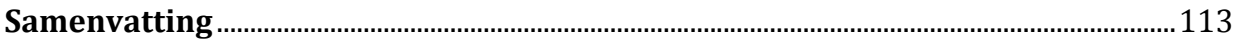

Hoofdstuk 1: Introductie ......................................................................................................... 115

Hoofdstuk 2: Leren in context - lacunes in onderzoek rondom transfer van medische communicatievaardigheden van training naar de klinische praktijk

Hoofdstuk 3: Barrières in het communicatieleerproces volgens AIOS - een vergelijking van twee medische werkplekken in de vervolgopleiding ................... 116

Hoofdstuk 4: Het communicatieleerproces op de werkvloer ontrafeld - een vijffasen model

Hoofdstuk 5: Transformerend leren van communicatie in een ziekenhuiscontext creëer de mogelijkheid voor zelfinzicht...................................................................... 118

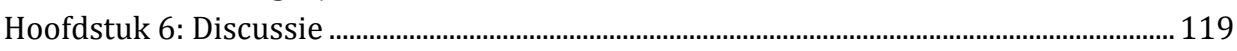

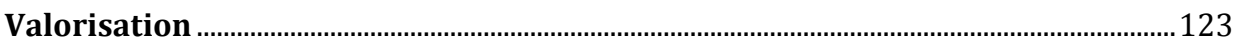

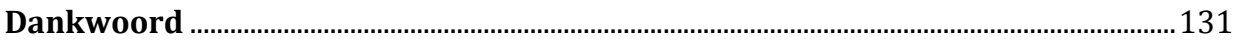

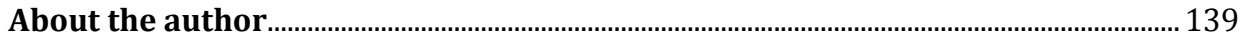

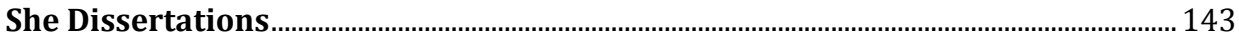


Chapter 1

\section{Introduction}



1. In my clinic I see a child who is suffering from brain injury caused by a collision with a car a couple of months ago. The child has since had a hard time keeping pace with his classmates and has fallen well behind. During the consultation it becomes clear to me that the parents are in the process of getting a divorce and are fighting a lot. To be able to send the child to a school for physically handicapped children, I need permission from both parents, and I discuss this with the mother and grandmother (in the presence of a supervisor). During my break I call the father. The next day, the grandmother calls me in a fury, "what were you thinking to ring the father?" I feel myself turning red, and, having the stress of an overcrowded waiting room at the back of my mind, I don't know how best to communicate so as to solve this incident swiftly and efficiently.

2. A fifty-year-old man comes to hear the results of a brain scan after having fainted a couple of times for no apparent reason. The test, however, does not reveal any abnormalities and this is what I tell the patient. The news upsets him and he replies dejectedly that his complaint is not taken seriously. I am having a hard time digesting the emotions in his reaction; as if I as a doctor am doing this to the patient...helping everyone is my single most priority, that is why I chose this profession, but the bounds of my profession do not allow me to help him further. I usually spell this out, but I definitely don't always manage to mitigate patients' strong emotions during a consultation by way of good communication.

The above two narratives are real-life scenarios brought forward by residents during a postgraduate medical communication skills training. By reading these cases it becomes evident and understandable that residents feel a need to improve their communication skills in order to handle such everyday medical situations more effectively. Research focusing on effective ways to learn and improve communication skills in a medical work context is therefore relevant and important. This begs the question, what does such a learning process look like? And what factors help residents in their daily work context to render this learning process effective? The present dissertation addresses these questions and seeks to unravel the process of learning communication skills, thereby shedding light on the factors that influence its effectiveness.

Research has confirmed that residents perceive a need for support in medical communication skills [1-3]. 0' Neill et al. [4], for instance, unveiled that residents feel unprepared and insecure about the emotional involvement with patients. Rider et al. [5] found that less than half of all residents felt confident about their more advanced communication skills such as breaking bad news, dealing with end-of-life issues, and communicating with difficult patients and seriously ill children. Additionally, not only residents, but also experienced staff often feels insufficiently competent to provide adequate support and feedback regarding communication issues [6]. 


\section{Relevance of effective communication}

We first wish to articulate why it is important that this need for support in effective communication skills be recognized. The sentence "No matter how knowledgeable the clinician might be, if he/she is not able to open good communication channels with the patient, he/she may be of no help" [7], captures the crucial role communication plays. There is compelling research evidence pointing toward strong positive relationships between a health care team member's communication skills and a patient's capacity to follow through with medical recommendations, self-manage a chronic medical condition, and adopt preventive health behaviors [8]. Studies conducted during the past three decades reveal that the clinician's ability to explain, listen and empathize can have a profound effect on biological and functional health outcomes as well as on patient satisfaction and experience of care [9-13]. The connection that patients feel with their clinicians can ultimately improve their health, mediated through participation in their care, adherence to treatment, and patient self-management [14-19]. Bensing and Benedetti call this powerful effect of using the appropriate words and adopting the right attitude "the therapeutic effect of good communication" [20,21] and urge doctors to make more conscious use of it for the benefit of increased health outcomes and reduced costs. Larson and Yao [22], moreover, unearthed a direct relationship between clinicians' ability to build rapport and express care and warmth toward patients and their level of satisfaction and burnout. Last but not least, evidence continues to mount that effective communication significantly reduces malpractice claims [23, 24].

Although the patient interview takes center stage in everyday clinical practices, historically, communication skills have received scant attention in the training of clinicians and other health care professionals compared to other clinical tasks. Given the wealth of evidence linking ineffective clinician-patient communication with undesired outcomes, it is of utmost importance that communication skills training is adequately attended to.

\section{Challenges in medical communication skills training}

The question remains, however, whether "good communication" really is teachable. Can doctors learn to wield their communication skills more consciously to achieve this therapeutic effect? It appears that, similar to other health care procedures, communication skills can be learned and improved [8, 25-27]. Taking this knowledge to heart, undergraduate medical schools have gradually incorporated communication skills trainings in the past decade. Many undergraduate medical schools now offer training programs in communication as an integral part of their courses. However, the longterm effectiveness of these training programs should not be taken for granted. Undergraduate students undergo communication skills trainings while they do not yet have regular contact with patients. When entering the clinical phase and being exposed to clinicians' communication styles in real hospital settings, many students experience a 
culture shock: the communication styles of real doctors differ significantly from those preached during undergraduate training $[28,29]$. Considering the strong socialization and adaptation processes that the new setting requires, it is not surprising that students face difficulties transferring the communication skills they learned in medical school to the clinical workplace [28]. Why is there such little concordance between undergraduate communication skills training programs and real medical practice?

As for postgraduate education, we find that it is not common for residencies, general practice excepted, to include communication skills trainings in their programs [30, 31]. Moreover, when such trainings are offered, this is mostly done off-site without departmental embedment. Studies on the effectiveness of these off-site training programs have reported contradictory and variable findings [32-38]. These ambiguous results have incentivized researchers to search for explanations and alternative approaches to teaching, learning and assessing communication skills. Over the past 40 years, this search has evolved in such a way that a continuum between two stances gradually developed [39]: on the one extreme we find researchers describing and measuring physician communication behaviors and designing and testing interventions to improve these; on the other extreme of the spectrum we find those accentuating the prerequisites for communication competencies, such as self-awareness, reflection, compassion, and self-growth objectives. In order to develop good communication skills, a mixture of both stances seems desirable [40-48]. Interestingly, however, there is at present a paucity of research specifically exploring how doctors learn, develop and hone this mixture of aspects during medical practice. Besides, much is assumed about the process of learning communication skills, while few have sought to investigate this process by exploring learners' own experiences. This knowledge gap formed the main incentive for starting the research reported in this dissertation. Hence, throughout our research, we took an interest in explaining why present-day communication skills learning and teaching practices often lack long-term effectiveness.

\section{Unravelling effectiveness}

Upon scrutiny of the literature regarding effectiveness of postgraduate communication skills trainings, it became clear that the concept of effectiveness itself merits further elucidation. More specifically, we found that the literature distinguished four different levels of training effectiveness, as showcased in figure 1 , which can each be measured separately[49]. 


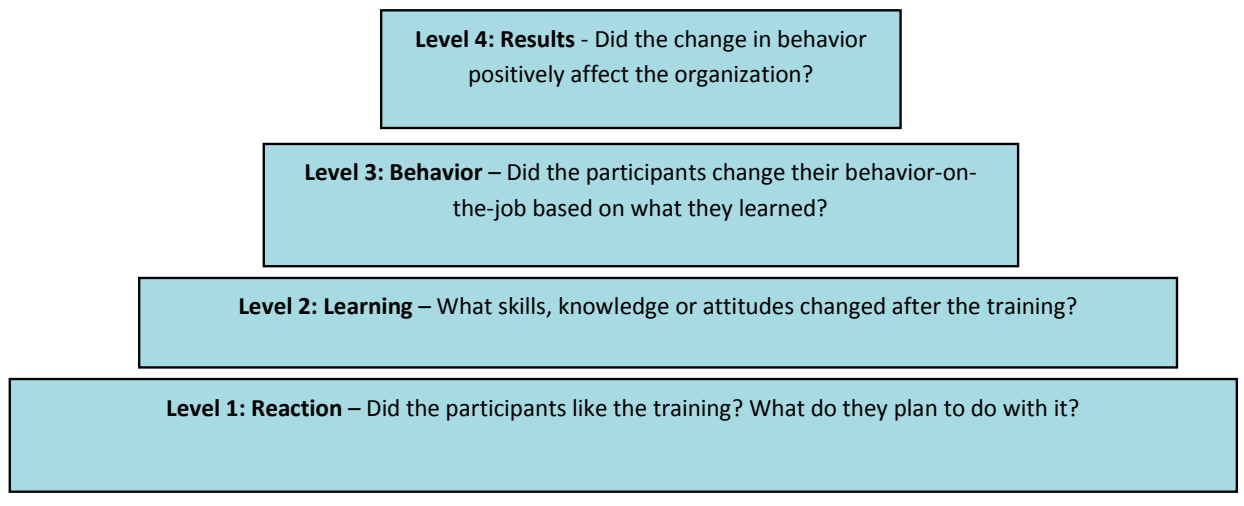

Figure 1: Kirkpatrick's four levels of evaluation (Kirckpatrick, 1998).

In this model, level 3 represents "transfer" or the transmission of learned skills from training to daily practice. Since actual behavioral change at the work floor is what we really wish to accomplish, levels 3 and 4 are foundational to the present discourse. For, as Hawken [50] aptly concludes: "Problems no longer only lie in demonstrating the effect of communication skills training, rather, today's problems are concerned mainly with how to transfer such skills from training programs to daily practice." What complicates matters, however, is the fact that the said levels are more difficult to measure than levels 1 and 2. Consequently, evidence for transfer of training to real patient encounters and patient outcomes (effects of levels 3 and 4) is slender [51-52]. Moreover, we have observed that many effectiveness studies appear weak in terms of design, whereas those whose research designs are more robust and valid report the lowest training effects. The next generation of studies should therefore focus on the realization of transfer of learned skills to different specific clinical situations and on long-term retention [53-56]. To be able to do so, however, we need more clarification research into the factors that inhibit or facilitate transfer and implementation of skills in daily practice. In other words, these factors should reveal what doctors need in order to effectively improve their communication skills. Out of these ponderations the first Research Question of this dissertation was born: What factors influence the weak transfer of medical communication skills from postgraduate training to medical practice?

\section{The importance of context}

The previously introduced research question 1 provides the springboard for the next two chapters (2-3), which home in on the main factors that help make or break transfer and learning of medical communication skills. The chapters describe a gradual shift away from the concept of transfer toward the concept of learning. As James Desse already pointed out in 1958 "There is no more important topic in the whole psychology of learning than transfer of learning." In other words, if we are to better understand the 
concept of transfer, what we actually should do is try to disentangle the learning process. Context appears crucial in this regard. More specifically, for learning to be effective or transferable, the learning process cannot be separated from the context in which it takes place. Consequently, non-contextual teaching does not lead to the desired effects [57]. It was precisely this knowledge of context playing such a pivotal role in the process of learning and transfer that motivated us to further explore the process of transfer and learning of communication skills within the work and learning context of residents. In fact, if we ever want to improve the effectiveness of postgraduate communication skills training, an important first step is to better understand the learning process itself and learner essentials for rendering this process effective. This brings us to the second Research Question of this dissertation: What does the process of learning medical communication look like and what do residents need in order to render this learning process effective/transferable?

We chose to focus on the perceptions and experiences of residents, as they represent a group of learners who, unlike undergraduates, have daily authentic patient contacts, making transfer of learned skills to daily medical practice a relevant issue to interview them about. Moreover, with communication skills ranking among the CanMEDS competencies [58], the medical program requires them to actively seek to improve these skills.

\section{Theoretical orientation}

In our quest for insight into the process of medical communication skills learning, the question arose as to what theoretical underpinnings should guide our research questions. The medical education realm has seen a host of theoretical scaffoldings, and each of them approaches the learning process from a different perspective [59]. The present dissertation draws from the theoretical constructs of humanism and social constructivism: the humanistic theory of learning places trust in the ability of learners to cater to their own development and to heed factors and processes that facilitate this development [60]. An example of such a theory of adult learning is transformative learning theory which is proposed to provide a good theoretical background for improving medical communication skills learning [61,62]. Developed by Mezirow [63-65] and sometimes referred to as triple-loop learning [65], it posits that deep learning results from reflection on and changes in an individual's frame of reference and underlying assumptions and beliefs. Moreover, it holds that the process of mastering and developing complex competencies such as communication skills is three-dimensional, involving psychological (changes in understanding the self), convictional (revision of belief systems), and behavioral (changes in action) transformations $[65,67]$.

Social constructivism assumes that learning is nested in social activity: it is considered the product of interactions with the environment, and in this reciprocal relationship they learn [68]. In humanist theories, perceptions of learners are key and taken to 
provide important information about how they learn and what they need to make their learning effective. For this reason we based our studies on perceptions of residents. Since we unravel this learning process within the daily context of residents, we try to further unravel the reciprocal relationship between the learner and his/her context as social constructivists do.

\section{Dissertation outline}

While the present chapter has introduced the dissertation's central theme, that is, effectiveness of medical communication skills learning, chapters 2 and 3 home in on the factors that help make or break transfer of postgraduate communication skills training programs; in doing so, they address the first research question. The subsequent two chapters concentrate on the second research question. More explicitly, chapter 4 seeks to unravel the process of medical communication skills learning by surveying residents in a general practice work context, while chapter 5 explains how residents in hospital settings regard their communication skills learning process and shows what these residents need in order to make their learning process effective. Chapter 6 then summarizes and synthesizes the results of previous chapters, by reflecting on the strengths and limitations of this dissertation. Chapter 6 also considers implications for practice and future research. As this dissertation is based on published journal papers, some repetition across chapters is inevitable. 


\section{References}

1. Williams C, Cantillon P, Cochrane M. The doctor-patient relationship: from undergraduate assumptions to pre-registration reality. Med Educ 2001;35:743-7.

2. Back A, Arnold R, Baile W, Tulsky J, Barley G, Pea R, et al. Faculty development to change the paradigm of communication skills teaching in oncology. J Clin Oncol 2009;27:1137-41.

3. Junod P, Sommer J, Hudelson P, Demaurex F, Luthy C, Louis-Simonet M, et al. Residents' perceived needs in communication skills training across in- and outpatient clinical settings. Educ Health 2009;22:280-94.

4. O'Neill PA, Jones A, Willis SC, McArdle PJ. Does a new undergraduate curriculum based on tomorrow's doctors prepare house officers better for their first post? A qualitative study of the views of preregistration house officers using critical incidents. Med Educ 2003;37:1100-8.

5. Rider E, Volkan K, Hafler J. Pediatric residents' perceptions of communication competencies: implications for teaching. Med Teach 2008;30:208-17.

6. Junod P, Sommer J, Hudelson P, Demaurex F, Luthy C, Louis-Simonet M, et al.Clinical supervisors' perceived needs for teaching communication skills in clinical practice. Med Teach 2009;31:316-22.

7. Ansani M. Patient-physician communication. WestIndian Med J 2009;58:357-61

8. Kurtz S, Silverman J, Draper J, van Dalen J, \& Platt F. Teaching and learning communication skills in medicine. Oxford: Radcliffe Pub.2005.

9. Epstein RM, Street Jr RL. Patient-centered communication in cancer care: promoting healing and reducing suffering. National Cancer Institute, NIH Publication 2007;07:6225.

10. Kaplan SH, Greenfield S, Ware J. Assessing the effects of physician-patient interactions on the outcomes of chronic disease. Med Care 1989;27:110-27.

11. Ong L, de Haes J, Hoos A, Lammes F. Doctor-patient communication: a review of the literature. Soc Sci Med 1995;40:903-18.

12. Stewart MA. Effective physician-patient communication and health outcomes: a review. Can Med Assoc J 1995;152:1423-33.

13. Street Jr R, Makoul G, Arora N, Epstein R. How does communication heal? Pathways linking clinicianpatient communication to health outcomes. Patient Educ Couns 2009;74:295-301.

14. Duffy F, Gordon G, Whelan G, Cole-Kelly K, \& Frankel R. Assessing competence in communication and interpersonal skills: The Kalamazoo II report. Acad Med 2004;79:495-507.5.

15. Heisler M, Bouknight R, Hayward R, Smith D, \& Kerr E. The relative importance of physician communication, participatory decision-making, and patient understanding in diabetes self-management. J Gen Int Med 2002;17:243-52.

16. Renzi C, Abeni D, Picardi A, Agostini E, Melchi C, Pasquini P, Prudu P, \& Braga M. Factors associated with patient satisfaction with care among dermatological outpatients. Brit J Dermatology 2001;145: 617-623.

17. Safran D, Taira D, Rogers W, Kosinski M, Ware J, \& Tarlov A. Linking primary care performance to outcomes of care. J Fam Pract 1998; 47:213-20.

18. Sullivan L, Stein M, Savetsky J, \& Samet J. The doctor-patient relationship and HIV-infected patients' satisfaction with primary care physicians. J Gen Int Med 2000;15:462-69.

19. Zachariae R, Pederson C, Jensen A, Ehrnrooth E, Rossen P, Von der Maase H. Association of perceived physician communication style with patient satisfaction, distress, cancer-related self-efficacy, and perceived control over the disease. Brit J Cancer 2003; 88:658-65.

20. Bensing J, Verheul W. The silent healer: the role of communication in placebo effects. Patient Educ Couns 2010;80:293-9.

21. Benedetti F, Lanotte M, Lopiano L \& Colloca L. When words are painful: unravelling the mechanisms of the nocebo effect. Neuroscience 2007;147:260-71.

22. Larson,E, \& Yao X. Clinical empathy as emotional labor in the patient-physician relationship. J Am Med Assoc 2005;293:1100-06.

23. Huntington B, \& Kuhn N. Communication gaffes: A root cause of malpractice claims. Baylor University Medical Center Proceedings 2003;16:157-61.

24. Beckman H, Markakis K, Suchman A, \& Frankel R. The doctor-patient relationship and malpractice. Lessons from plaintiff depositions. Arch Int Med 1994;154:1365-70.

25. Elaine R. Morgan, MD; Robert J. Winter. Teaching Communication Skills An Essential Part of Residency Training, Arch Pediatr Adolesc Med. 1996;150:638-42 . 
26. Institute of Medicine. Health professions education: A bridge to quality. Washington, D.C.: National Academies Press 2003.

27. Lein C, \& Wills C. Using patient-centered interviewing skills to manage complex patient encounters in primary care. Am Acad Nurse Pract 2007;19:215-20.

28. Bombeke K, Symons L, Debaene L, De Winter B, Schol S, \& Van Royen P. Help, I'm losing patientcentredness! Experiences of medical students and their teachers. Med Educ 2010;44:662-73.

29. Essers G, Van Weel-Baumgarten E, \& Bolhuis S. (2012). Mixed messages in learning communication skills? Students comparing role model behaviour in clerkships with formal training. Med teach 2012;34:e659-65.

30. Rotthoff T, Baehring T, David D, Bartnick C, Linde F, Willers R, et al. The value of training in communication skills for continuing medical education. Patient Educ Couns 2011;84:170-5.

31. Silverman J. Clinical communication training in continuing medical education: possible, do-able and done? Patient Educ Couns 2011;84:141-2.

32. Berkhof M, van Rijssen H, Schellart A, Anema J, van der Beek A. Effective training strategies for teaching communication skills to physicians: an overview of systematic reviews. Patient Educ Couns 2011;84:15262.

33. Hulsman R, Ros W, Winnubst J, Bensing J. Teaching clinically experienced physicians communication skills. A review of evaluation studies. Med Educ 1999;33:655-68.

34. Maguire P, Faulkner A, Booth K, Elliott C, Hillier V. Helping cancer patients disclose their concerns. Eur J Cancer 1996;32:78-81.

35. Salmon P \& Young B. Creativity in clinical communication: from communication skills to skilled communication. Med Educ 2011;45:217-26.

36. van Dulmen A, Holl R. Effects of continuing pediatric education in interpersonal communication skills. Eur J Pediatr 2000;159:489-95.

37. van Dulmen A \& van Weert J. Effects of gynaecological education on interpersonal communication skills. Br J Obstet Gynaecol 2001;108:485-91.

38. van Dulmen S. Patient-centredness. Patient Educ Couns 2003;51:195-6.

39. Clarke A. Teaching Physicians Communication Skills: Where We Are, How We Got Here. Research Project Submitted In Partial Fulfillment of the Requirements for the Degree of Master of Education. Simon Fraser University 2013.

40. Levesque M, Hovey R, Bedos C. Advancing patient-centered care through transformative educational leadership: a critical review of health care professional preparation for patient-centered care. $J$ Healthcare Leadership 2013;5:35-46.

41. Bombeke K, Symons L, Vermeire E, Debaene L, Schol S, de Winter B. Patientcentredness from education to practice: the 'lived' impact of communication skills training. Med Teach 2012;34:338-48.

42. Salmon P, Young B. Core assumptions and research opportunities in clinical communication. Patient Educ Couns 2005;58:225-34.

43. Riess H, Kraft-Todd G. EMPATHY: A tool to enhance nonverbal communication between clinicians and their patients.J Assoc Americ Med Coll 2014;89:1108-12.

44. van Es M, Wieringa-de Waard J, Visser M. Differential growth in doctor-patient communications skills. Med Educ 2013;47:691-700.

45. Blanco M, Maderer A, Price L, Epstein S, Summergrad P. Efficiency is not enough; you have to prove that you care: Role modelling of compassionate care in an innovative resident-as-teacher initiative. Educ for Health 2013;26:60-5.

46. Khanum Z. Effectiveness of reflective exercises for obstetrics and gynaecological residents. J Coll Phys Surg 2013;23:468-71.

47. Bensing J, van Dulmen S, Tates K. Communication in context: new directions in communication research. Patient Educ Couns 2003;50:27-32.

48. Salmon P, Mendick N, \& Young B. Integrative qualitative communication analysis of consultation and patient and practitioner perspectives: towards a theory of authentic caring in clinical relationships. $\mathrm{Pa}$ tient Educ Couns 2011;82:448-54.

49. Kirkpatrick D. Techniques for evaluating training programs. Training development J 1979;33:78-92.

50. Hawken S. Good communication skills: benefits for doctors and patients. N Z Fam Pract 2005;32:185-9. 
51. Henwood P, Altmaier E. Evaluating the effectiveness of communication skills training: a review of research. Clin Perform Qual Health Care 1996;4:154-8.

52. Libert Y, Conradt S, Reynaert C, Janne P, Tordeurs P, Delvaux N, et al. Improving doctor's communication skills in oncology: review and future perspectives. Bull Cancer 2001;88:1167-76.

53. Heaven C, Clegg J, Maguire P. Transfer of communication skills training from workshop to workplace: the impact of clinical supervision. Patient Educ Couns 2006;60:313-25.

54. Fallowfield L, Jenkins V, Farewell V, Solis-Trapala I. Enduring impact of communication skills training: results of a 12-month follow-up. Br J Cancer 2003;89:1445-9.

55. Lienard A, Merckaert I, Libert Y, Bragard I, Delvaux N, Etienne A-M, et al. Transfer of communication skills to the workplace during clinical rounds: impact of a program for residents. PLoS One 2010;5:e12426.

56. Rollnick S, Kinnersley P, Butler C.Context-bound communication skills training: development of a new method. Med Educ 2007;41:138-45

57. Frank J, Snell L, Cate O, Holmboe E, Carraccio C, Swing S, Harris K. Competency-based medical education: theory to practice. Med Teach 2010;32:638-645.

58. Mann K. Theoretical perspectives in medical education: past experience and future possibilities. Med Educ 2011;45:60-68.

59. Mann K, Teunissen P, Dornan T. Perspectives on learning. In Dornan T, Mann K, ScherpbierA, SpencerJ, eds. Medical Education Theory and Practice. Churchill, Edinburgh, 2010.

60. Lévesque M, Hovey R, Bedos C. Advancing patient-centered care through transformative educational leadership: a critical review of health care professional preparation for patient-centered care. $J$ Healthcare Leadership 2013;5:35-46.

61. Khanum Z. Effectiveness of reflective exercises for obstetrics and gynaecological residents. J College Physicians Surgeons 2013;23:468-71.

62. Mezirow J. Transformative learning: Theory to practice. New Dir Adult Cont Educ 1997;74:5-12.

63. Mezirow J. Transformative dimensions of adult learning. San Francisco: Jossey-Bass; 1991.

64. Mezirow J. Transformative learning as discourse. J Transform Educ 2003;1:58-63.

65. Peschl M. Triple-loop learning as foundation for profound change, individual cultivation, and radical innovation. Construction processes beyond scientific and rational knowledge. Constructivist Found 2007;2:136-45.

66. Elias M, O’Brien M, Weissberg R. Transformative leadership for social-emotional learning. Principal Leadership 2006;7:10-3.

67. Vagan A. Towards a Sociocultural Perspective in Identity Formation in Education. Mind, Culture, and Activity. 2011;18:43-57. 



\section{Chapter 2}

\section{Learning in context:}

Identifying gaps in research on the transfer of medical communication skills to the clinical workplace

Valerie van den Eertwegh

Sandra van Dulmen

Jan van Dalen

Albert Scherpbier

Cees van der Vleuten

Patient Educ Couns 2013;90:184-92 


\section{Abstract}

Objective: In order to reduce the inconsistencies of findings and the apparent low transfer of communication skills from training to medical practice, this narrative review identifies some main gaps in research on medical communication skills training and presents insights from theories on learning and transfer to broaden the view for future research.

Methods: Relevant literature was identified using Pubmed, GoogleScholar, Cochrane database, and Web of Science; and analyzed using an iterative procedure.

Results: Research findings on the effectiveness of medical communication training still show inconsistencies and variability. Contemporary theories on learning based on a constructivist paradigm offer the following insights: acquisition of knowledge and skills should be viewed as an ongoing process of exchange between the learner and his environment, so called lifelong learning. This process can neither be atomized nor separated from the context in which it occurs. Four contemporary approaches are presented as examples.

Conclusion: The following shift in focus for future research is proposed: beyond isolated single factor effectiveness studies toward constructivist, non-reductionist studies integrating the context.

Practice implications: Future research should investigate how constructivist approaches can be used in the medical context to increase effective learning and transition of communication skills. 


\section{Introduction}

There is compelling evidence that communication affects numerous important and meaningful health outcomes, such as adherence to drug regimens and diets, pain control, and improvements in physical, functional, and psychological well-being [1-5]. Despite the importance of communication, there are frequent reports of low satisfaction with the communication between practicing doctors and their patients [6,7]. Medical education has recognized the importance of communication skills, as evident from the fact that dedicated training programs have become an integral component of the undergraduate medical curriculum. Paradoxically, however, systematic communication skills training is quite rare during postgraduate training where residents learn in the clinical workplace with day-to-day contacts with patients [8-11]. This contrasts sharply with research reporting a strong need for communication training at postgraduate level [12]. Rider et al. [13] for instance showed that less than half of all residents were confident about their more advanced communication skills, such as breaking bad news, dealing with end-of-life issues and communicating with difficult patients and seriously ill children. O'Neill et al. [14] confirmed that residents feel unprepared for the required extent of emotional involvement with patients. There is an unfortunate discrepancy between this obvious need for training and the absence of communication training programs reaching out to high numbers of residents [10,11]. General practice may be an exception to this situation, since its residency program does pay attention to communication skills on a more regular basis.

Studies on the effectiveness of postgraduate communication training have reported contradictory and variable findings [15-21]. This suggests that this research area might benefit from a new approach, moving beyond single effectiveness studies to a broader, non-reductionist view on the issue at hand $[18,22]$. This paper is an attempt to develop such a broader view.

The broader view on communication skills training we propose in this review is driven by a main problem in the field: absence of consensus on how to define and capture effectiveness. In fact, effectiveness has been defined in numerous ways by many different theorists and researchers. Well-known in this regard are the four levels of evaluation developed by Kirkpatrick (Fig. 1) [23].

In recent years however the suitability of Kirkpatrick's levels to evaluate the effectiveness of interventions has been questioned [24-26,27]. The main critique is that it involves many implicit assumptions [26], masking underlying mechanisms and causal relationships between the intervention and its outcomes [25]. Besides, organizations prefer to measure the first two levels rather than the last two, which are harder to measure [24]. Levels three and four are however most interesting to know, since they measure whether real change has occurred due to the intervention.

Looking at effectiveness of communication skills, what we are striving for is an observable change in the communication behavior of clinicians in their daily practice. Hawken [28] defines this as transfer of communication skills from training to daily practice, equaling level three of Kirkpatrick. 


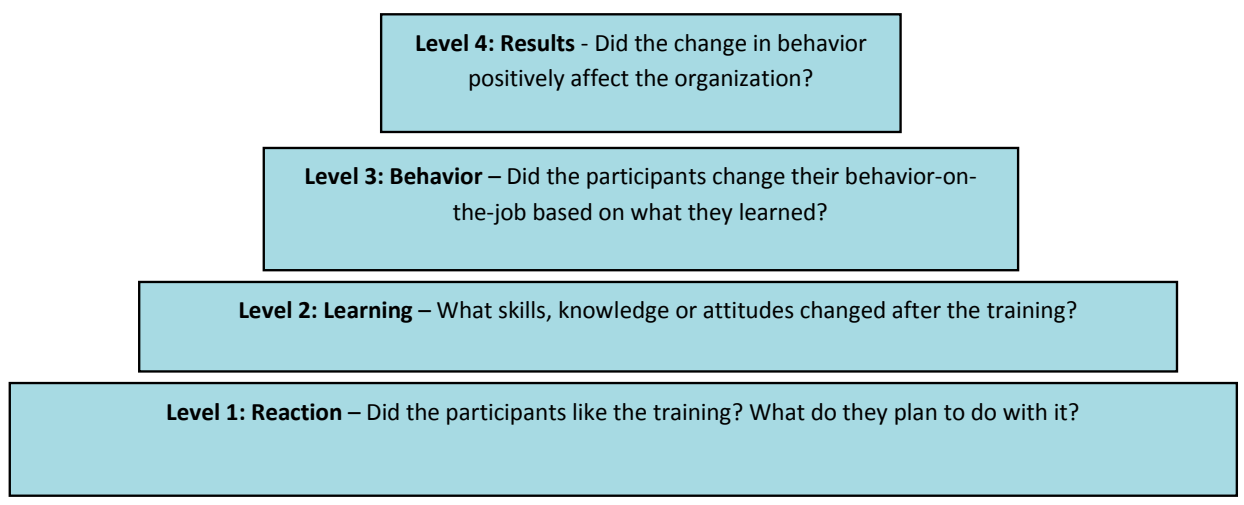

Figure 1: Kirkpatrick's four levels of evaluation (Kirkpatrick, 1998).

If we want to increase this transfer or transition in communication skills, much is to be gained by more clarity about the underlying assumptions of what makes learning and transfer effective.

The objective of this article therefore is to identify gaps in the literature on effectiveness of postgraduate communication skills training and discuss relevant theories and insights in the literature on transfer and learning, to gain more clarity about underlying principles and to guide future research. In order to do so, relevant literature will be reviewed.

More specifically, the following research questions will guide and structure this article:

1. Which gaps can be identified in the research on effectiveness of postgraduate communication skills training?

2. Which relevant insights can be identified in the research on transfer of training and theories on learning, to guide future research in the field of postgraduate communication skills training?

We present the results in a narrative review as this format seems particularly suited to comparing and interpreting complex, multi-faceted concepts and findings [29].

\section{Methods}

\subsection{Literature search}

In this narrative review we present and interpret general findings on medical communication skills training and transfer of training and learning, combining different perspectives. We searched for literature studies, systematic reviews, and empirical studies on the subjects "medical communication skills (training)" and "transfer of training and learning". The following keywords were used to search Pubmed, GoogleScholar, Cochrane database, and Web of Science: "medical communication skills", "medical 
communication skills training (programs)", "transfer of training", "transfer of learning" and "transfer of medical communication skills". Manual searches of other relevant journals were also conducted. In executing our search we used an open to closed inclusion strategy. We started by including articles on medical communication skills training in general to look which gaps in the literature they revealed. The titles and abstracts of the retrieved articles were screened, after which the full text of included articles was read. Next, a more closed reference search of the already included articles was performed. This process of snowballing was done until saturation was reached, ending up with five main topics as emerging problems or gaps in the literature. A total of 250 articles written in English and published before November 2011 were included (available from the first author upon request). We conducted a narrative review, to underline the iterative process of literature selection.

\subsection{Mind maps and iterative validation}

During our literature search, the first author composed mind maps to visualize, structure, and classify the findings from the articles. We used this mind mapping as a starting point technique to categorize the data, because it is an effective way to classify chunks of information and show interrelations between the information from the articles included [30]. In this way, we identified five main categories in 250 articles: intervention studies with significant training effects, Intervention studies with no significant training effects, Assessment of communication skills, research needs, and current needs in systematic communication skills training implementation at post graduate level. From these five categories or groups of papers, five main gaps were formulated. To increase the reliability of the main gaps identified by the first author, we applied an iterative approach. This included cross-validating the main gaps through peerdiscussion and evaluation by the co-authors and double checking by four other experts in the field of communication research. This process was done in several rounds until consensus was reached.

\section{Results}

\subsection{Gaps in the research evidence on postgraduate medical communication skills training}

Since the vast majority of the papers addressed more than one of the gaps described below, no precise number of papers in each of these categories can be provided. However, the gaps are presented in the order of 'most often mentioned' to 'least often mentioned', where 'most often' indicates that more than half of the papers addressed this gap, and 'least often' still means that about one third of the papers discussed the issue. 


\section{$\underline{\text { 3.1.1 Effectiveness of postgraduate communication skills training interventions }}$}

More than half of the 250 studies have examined the effectiveness of postgraduate communication skills training. A review study by Hulsman et al. [16] showed that the design of many of these studies was weak and that stronger and more valid research designs yielded the lowest training effects. This might reveal that communication training does not necessarily produce the expected results. Bloom [31] also concludes in his review that even though most methods or techniques for continuing medical education proved to be effective, the use of least effective techniques predominates, having little or no beneficial effect in changing physician practice. As a reaction to Hulsman's review, van Dulmen and Bensing [32] questioned the validity of evaluation techniques, arguing that inadequate evaluation techniques might explain (some of) the negative results and absence of effectiveness. They advised widening the scope of communication skills research and training, arguing that communication does not take place in a vacuum but is influenced by the context in which it takes place [22,33]. Rollnick et al. [34] developed for instance a new context-bound training method, emphasizing the role of an authentic context when designing a communication skills training program. However, measurement of its effectiveness remains a challenge.

The inconsistent results of effectiveness studies may also be explained by the different levels at which effectiveness was measured. It appears that most effectiveness studies conduct evaluations at level 1 or level 2 of Kirkpatrick's model (Fig. 1). Hulsman et al. however, also measured level 3 effects by adding independent behavioral observations and patient outcomes to physicians' self-ratings. Since level 3 effects are more difficult to measure and obtain, this may also partially explain why the more valid research designs revealed the weakest training effects. In order to enhance the comparability of training programs, it would be commendable to arrive at general agreement on how to define and measure effectiveness [15].

Libert et al. [35], Fallowfield et al. [8], and Heaven et al. [36] were among the first to research effectiveness in terms of transfer of medical communication skills from training to clinical practice. They confirmed the paucity of empirical data from methodologically sound studies. In 2010, Lienard et al. [9] pointed out that until then only three controlled studies had shown efficacy in terms of transfer to clinical practice, and that the way transfer was assessed in these studies was good but not optimal. In response to this, Lienard conducted one of the first studies to assess transfer of communication skills training for residents in a randomized controlled design. It showed that transfer of communication skills was directly related to the training attendance, but the transfer effect remained limited. Henwood et al. confirmed that evidence for transfer of training to real patient encounters and patient outcomes (level 3 effects) are still scarce [37]. Lienard thus concluded that the next generation of studies should focus on the generalization of transfer of learned skills to different specific clinical situations and on the maintenance of it over time [9]. 


\subsubsection{Context-related assessment of communication skills}

Measurement of effectiveness requires assessment of participants' communication skills. However, residents and clinicians often perceive the assessment of their communication skills as subjective [38,39], claiming that not all factors influencing the communication process are taken into account. Since conducting a consultation or building a relationship cannot be atomized into component skills, it is questionable whether it is acceptable to assess communication using behavioral coding schemes that only measure the frequency of some predefined skills and thus do not (fully) take into consideration the context in which the communication occurs [18]. Since context is supposed to influence communication, it should be included in the evaluation of effectiveness to obtain a broader and more realistic picture. Bensing et al. [22] already suggested to expand the focus of medical communication research to include the context where health care professionals apply their communication skills. According to Hager and Hodkinson [40] much about skills remains implicit and tacit. Attempts to describe precisely the human capacities that underpin successful performance in a field are always somewhat speculative and, hence, are subject to contestation and revision. This has important implications for the way we look the acquisition and transition of communication skills as well. Descriptions of performance outcomes should not erroneously be taken as descriptions of the skills that enable these outcomes [40].

\subsubsection{Clarification research and conceptual models}

As pointed out by Cook et al. in 2008 [41], there is an urgent need for clarification research to advance the science of medical education. Their review showed that only 12 percent of experimental studies addressed questions of "why did this work" or "how did this work". To remedy this, Cook called for increased use of theoretical models in the concepts and designs of medical education studies [41]. This view is supported by de Haes et al. [42], who stated that the evidence on medical communication is underdeveloped. Conceptual models in this area are still lacking, and will have to be developed to advance the science of medical communication skills training.

\subsubsection{Systematic implementation at organizational level}

Visser and Wysmans [43] pointed to the need for more attention to ways of ensuring systematic and lasting implementation of the effects of communication training, since their study showed disappointing results for the long-term implementation of the effects. They argued that systematic implementation is often poorly developed or missing altogether, as was also demonstrated in earlier reviews of health care innovations by Grol et al. [44-47] and Greenhalgh et al. [48]. Successful transfer and long lasting implementation require an organization-oriented change strategy at the level of the department or organization [43]. Silverman [11] confirmed that, without nurturing and 
integration, improvements as a result of communication training are often likely to flounder in the face of pressures from workload, time issues, inappropriate modeling, and apparent failure to recognize the value of this central clinical skill. This confirms earlier findings from Mazmanian and Davis [49] that continuing medical education activities must be truly continuing and not causal, sporadic or opportunistic, to achieve their greatest potential.

\subsubsection{Mechanisms or factors that (fail to) produce change}

Transfer can be regarded as an essential preliminary step before the actual implementation of newly learned skills. This makes it worthwhile to consider insights from implementation research. Extensive implementation research by van der Weijden et al. [50] and by Grol et al. [44-47] has yielded valuable insights into factors influencing the effective implementation of interventions to improve quality in health care systematically. Because interactions of factors at multiple levels influence the success or failure of quality improvement interventions, an understanding of these factors (the obstacles to and incentives for change) is crucial to an effective intervention [51]. Greenhalgh et al. [48] also emphasized the need for future research to study hypothesized links between interventions and outcomes and the need for refinement of the mechanisms by which and within which these links produce (or fail to produce) change. Along the same lines, Hulsman et al. [16] also concluded that future research might benefit from focusing on factors that inhibit or facilitate physicians' implementation of skills in their actual behaviors in daily practice.

\subsection{Literature on transfer and theories of learning}

The five main gaps discussed above urged the authors to have a closer look at underlying assumptions of what makes transfer (or transition) of what is learned effective. In the next four paragraphs some main developments in the field of transfer and learning are discussed, since their findings and views have not yet been widely translated to the field of medical communication skills training.

\subsubsection{Traditional and contemporary schools on learning and transfer}

In several fields outside medicine the importance of the concept of transfer is widely acknowledged. As early as 1958, James Desse stipulated that "there is no more important topic in the whole psychology of learning than transfer of learning. What has emerged from the stream of research is a view of transfer as a complex and dynamic process" [52]. It is important to mention that there are different schools of theorizing about learning and transfer. A main distinction can be made between traditional and contemporary views on learning, each having their own assumptions on transfer. The traditional view is based on behaviorist and cognitive paradigms of learning and con- 
siders what is learned as a product that is independent of the learner which can be moved from place to place, separate from the context in which it is learned [40]. In this view we have failed to achieve transfer of learning at very significant levels [52], thus calling for alternative views on learning and transfer.

The contemporary view on learning and transfer on the other hand, is based on the research paradigm of constructivism, which equates learning with creating meaning from experience. Knowledge and skills are not mind-independent in this regard and cannot be mapped onto a learner, as cognitivists and behaviorists believe. Instead humans create meaning as opposed to acquiring it [53]. Learners do not transfer knowledge from the external world into their memories, rather they build personal interpretations of the world based on individual experiences and interactions [54-60]. van Oers [61], like Beach [62-64] and Engestrom [55-57], start from the premise that the process by which people acquire knowledge or skills cannot be separated from the context in which they find themselves. If learning is decontextualized, there is little hope for transfer to occur. This school is also called the socio- cultural tradition within contemporary learning theory. It offers a reconceptualization of transfer, arguing to use the term "transition" or "cross boundary learning", since it is people who move, not knowledge or learning. This contemporary stance toward transfer phenomena sees continuity and transformation in learning as an ongoing relation between changing individuals and changing social contexts [62].

Measuring transfer is by no means a simple undertaking as transfer is difficult to study and even more difficult to foster intentionally [62]. Even successful training or educational pro- grams cannot guarantee that newly learned knowledge and skills will be transferred to the workplace [24]. Given the many factors to be considered in measuring transfer coupled with the lack of a widely accepted and standardized evaluation methodology, there currently does not seem to be a valid basis for generalizations about the overall transfer of training [65]. In the traditional view, transfer has been measured as the use or application of a specific skill that has been learned. Contemporary views on transfer measure it as an ongoing process influenced by and influencing the environment, rather than as a series of discrete acquisition events [40]. Clearly, these different ways of conceptualizing or capturing transfer have a significant effect on the relationships that are ultimately reported [66], as will become clear in the following paragraphs.

\subsubsection{Capturing transfer}

Over the past decades of research on transfer, many factors have been shown to influence the process of transfer. From the 1960s to the late 1980s, the contributions of Baldwin and Ford [67] focused on a traditional model of transfer of training, highlighting trainee characteristics, training design and delivery, and work environment as the three primary domains influencing the process of transfer. Since then, substantial progress has been made by investigating each of these domains in greater detail. A review by Burke and Hutchins [68] gives an overview, by domain, of many of the variables that 
have been studied. From this review it can be concluded that strong or moderate relationships have been proven to exist for most of the variables within each of these three main domains (Fig. 2a-c), but more research is needed to clarify or confirm the findings since inconsistencies in the influence of factors still remain to be clarified [68].

These inconsistencies have led Blume et al. [66] to undertake the first full-scale quantitative review of 89 empirical studies examining the influence of variables and moderator effects for each of the three main domains. This resulted in an overview of quantitative values. Little is known, however, about the interplay between these factors in specific contexts, since these factors were measured in isolation from the context or work environment in which they normally occur. Grossman and Salas [69] therefore concluded that, although a wealth of information regarding the transfer of training has been uncovered by researchers, inconsistencies remain and organizations may find it difficult to pinpoint exactly which factors are critical when they consider applying the findings in their own context. Researchers should therefore shift their attention away from measuring isolated factors toward measuring factors within specific work contexts or conditions $[66,69]$. Even within the field of workplace learning most models of work experience have either ignored the influence of context upon learning or approached this issue mechanically [59,60]. Or as Hager and Hodkinson [40] put it, since skillful practice is both holistic and significantly contextual rather than atomistic and context-free, measuring transfer decoupled from context, does not make much sense. Van Oers even argued that the concept of context still remains ill-defined in literature and should be conceived of more dynamically [61]. In other words, the traditional approach and its resulting insights have significantly advanced research in the field, but appear somehow limited in their possibility to explain existing inconsistencies. This invites researchers to complement existing research outcomes and add more constructivist, contextual perspectives to investigate the issue at hand.

\section{A}

\begin{tabular}{|l|c|c|c|c|}
\hline Variable & $\begin{array}{c}\text { Strong or } \\
\text { Moderate } \\
\text { relationship with } \\
\text { transfer }\end{array}$ & Mixed support & $\begin{array}{c}\text { Minimal } \\
\text { empirical } \\
\text { research exists }\end{array}$ & $\begin{array}{c}\text { Research is } \\
\text { needed to clarify } \\
\text { or to build } \\
\text { findings }\end{array}$ \\
\hline Cognitive ability & $\checkmark$ & $\checkmark$ & & \\
\hline Self-efficacy & $\checkmark$ & & $\checkmark$ & $\checkmark$ \\
\hline Pre-training motivation & & & $\checkmark$ & $\checkmark$ \\
\hline Motivation to learn & & & & $\checkmark$ \\
\hline Motivation to transfer & $\checkmark$ & & & \\
\hline Extrinsic vs. intrinsic motivation & & & & $\checkmark$ \\
\hline Anxiety/ neg. affectivity & $\checkmark$ & & & $\checkmark$ \\
\hline Conscientiousness & & & & \\
\hline Openness to experience & & & & \\
\hline
\end{tabular}




\begin{tabular}{|l|c|c|c|c|}
\hline Extroversion & & & $\checkmark$ & $\checkmark$ \\
\hline Perceived utility & $\checkmark$ & & & \\
\hline Career planning & $\checkmark$ & & & \\
\hline Organizational commitment & $\checkmark$ & & & $\checkmark$ \\
\hline $\begin{array}{l}\text { External vs. internal locus of } \\
\text { control }\end{array}$ & & $\checkmark$ & & \\
\hline
\end{tabular}

\section{B}

\begin{tabular}{|l|c|c|c|c|}
\hline Variable & $\begin{array}{c}\text { Strong or } \\
\text { Moderate } \\
\text { relationship with } \\
\text { transfer }\end{array}$ & Mixed support & $\begin{array}{c}\text { Minimal } \\
\text { empirical } \\
\text { research exists }\end{array}$ & $\begin{array}{c}\text { Research is } \\
\text { needed to clarify } \\
\text { or to build } \\
\text { findings }\end{array}$ \\
\hline Needs analysis & $\checkmark$ & $\checkmark$ & $\checkmark$ \\
\hline Learning goals & $\checkmark$ & & & \\
\hline Content relevance & $\checkmark$ & & & $\checkmark$ \\
\hline Practice \& feedback & & & & $\checkmark$ \\
\hline Over-learning & & & & $\checkmark$ \\
\hline Cognitive overload & $\checkmark$ & & & \\
\hline Active learning & $\checkmark$ & & & $\checkmark$ \\
\hline Behavioral modeling & & & & $\checkmark$ \\
\hline Error-based examples & & & & $\checkmark$ \\
\hline Self-management strategies & & & & $\checkmark$ \\
\hline Technological support & & & & $\checkmark$ \\
\hline
\end{tabular}

C

\begin{tabular}{|l|c|c|c|c|}
\hline Variable & $\begin{array}{c}\text { Strong or } \\
\text { Moderate } \\
\text { relationship with } \\
\text { transfer }\end{array}$ & Mixed support & $\begin{array}{c}\text { Minimal } \\
\text { empirical } \\
\text { research exists }\end{array}$ & $\begin{array}{c}\text { Research is } \\
\text { needed to clarify } \\
\text { or to build } \\
\text { findings }\end{array}$ \\
\hline Strategic link & $\checkmark$ & $\checkmark$ & $\checkmark$ \\
\hline Transfer climate & $\checkmark$ & $\checkmark$ & & $\checkmark$ \\
\hline Supervisory support & $\checkmark$ & & & $\checkmark$ \\
\hline Peer support & $\checkmark$ & & & $\checkmark$ \\
\hline Opportunity to perform & & & & $\checkmark$ \\
\hline Accountability & & & & $\checkmark$ \\
\hline
\end{tabular}

Fig. 2. (a) Summary of the trainee characteristics - transfer link (Burke and Hutchins [68]). (b) Summary of the training design and delivery - transfer link (Burke and Hutchins[68]). (c) Summary of the work environment - transfer link (Burke and Hutchins [68]). 


\subsubsection{Qualitative system-oriented research}

So far, the use of qualitative methods in transfer research has been limited [70], especially in the traditional school of research on transfer. Cromwell and Kolb [71] discussed how qualitative approaches can be useful for generating more information about the systemic nature of transfer processes. If we are to understand more of the underlying mechanisms influencing transfer, it would be helpful to design research in which qualitative methods are used as a first step. Pope et al. [72] explored some of the qualitative methods that can be used to gather such information. As stipulated by Grol et al. [45], studying the effects of specific interventions in controlled trials will provide some answers to some questions about effective interventions and change, but will not address some of the basic questions about the critical success factors. In order to do so, existing studies will have to be complemented by more constructivist, observational and system-oriented qualitative studies $[44,46,47,73]$.

\subsubsection{Workplace learning and multilevel transfer models}

At the same time as research on transfer of training has continued, there has been a rise in interest in new schools of thought specifically aiming at learning at work. This recent emphasis on 'workplace learning' suggests that conventional training transfer research may be inadequate to understand the dynamics of performance improvement through training. Cheng et al. suggest however that, rather than the replacement of transfer by workplace learning, training transfer issues still need to be solved. No matter how knowledge (or 'learning outcomes') is acquired (whether through the workplace or not), it needs to be transferred to the job, within a job or from one job to another $[24,74,75]$.

The workplace is a type of learning environment well recognized and emphasized by contemporary researchers to bring new perspectives to research on learning $[59,74,75]$, but under- researched in traditional models [76]. In workplace learning, learning is more informal in nature (in contrast to formal learning by training). Since much of this type of learning is invisible, tacit or occurring without awareness, it is a challenging process to research in relation to transfer. Eraut [77] has defined transfer in this regard as five interrelated stages: extraction of knowledge from the context, understanding the new situation, recognizing what knowledge and skills are relevant, transforming them to fit the new situation, and integrating them with other knowledge and skills in order to act in the new situation. This whole process is much more complicated than just desituating and resituating a piece of knowledge and the fourth and fifth stage are often ignored in research. The fifth stage in this transfer process draws attention to the holistic nature of performance in most workplaces. Evans [74,75] confirmed that naive mapping of key skills between environments does not work. In addition, skills gained from various life experiences (such as travel and bringing up children) are a central part of a person's learning process, mutually interacting with and changing the environment in which they are deployed, but often ignored by researchers. 
In order to capture these multiple factors influencing learning and transfer in the workplace, such processes should be studied from a more contemporary, multilevel (rather than a linear) perspective, meaning that contextual influences should be investigated [68]. Most existing traditional models on transfer use a linear perspective in which the influence of the context is not directly included.

As a first example of a contemporary multilevel approach, Guile et al. present a model that embodies the concept of connectivity as a basis for a productive and useful relationship between formal and informal learning and transfer at the workplace [59]. A second example of a multilevel approach to transfer is Holton's transfer model and related instrument, the learning transfer system inventory (LTSI) [78]. Holton [25,7880] describes transfer as a function of a system of influences, stating that transfer can only be completely understood and influenced by examining the entire system. Holton and Bates [79] contended that most studies have stopped at the point of identifying, describing, or measuring factors that may influence transfer, without proceeding to investigate how those factors might be effectively changed or managed. Holton et al. brought this research a bit further by building an action-oriented approach to transfer intervention based on the LTSI. This helps to explore ways to change and manage effectively the factors influencing transfer processes [24].

A third example of a contemporary multilevel approach is called activity theory. This theory states that a systems view of the organization alone is insufficient if one truly wants to understand and facilitate learning and change, since change must be initiated and nurtured at the individual level by real identifiable people and groups [57]. Activity theory is a framework aimed at transcending this dichotomy between micro level (individual) learning processes and macro level (organizational) structures.

A fourth and final example of a multilevel approach to learning and transfer is developed by Mezirow [81] and called transformative learning theory. Key to the process of learning here is that the learner has to recognize narrow frames of references within him or herself through a disorientating experience thereby problematizing current attitudes, values and beliefs. This confronting experience creates new frames of references within the person. Since these new frames of reference are a way of personalized, deep level learning, they are transferred more easily across boundaries [73,8183].

More research is needed to test these existing multilevel models and approaches in specific contexts, such as the medical environment in which clinicians operate.

\section{Discussion and conclusion}

\subsection{Discussion}

Most studies on effectiveness and transfer of medical communication skills examine the extent to which communication skills - learned off the job - are transferred to the clinical workplace. This way of looking at learning and transfer fits more the traditional 
view of learning. This view may not be sufficient to understand the mechanisms underlying the learning and transition of communication skills for clinicians. A broader, more contemporary view on learning and transfer views effectiveness of communication skills training as a continuing change and transition in both the learner and its environment, instead of mere acquisition of predefined skills that are transferred from training to workplace. This contemporary view may fit better when dealing with such tacit skills as communication skills, since they cannot and should not be atomized, as seen in Section 3.1.2.

In addition, the influence of the medical context (defined as the work environment in which clinicians have to learn, transfer and integrate communication skills) may also have to be taken more into account when examining the effectiveness of communication training programs. By focusing on the whole system, a more complete or accurate view can be obtained. This may be especially relevant for communication skills learning in medical environments, since in most hospitals the learning of communication skills through informal processes of socialization and role modeling is dominant over formal learning by training. These are important contextual factors to take into account and to investigate in more detail. Figure. 3 gives an overview of the findings in light of our two research questions and possible remedies.

This review has been limited to publications in the English language and one Dutch publication. Moreover, findings from reviews are vulnerable to interpretation bias. In this narrative review we have reduced the risk of interpretation bias by using an open to closed inclusion strategy and by discussing all research findings, conclusions and recommendations with four experts and all co-authors in an iterative procedure until consensus was reached.

\subsection{Conclusion}

From our review we conclude that existing gaps in the literature on effectiveness of communication skills training can be explained or understood better if we look at insights from theories on transfer and learning. The existence of different views on and examination of transfer and learning may explain why findings of current studies are not conclusive or inconsistent. A broader view in which the learning and measurement of communication skills is interpreted in the light of contemporary, constructive theories seems to be a promising way forward and of added value to existing research. Pursuing this line of inquiry is challenging and worth investigating to provide more pieces to complete the puzzle of transfer (transition) of communication skills training in the medical domain. 


\begin{tabular}{|c|c|c|}
\hline $\begin{array}{l}\text { Gaps in research on } \\
\text { effectiveness of } \\
\text { communication skills } \\
\text { (CS) training (R.Q.1) }\end{array}$ & $\begin{array}{l}\text { Relevant insights from research on transfer } \\
\text { and theories on learning to build a broader } \\
\text { view and guide research in the field of } \\
\text { medical communication skills(R.Q.2) }\end{array}$ & Possible remedy \\
\hline $\begin{array}{l}\text { 1. - Inconsistency and } \\
\text { variability in findings on } \\
\text { effectiveness. }\end{array}$ & $\begin{array}{l}\text { 1. Constructivist theories regard } \\
\text { learning (of skills) as a continuous process of } \\
\text { exchange between the learner and his } \\
\text { environment (non- reductionist approach), }\end{array}$ & $\begin{array}{l}\text { 1. -Establish more consensus } \\
\text { on defining and measuring } \\
\text { effectiveness of CS training. }\end{array}$ \\
\hline $\begin{array}{l}\text { - No consensus on how to } \\
\text { measure effectiveness. }\end{array}$ & $\begin{array}{l}\text { instead of regarding learning as acquiring and } \\
\text { transferring atomized skills isolated from the } \\
\text { context. }\end{array}$ & $\begin{array}{l}\text { - Establish more accurate } \\
\text { assessment methods that can } \\
\text { be applied in daily practice. }\end{array}$ \\
\hline $\begin{array}{l}\text { 2. Lack of context-related } \\
\text { assessment of CS. }\end{array}$ & $\begin{array}{l}\text { 2. Measuring transfer decoupled from context, } \\
\text { does not make much sense, since learning is } \\
\text { shaped by and shaping the context in which it } \\
\text { occurs. }\end{array}$ & $\begin{array}{l}\text { 2. Meet the need for context- } \\
\text { specific estimates to better } \\
\text { capture transfer } \\
\text { relationships. }\end{array}$ \\
\hline $\begin{array}{l}\text { 3. Need for more } \\
\text { clarification research and } \\
\text { conceptual models. }\end{array}$ & $\begin{array}{l}\text { 3. Contemporary schools encourage qualitative } \\
\text { research to clarify and conceptualize underlying } \\
\text { processes of learning and transfer, thereby } \\
\text { incorporating the whole system. }\end{array}$ & $\begin{array}{l}\text { 3. Conduct more clarification } \\
\text { research and gain insight in } \\
\text { underlying mechanisms. }\end{array}$ \\
\hline $\begin{array}{l}\text { 4. Lack of systematic } \\
\text { implementation at } \\
\text { organizational level. }\end{array}$ & $\begin{array}{l}\text { 4. Understanding which mechanisms influence } \\
\text { transfer and implementation requires multilevel } \\
\text { approaches instead of linear approaches. } \\
\text { Examples of constructivist multilevel models } \\
\text { include Guile's connectivity model, Holton's } \\
\text { transfer model/action approach, Engestrom's } \\
\text { activity theory, and Mezirow's transformative } \\
\text { learning theory. }\end{array}$ & $\begin{array}{l}\text { 4. Make the learning of CS a } \\
\text { more integral part of the } \\
\text { existing organizational } \\
\text { climate by applying } \\
\text { constructivist multilevel } \\
\text { approaches to transfer and } \\
\text { learning. }\end{array}$ \\
\hline $\begin{array}{l}\text { 5. Lack of insight in which } \\
\text { mechanisms or factors } \\
\text { inhibit or facilitate } \\
\text { physicians' implementation } \\
\text { of CS in their daily practice. }\end{array}$ & $\begin{array}{l}\text { 5. Constructivist multilevel approaches should } \\
\text { be tested in specific contexts. }\end{array}$ & $\begin{array}{l}\text { 5. Investigate which } \\
\text { constructivist multilevel } \\
\text { approach(es) can be used in a } \\
\text { medical context to increase } \\
\text { insight in which factors (fail } \\
\text { to) produce learning and } \\
\text { transfer of CS. }\end{array}$ \\
\hline
\end{tabular}

Fig. 3: Overview of results according to the two research questions and possible remedies.

\subsection{Practice implications}

We suggest that future research should focus on investigating which of the constructivist multilevel approaches to learning and transfer, as presented in this review, can best be used in a medical context to increase our insight into the mechanisms that (fail to) promote transition and integration of communication skills training. 


\section{References}

1. Epstein R, \& Street Jr R. Patient-centered communication in cancer care: promoting healing and reducing suffering. National Cancer Institute, NIH Publication 2007;07:6225.

2. Kaplan S, Greenfield S, Ware J. Assessing the effects of physician-patient interactions on the outcomes of chronic disease. Med Care 1989;27:110-27.

3. Ong L, de Haes J, Hoos A, Lammes F. Doctor-patient communication: a review of the literature. Soc Sci Med 1995;40:903-18.

4. Stewart M. Effective physician-patient communication and health out- comes: a review. Can Med Assoc J 1995;152:1423-33.

5. Street Jr R, Makoul G, Arora N, Epstein R. How does communication heal? Pathways linking clinicianpatient communication to health outcomes. Patient Educ Couns 2009;74:295-301.

6. Kurtz S, Silverman J, Draper J. Teaching and learning communication skills in medicine. Oxford: Radcliffe Publishing; 2005.

7. Shilling V, Jenkins V, Fallowfield L. Factors affecting patient and clinician satisfaction with the clinical consultation: can communication skills training for clinicians improve satisfaction? Psycho-oncology 2003;12:599-611.

8. Fallowfield L, Jenkins V, Farewell V, Solis-Trapala I. Enduring impact of communication skills training: results of a 12-month follow-up. BrJ Cancer 2003;89:1445-9.

9. Lienard A, Merckaert I, Libert Y, Bragard I, Delvaux N, Etienne A-M, et al.Transfer of communication skills to the workplace during clinical rounds: impact of a program for residents. PLoS One 2010;5:e12426.

10. Rotthoff T, Baehring T, David D, Bartnick C, Linde F, Willers R, et al. The value of training in communication skills for continuing medical education. Patient Educ Couns 2011;84:170-5.

11. Silverman J. Clinical communication training in continuing medical education: possible, do-able and done? Patient Educ Couns 2011;84:141-2.

12. Back A, Arnold R, Baile W, Tulsky J, Barley G, Pea R, et al. Faculty development to change the paradigm of communication skills teaching in oncology. J Clin Oncol 2009;27:1137-41.

13. Rider E, Volkan K, Hafler J. Pediatric residents' perceptions of communication competencies: implications for teaching. Med Teach 2008;30:208-17.

14. O'Neill P, Jones A, Willis S, McArdle P. Does a new undergraduate curricu- lum based on tomorrow's doctors prepare house officers better for their first post? A qualitative study of the views of preregistration house officers using critical incidents. Med Educ 2003;37:1100-8.

15. Berkhof M, van Rijssen H, Schellart A, Anema J, van der Beek A. Effective training strategies for teaching communication skills to physicians: an over- view of systematic reviews. Patient Educ Couns 2011;84:152-62.

16. Hulsman R, Ros W, Winnubst J, Bensing J. Teaching clinically experienced physicians communication skills. A review of evaluation studies. Med Educ 1999;33:655-68.

17. Maguire P, Faulkner A, Booth K, Elliott C, Hillier V. Helping cancer patients disclose their concerns. Eur J Cancer 1996;32:78-81.

18. Salmon P, Young B. Creativity in clinical communication: from communication skills to skilled communication. Med Educ 2011;45:217-26.

19. van Dulmen A, \& Holl R. Effects of continuing paediatric education in interpersonal communication skills. Eur J Pediatr 2000;159:489-95.

20. van Dulmen A, van Weert J. Effects of gynaecological education on interpersonal communication skills. $\mathrm{Br}$ J Obstet Gynaecol 2001;108:485-91.

21. van Dulmen S. Patient-centredness. Patient Educ Couns 2003;51:195-6.

22. Bensing J, van Dulmen S, Tates K. Communication in context: new directions in communication research. Patient Educ Couns 2003;50:27-32.

23. Kirkpatrick D. Evaluating training programs: the four levels. Berrett-Koehler;1998.

24. Cheng E, Hampson I. Transfer of training: a review and new insights. Int J Manage Rev 2008;10:327-41.

25. Holton E. The flawed four-level evaluation model. Hum Resour Dev Quart 1996;7:5-22.

26. Yardley S, Dornan T. Kirkpatrick's levels and education evidence. Med Educ 2012;46:97-106.

27. Bates R. A critical analysis of evaluation practice: the Kirkpatrick model and the principle of beneficence. Eval Program Plann 2004;27:341-7. 
28. Hawken S. Good communication skills: benefits for doctors and patients. N Z Fam Pract 2005;32:185-9.

29. Collins J, Fauser B. Balancing the strengths of systematic and narrative reviews. Hum Reprod Update 2005;11:103-4.

30. Farrand P, Hussain F, Hennessy E. The efficacy of the mind map' study technique. Med Educ 2002;36:426-31.

31. Bloom B. Effects of continuing medical education on improving physician clinical care and patient health: a review of systematic reviews. Int J Technol Assess Health Care 2005;21:380-5.

32. van Dulmen S, Bensing J, Kruijver I. De schoen wringt, maar waar? Discre- panties. tussen het trainen, evalueren en praktiseren van consultvoeringsvaardigheden. Huisarts en Wetenschap 2002;19-22.

33. Veldhuijzen W, Ram P, van der Weijden T, Wassink M, van der Vleuten C. Much variety and little evidence: a description of guidelines for doctor patient communication. Med Educ 2007;41:138-45.

34. Rollnick S, Kinnersley P, Butler C. Context-bound communication skills training: development of a new method. Med Educ 2002;36:377-83.

35. Libert Y, Conradt S, Reynaert C, Janne P, Tordeurs P, Delvaux N, et al. Improving doctor's communication skills in oncology: review and future perspectives. Bull Cancer 2001;88:1167-76.

36. Heaven C, Clegg J, Maguire P. Transfer of communication skills training from workshop to workplace: the impact of clinical supervision. Patient Educ Couns 2006;60:313-25.

37. Henwood P, Altmaier E. Evaluating the effectiveness of communication skills training: a review of research. Clin Perform Qual Health Care 1996;4:154-8.

38. van Nuland M, Thijs G, Van Royen P, Van den Noortgate W, Goedhuys J.Vocational trainees' views and experiences regarding the learning and teach- ing of communication skills in general practice. Patient Educ Couns2010;78:65-71.

39. Veldhuijzen W, Ram P, van der Weijden T, Niemantsverdriet S, van der Vleuten C. Characteristics of communication guidelines that facilitate or impede guideline use: a focus group study. BMC Fam Pract 2007;8:31-44.

40. Hager P, Hodkinson P. Moving beyond the metaphor of transfer of learning. Br Educ Res J 2009;35:61938.

41. Cook D, Bordage G, Schmidt H. Description, justification and clarification: a framework for classifying the purposes of research in medical education. Med Educ 2008;42:128-33.

42. de Haes H, Bensing J. Endpoints in medical communication research, proposing a framework of functions and outcomes. Patient Educ Couns 2009;74:287-94.

43. Visser A, \& Wysmans M. Improving patient education by an in-service communication training for health care providers at a cancer ward: communication climate, patient satisfaction and the need of lasting implementation. Patient Educ Couns 2010;78:402-8.

44. Grol R. Successes and failures in the implementation of evidence-based guide- lines for clinical practice. Med Care 2001;39:46-54.

45. Grol R, Baker R, Moss F. Quality improvement research: understanding the science of change in health care. Qual Saf Health Care 2002;11:110-1.

46. Grol R, Bosch M, Hulscher M, Eccles M, Wensing M. Planning and studying improvement in patient care: the use of theoretical perspectives. Milbank $Q 2007 ; 85: 93-138$.

47. Grol R, \& Grimshaw J. From best evidence to best practice: effective implementation of change in patients' care. Lancet 2003;362:1225-30.

48. Greenhalgh T, Robert G, MacFarlane F, Bate P, Kyriakidou O. Diffusion of innovations in service organizations: systematic review and recommendations. Milbank $Q$ 2004;82:581-629.

49. Mazmanian P, \& Davis D. Continuing medical education and the physician as a learner. J Am Med Assoc 2002;288:1057-60.

50. van der Weijden T, van Veenendaal H, Timmermans D. Shared decision- making in the Netherlandscurrent state and future perspectives. Ger J Qual Health Care 2007;101:241-6.

51. Bosch M, van der Weijden T, Wensing M, Grol R. Tailoring quality improvement interventions to identified barriers: a multiple case analysis. J Eval Clin Pract 2007;13:161-8.

52. Haskell R. Transfer of learning: cognition, instruction, and reasoning. Academic Press; 2001.

53. Ertmer PA, Newby TJ. Behaviorism, cognitivism, constructivism: comparing critical features from an instructional design perspective. Perform Improv Quart 1993;6:50-72.

54. Engestrom Y. Activity theory and individual and social transformation. Perspect Act Theory 1999;19-38. 
55. Engestrom Y. Activity theory as a framework for analyzing and redesigning work. Ergonomics 2000;43:960-74.

56. Engestrom Y. Expansive learning at work: toward an activity theoretical reconceptualization. J Educ Work 2001;14:133-56.

57. Engestrom Y, Kerosuo H. From workplace learning to inter-organizational learning and back: the contribution of activity theory. J Workplace Learn 2007;19:336-42.

58. Engestrom Y, Sannino A. Studies of expansive learning: foundations, findings and future challenges. Educ Res Rev 2010;5:1-24.

59. Guile D, Griffiths T. Learning through work experience. J Educ Work2001;14:113-31.

60. Guile D, Young M. Transfer and transition in vocational education: some theoretical considerations. Between school and work: new perspectives on transfer and boundary crossing; 2003. p. 63-84.

61. van Oers B. From context to contextualizing. Learn Instr 1998;8:473-88.

62. Beach K. Consequential transitions: a sociocultural expedition beyond transfer in education. Rev Res Educ 1999;24:101-39.

63. Beach K. Consequential transitions: a developmental view of knowledge propagation through social organizations. In: Between school and work: new perspectives on transfer and boundary-crossing; 2003. p. 39-62.

64. Beach M, Roter D, Wang N, Duggan P, Cooper L. Are physicians' attitudes of respect accurately perceived by patients and associated with more positive communication behaviors? Patient Educ Couns 2006;62:347-54.

65. Farrington J. Training transfer: not the 10\% solution. Perform Improv Quart 2011;24:117-21.

66. Blume B, Ford J, Baldwin T, Huang J. Transfer of training: a meta-analytic review. J Manage 2010;36:1065-105.

67. Baldwin T, \& Ford J. Transfer of training: a review and directions for future research. Pers Psychol 1988;41:63-105.

68. Burke L, \& Hutchins H. Training transfer: an integrative literature review.Hum Resour Dev Rev 2007;6:263-96.

69. Grossman R, \& Salas E. The transfer of training: what really matters. IJTD 2011;15:103-20.

70. Leberman S, McDonald L, Doyle S. The transfer of learning: participants' perspectives of adult education and training. Burlington: Gower Publishing Company Limited; 2006.

71. Cromwell S, \& Kolb J. An examination of work-environment support factors affecting transfer of supervisory skills training to the workplace. Hum Resour Dev Quart 2004;15:449-71.

72. Pope C, Van Royen P, Baker R. Qualitative methods in research on healthcare quality. Qual Safe Health Care 2002;11:148-52.

73. Mezirow J. Learning as transformation: critical perspectives on a theory in progress. San Francisco: Jossey-Bass Inc Pub; 2000.

74. Evans K, Fuller A. Improving workplace learning. New York: Routledge, Taylor \& Francis; 2006.

75. Evans K, Kersh N. Recognition of tacit skills and knowledge: sustaining learning outcomes in workplace environments. J Workplace Learn 2004;16:63-74.

76. Eraut M. Learning from other people in the workplace. Oxf Rev Educ 2007;33:403-22.

77. Eraut M. Informal learning in the workplace. Stud Contin Educ 2004;26:247-73.

78. Holton E. Holton's evaluation model: new evidence and construct elaborations. Adv Dev Hum Resour 2005; 7:37-54.

79. Holton E, Bates R, Ruona W. Development of a generalized learning transfer system inventory. Hum Resour Dev Quart 2000;11:333-60.

80. Holton E, Bates R, Seyler DL, Carvalho MB. Toward construct validation of a transfer climate instrument. Hum Resour Dev Quart 1997;8:95-114.

81. Mezirow J. Transformative learning as discourse. J Transform Educ 2003;1:58-63.

82. Mezirow J. Transformative dimensions of adult learning. San Francisco: Jossey-Bass; 1991.

83. Mezirow J. Transformative learning: theory to practice. New Dir Adult Cont Educ 1997;1997:5-12. 
Chapter 3

\title{
Residents' perceived barriers to communication skills learning: comparing two medical work contexts in postgraduate training
}

\author{
V. van den Eertwegh \\ J. van Dalen \\ S. van Dulmen \\ C. van der Vleuten \\ A. Scherpbier
}

Patient Educ Couns 2014:95:91-97 


\section{Abstract}

Background: Contextual factors are known to influence the acquisition and application of communication skills in clinical settings. Little is known about residents' perceptions of these factors.

Objective: To explore residents' perceptions of contextual factors affecting the acquisition and application of communication skills in the medical workplace.

Method: We conducted an exploratory study comprising seven focus groups with residents in two different specialities: general practice $(n=23)$ and surgery $(n=18)$.

Results: Residents perceive the use of summative assessment checklists that reduce communication skills to behavioral components as impeding the learning of their communication skills. Residents perceive encouragement to deliberately practice in an environment in which the value of communication skills is recognized and support is institutionalized with appropriate feedback from role models as the most important enhancing factors in communication skills learning.

Conclusion: To gradually realize a clinical work environment in which the above results are incorporated, we propose to use transformative learning theory to guide further studies.

Practical implications: Provided it is used continuously, an approach that combines self-directed learning with observation and discussion of resident-patient consultations seems an effective method for transformative learning of communication skills. 


\section{Introduction}

There seems to be a mismatch between the increasing prominence of communication in health care and doctors' training and skills in this respect. Although medical educators are increasingly taking account of the shift from biomedical to bio psychosocial care and, more recently, from patient-centered to relationship-centered care [1-5], postgraduate communication skills training is still reported to be deficient in structure and continuity $[6,7]$. Patients increasingly call for doctors who listen, and complain of doctors' lack of involvement and inadequate provision of information [8-13]. Doctors, however, report knowing about the importance of adequate doctor-patient communication but having difficulty applying those communication skills in their actual workplace [14-17]. Bombeke et al. [18] recently validated earlier findings that students' patient-centeredness declines during medical training, and that their communication skills, acquired at the undergraduate stage of their training, were not applied in the workplace. Consequently, there is a need for improvement of and more attention to transfer of communication skills at postgraduate level.

Transfer of learning in general has among others been addressed by Burke et al. [19], who mapped influencing variables in the trainee, the training design and delivery, and the work environment. The main influencing variables found in other studies are a supportive social environment, time constraints, fatigue, and existing beliefs and attitudes [20-25]. Exactly how this complex interaction of factors seems to be influencing the acquisition and application of new skills and knowledge is not fully understood yet. A recent literature review identified gaps in research on the transfer of communication skills to the clinical workplace [26]. It concludes that effective communication skills training is recommended to be based on constructivist principles and that learning is not an isolated activity in a teaching setting, but an ongoing process in interaction with the demands of the workplace. To facilitate transfer, teaching should meet the needs of the learners and should be offered in representative contexts [26]. But little is known about how these contexts influence the learning and transfer of communication skills. More attention should thus be paid to investigate which factors in specific medical work contexts influence the transfer of communication skills [20,24-26]. Given the paucity of literature on this topic, we addressed the following research question: What factors do medical residents perceive to be obstacles or facilitators with regard to the acquisition and application of communication skills in their clinical context?

We decided to investigate residents' perceptions, since residents are learning communication skills while applying these skills in practice. Consequently they have first-hand experience of contextual factors at play in the transfer of communication skills from training to practice. 
In this study we used the term 'context' to mean the work environment that is actively produced and influenced by interactions between individuals and their environment [27-29].

In order to clarify characteristics of the work environment that may influence the development of communication skills, we chose to compare perceptions of residents from two different work contexts. White et al. [30] showed that surgeon-patient consultations differed systematically from primary care consultations, as have several other studies [31,32]. We therefore chose to investigate and compare perceptions of residents general practice and residents surgery.

\section{Methods}

\subsection{Study design}

We chose to interview focus groups as this method is particularly appropriate for this type of exploratory research [33]. In comparison to individual interviews, focus groups enable the researcher to collect a broad range of perceptions as the group interaction stimulates participants to reflect more deeply on their own perceptions. Ideas expressed by participants act as triggers for other participants to explicate latent thoughts, perceptions and experiences [34-39].

\subsection{Sampling}

To explore the influence of different clinical contexts on residents' communication skills training, we sought the perspectives of general practice (GP) and surgical residents. The main differences between the actual work contexts we studied are described in table 1 . The most striking distinction appears to relate to systematic and continuous attention to communication skills, which is an integral component of GP training but not of surgical residency.

Study participants were recruited from residents in the first and third years of the postgraduate GP program of Maastricht University Medical Centere (MUMC) and among all surgical residents in training at the time of the study in the departments of surgery and orthopedic surgery of MUMC and Atrium Hospital Heerlen, the Netherlands. We obtained permission for recruiting residents for the study from the heads of the departments. GP residents were approached during one of their weekly sessions at the Department of Family Practice, and surgical residents were approached by the first author (VvdE) during regular resident meetings in their hospitals. After the set-up of the study was explained, residents were invited to volunteer for participation in a focus group to be held between January 2012 and February 2013. 
Table 1: Differences in work context between general practice and surgical postgraduate training

Postgraduate training and work context of the GP residents in our study:

Training lasts three years: 1 year in one GP practice, 1 year of three clinical placements in institutions, 1 year in another GP practice.

Every week residents attend a day release program at the Department of Family Practice.

Weekly training in communication skills consists in small group discussions of residents' videotaped consultations, facilitated by a GP and a behavioral scientist.

GP trainers have received special training to give residents feedback on communication skills and provide continuous individual support.

Residents hand in 40 video recordings of patient consultations they have conducted, of which six are used for the end-of-year summative assessment using a behavioral checklist.
Postgraduate training and work context of the surgical residents in our study:

Residency lasts 5 or 6 years depending on the speciality and residents have placements in regional and academic hospitals.

The program does not include an off-site day release program.

Supervisors observe residents daily during patient encounters, but the focus is on surgical knowledge and skills.

Supervisors have not been trained to teach and give feedback on communication skills.

Off-site communication skills training is available for surgical residents in the form of a four-hour communication skills session within the annual course on the CanMEDS competencies.

Of 32 GP residents who volunteered, eight were unable to participate for personal reasons, resulting in a total of 23 participants. Four focus groups were composed in accordance with residents' date and time preferences. A total of 24 surgical residents were willing to participate, and the department secretariats selected appropriate time slots for three focus-group sessions. Six residents appeared unable to participate for personal reasons or because they were still in theatere at the time of the session, yielding a total of 18 participants. The mean age was 30 years for GP residents and 29 years for surgical residents. The male-female ratio was 20:80 for GP and 40:60 for surgical residents. In compensation for their participation the residents were offered refreshments during the sessions.

\subsection{Procedure}

The focus-group interviews lasted around 90 minutes. The sessions were guided by one moderator and one observer (who monitored process and content of the interview). All were experienced interviewers, who had no functional or professional relationship with any of the participants. In order to help the group get into the topic at the beginning of sessions, the_moderator asked the participants to think about their experiences regarding communication skills training at under- and postgraduate level. After a few minutes the moderator opened the discussion by asking: 'What factors influence the way you apply in practice those communication skills that you acquired earlier.' 
Except for asking probing questions when needed, the moderator provided no active guidance. As no new information with relevance to the research question emerged during the fourth focus group of GP residents and the third focus group of surgical residents, it was concluded that saturation of data had been attained.

\subsection{Analysis}

For maximum consistency of data collection across groups, the moderators and observer met in between sessions to discuss the preceding sessions and prepare for the next one. With the participants' consent, all interviews were audio taped and transcribed verbatim. Each session was followed by a member checking procedure._VvdE and JvD independently analyzed and coded the transcripts. Using principles of thematic analysis [40] the researchers further analyzed the coded data, clustering codings into coherent categories by abstracting salient themes and exploring patterns and relationships. While the dataset was treated as a whole, special attention was paid to the differences between the surgical and the general practice residents as these two contexts were expected to lead to diverging perceptions on the role of communication skills practice. In an iterative process, $\mathrm{VvdE}$ and JvD discussed and compared their codings until consensus was reached and emerging themes were established. All authors discussed and agreed on the main themes.

\subsection{Ethics}

The study was approved by the Ethics Committee of the Dutch Association for Medical Education (NVMO) (file no. 159). At the beginning of each session, it was explained to the participants that the data would be processed anonymously and they were free to withdraw from the study at any stage. Consent was obtained from each participant at the start of the session and signed consent forms were collected at the end.

\section{Results}

Five main factors appeared to impede or enhance the learning and application of residents' communication skills. The factors appeared applicable to both groups of data (GP as well as surgery) and are described below. Quotes are coded with GP or surgery followed by the number of the focus group the quote comes from. The influence of the two different work contexts is discussed throughout the results section.

Residents reported being deeply motivated to improve their communication with patients. Residents in general practice as well as their colleagues in surgery mentioned working beyond their regular work hours to check on patients whom they thought had not understood the doctor's information or who they remembered being worried earlier during the day. 
One of the strongest inhibiting factors on the learning of communication appeared to be the current form of assessment by checklists (MAAS-Global [41] in GP and Mini-CEX in surgery). These checklists did not do justice to the qualities of doctor-patient communication the residents wanted to improve.

"Of the 40 videos you have to record, 6 are watched and assessed. And when you are recording, you keep thinking 'oh, this consultation may be selected for the test.' You become a different kind of doctor when you are recording, just to get a good rating on the video test."(GP1)

Although GP residents were perfectly aware that not every consultation calls for the use of the full spectrum of behavioral options, when recording a consultation they felt compelled to display a type of artificial communication behavior that would tick as many checklist boxes as possible.

"We always want to make sure that we have covered all items of the Maas-Global assessment checklist. I feel that is what we are expected to do from the way we are assessed. But I think it is a problem of our education system that we are focused on scoring items, instead of focusing on how to establish a positive relationship with the patient." (GP1)

Apart from its negative impact on patient consultations, the GP residents criticized the assessment format for being neither effective nor instructive as they received no or only very general feedback._The GP residents thought the checklist did not enhance skill development and felt the assessment was a goal in itself rather than an instrument for skills improvement.

"I have found the meetings and conversations with my supervisor, in which I get feedback on a specific learning goal we have set beforehand, to be far more helpful than all those video assessments put together." (GP3)

Additionally, the communication skills of the surgical residents were only seldom formally assessed. They were implicitly covered by the obligatory mini-CEXs (clinical examinations), but the primary focus of that assessment was their surgical performance. Just to make sure they met the target of ten mini-CEXs, the residents asked their supervisor to write the little communicational feedback on a mini-CEX form. As there was no link between their personal learning goals and the feedback or comments on the mini-CEX forms and no follow-up over time, residents considered the mini-CEX to be of hardly any benefit to their communication skills. Like the GP residents, the surgical residents appeared to experience an impeding effect of summative assessment on their communication learning. 
A learning environment in which you monitor things together and practise would be far more useful than just collecting the required number of mini-CEX forms. We think that would be really useful and would work best (S1).

Second, Confrontation with their communication behavior was reported as a powerful stimulating factor for learning. Surgical and GP residents both said it was necessary for them to be directly confronted with a communication problem before they would consider changing their behavior.

"When you see yourself on video it can be really scary, but you learn a lot from it. For instance typing and looking at the computer screen during a consultation with a patient. If you would never see or discuss that, you would just keep on doing it for ever. Videotapes confront you with what you do and make you aware of it. It is only then that you realize that you can do better." (GP4)

Being confronted with real situations was considered by the residents to be far more effective than sessions with simulated patients or role-play. The authenticity of the trigger for learning was a powerful incentive.

Surgical residents said they were only very rarely confronted with their own communication behaviors and consequently remained mostly unaware of weaknesses and how they might redress these. Supervisors paid no attention to communication behavior and there were no dedicated sessions in the training program for reflection on their performance. Some residents in surgery organized video recordings themselves, at the cost of running late in their office hours.

"Every morning, time is scheduled for one specialist to observe a consultation. During an observed consultation you may receive feedback but it is very unusual for feedback to deal with communication. It depends very much on the specialist in question whether you are confronted with your communication style. Most of them are not really inclined to discuss communication skills." (S3)

As a third factor repetition appeared to enhance the learning and application of communication skills. Residents repeatedly argued that communication was part of "who you are and how you develop as a person", and they thought that continuous attention and repeated practice with respect to communication skills should be an integral part of their training.

In the GP work context, residents received regular concrete feedback on recorded consultations with suggestions for alternative behavior, which they were encouraged to try out and practice. Residents emphasized that repeated practice of new behaviors was crucial, firstly to experience if the behavior was really effective, secondly to become accustomed to using the behavior, and finally to integrate it in their natural communication patterns. 
"If things go well, you think 'hey it works' and then you think, 'well I should do this more often' ... and then you find yourself relapsing if you do not continue to pay attention to it regularly." (GP1)

Most GP residents said their supervisors were usually willing to give them 10 to 15 minutes extra consultation time in addition to the usual ten minutes to practice new behavior during work hours. This prevented their reverting to old behavior due to stress or time constraints.

"You see patients every day, due to the attitude of my supervisor I continuously have the opportunity to learn and train and I only have to think back on what feedback I received from the video discussions and implement it to have another couple of practice moments for that day." (GP2)

Surgical residents encountered difficult situations in their daily work as well, but unlike their GP counterparts they did not discuss these situations with supervisors and consequently did not benefit from advice on alternative behaviors they might try. Also their daily workload left no time for experimentation with new approaches. They said they would like to be given regular opportunities to practice difficult situations in a safe group atmosphere.

"It would be useful if we had sessions about things many of us find difficult and if together we could have some hands-on practice. If you practice something, it is much easier to remember and recall later." (S2)

Fourth, GP residents testified to the effectiveness of systematic and continuous attention to communication.

"Most supervisors create a work climate in which you feel supported. Also because the supervisors are trained and know how to guide us and we have our weekly meetings in which we discuss communication matters." (GP3)

This was in sharp contrast to surgical residents who frequently reiterated: "We don't have time; we are too busy to spend time on communication issues". When this notion was explored it appeared that lack of time was rather a symptom of a work context failing to support residents in improving their communication skills. Residents observed that even though the department head acknowledged the importance of communication skills, this support did not materialize into concrete measures to stimulate skill development.

"No hard and fast rules are laid down in the training requirements stipulating how we have to pay attention to communication. The department head considers communication to be important so I think there is room for attention to it but there are 
no stimulating and supporting measures; you have to arrange for everything yourself and you are not given extra time to arrange this."(S2)

Surgical residents expressed a clear need for structured and continuous attention and support with regard to communication skills development. They indicated it was not enough for them to attend the isolated, off-site course every year without any follow-up or connection with their work context. Skills learned during such a course evaporated quickly. They suggested ways to improve their communication skills, such as installing a video in one of the consultation rooms to enable them to record their patient encounters without time loss, for discussion with senior residents, supervisors with an interest in communication, or behavioral scientists.

"In fact there is very little monitoring. There are plenty of opportunities for learning in practice but to make these effective more active facilitation and support is needed. The department could for instance buy a camera to give us the opportunity to record our own patient consultation." (S1)

Finally, good role modeling was seen as a powerful learning tool. Most GP residents had a trusting relationship with their supervisor and received feedback tailored to concrete individual learning goals. This was considered supportive of self-directed and effective learning.

"I am fortunate in that my supervisor is very good where matters of communication are concerned. We take time every week to discuss difficult situations and I really learn a lot from that." (GP2)

The surgical residents observed that it was not common practice for their clinical supervisors to attend training in how to support residents in the development of communication skills or how to give feedback on these skills. Consequently, surgical residents received little support and their supervisors' feedback was primarily focused on medical content and accurate diagnosis.

"Partly as a result of our undergraduate training we are sensitive to communication, we are trained to do it, and I think the same does not apply for most of our superiors. I don't think staff members really get it. Most of them have difficulty verbalizing things where communication is concerned, only some of them are very good at finding the right words. The focus is on medical matters only, there is no attention whatsoever given to communication." (S2)

Surgical residents also remarked that most supervisors in the hospital did not observe them while communicating with patients, causing many learning opportunities to go unused. However, they highly valued the feedback on communication they received from nurses and peers. 
"Supervisors may attend ward rounds, but they have no idea what is really going on and what is arranged on the ward. Nurses give you a very different sort of feedback, much more practical and related to communication. Senior staff would not even notice how you communicate." (S3)

"My peers are more useful to me than experienced doctors, because they give more feedback and point out more problem areas than does senior staff. They probably understand better what is going on with you". (S3)

\section{Discussion and Conclusion}

\subsection{Discussion}

Residents in general practice and their colleagues in surgery both mentioned being motivated for excellent doctor-patient communication. The value of being confronted with their own behavior was reported as a strong stimulus for learning. Practice and repetition was regarded as a necessary ingredient of adequate training, and such training was judged to be more effective when better embedded in institutionalized attention and support by the workplace's organization. Moreover, good quality and focus of feedback, tailored to their own learning needs was considered vital for good learning.

The reductionist effect of a behavioral checklist noted by GP residents is consistent with conclusions by Salmon \& Young [42] (and others like Epstein et al.[43] and Rees [44]) that communication skills cannot be atomized and are best assessed using a holistic approach. We would support this view provided generic communication skills are taught well in the undergraduate curriculum. The residents' complaints that assessment using a checklist does not promote learning is in accordance with the view expressed by White et al.[30] that there is no single or standard way for a consultation to play out, and with Veldhuijzen et al.'s call for awareness of the uniqueness and specific goals of each consultation [45]. We recommend that those in charge of the program should take to heart the adage 'assessment drives learning' [46] and recognize that the reductionist effect of the assessment checklist actually counteracts the positive effects of their systematic communication training efforts. As noted by Bombeke et al.[47]: "Without inner motivation and positive attitudes, communication skills training leads to short-term faking behavior. When residents formulate their own learning goals with help and support from supervisors, learning is likely to be more intrinsic and focused on personal development over time instead of on passing a checklist-type test" [48].

Our findings are in line with the opinions of Lévesque et al.[49] and Khanum [50], who proposed to use the theoretical underpinnings of transformative learning theory to improve medical communication skills learning, and we recommend further research to explore how principles of transformative learning can be applied to optimize the 
learning of medical communication skills, in line with our plea for a constructivist approach. Transformative learning theory, an adult learning theory developed by Mezirow [51-53] and sometimes referred to as triple-loop learning [54]posits that deep learning results from reflection on and changes in the frame of reference and underlying assumptions and beliefs of an individual, and that the learning and development of complex skills, like communication, entails three dimensions: psychological (changes in understanding of the self), convictional (revision of belief systems), and behavioral (changes in action) $[53,55]$. Because transformative learning focuses on these three dimensions, as opposed to an exclusive focus on behavior, we think it might provide an appropriate theoretical framework for an approach that promises lasting improvement of the learning and transfer of communication skills. In this way, learning is not a onetime occurrence but a lifelong development. This appears to echo the view expressed by residents that learning communication skills is an integral component of continuous personal development and a part of "who you are and how you develop as a person" implying the need for change at a deep, personal level. Transformative learning is also consistent with residents' perceived effects of confrontation as an incentive to take action to change their communication strategies, emphasizing that confrontation with a problem that needs to be solved sparks eagerness to learn. Transformative learning is also consistent with residents' perceived importance of repetition and practice in authentic situations as a prerequisite for lasting modifications of their frame of reference and behavior. Principles of transformative learning seem to be an excellent fit with the factors we distilled from the perceptions voiced by the residents.

Due to the design of the current study, focus groups in a Dutch healthcare setting, the transferability of the results presented in this study could be limited and deserves further investigation. We purposively selected participants from two different contexts; selection in a different medical context could elaborate our findings. We acknowledge that voluntary participation may have caused selection bias with low representation of residents with little interest in communication. However, when we recruited participants, we noticed that both residents with a positive and those with a more cynical attitude toward communication skills volunteered, which would diminish the likelihood of selection bias.

\subsection{Conclusion}

As early as the fourth century B.C. Aristotle wrote: "We are what we repeatedly do. Excellence is not an act, but a habit". This notion supports an important conclusion suggested by the findings: communication skills need continuous attention and practice to become an integral component of a doctor's clinical skills. More specifically we found that residents perceived training and transfer of doctor-patient communication to be impeded by the use of summative assessment checklists that reduce communication skills to behavioral components. Residents reported training and transfer of doctorpatient communication to be enhanced when they are encouraged to deliberately and 
frequently practice in an environment in which the value of these skills is recognized and acknowledged and where appropriate feedback from role models is available.

\subsection{Practice implications}

In order to foster transformative learning of communication skills, more attention should be given to contextual factors [56]. Setting up a system of work-based coaching that enables effective supervision of residents' communication skill development could foster a more reflective and non-threatening learning environment [16,17]. Observation of consultations (video or live) combined with self-directed learning and constructive feedback seems an effective method in this regard provided it is firmly embedded in the daily work context and used consistently and continuously. A sound structure for communication skill development could result in a safer and more effective learning climate and make the learning and application of communication skills a truly transformational process.

Acknowledgment: Special thanks to Renée Stalmeijer for her critical feedback on the methodological aspects of the study and Mereke Gorsira for the revision of the English language, Bas Maiburg Head of postgraduate department of general practice Maastricht, Ide Heyligers Head of orthopedic surgery Atrium Hospital Heerlen, Laurents Stassen Head of general surgery Maastricht Medical Center en Heleen Staal orthopedic surgery Maastricht Medical Center; for their help in facilitating the organization of the focus groups.

Conflict of interest: The authors have no conflict of interest.

Role of funding: The authors did not receive any funding for preparing and conducting this research. 


\section{References}

1. Engel G. How much longer must medicine's science be bound by a seventeenth century world view? Fam Syst Med 1992;10:333-46.

2. Simpson M, Buckman R, Stewart M, Maguire P, Lipkin M, Novack D, Till J. Doctor-patient communication: the Toronto consensus statement. BMJ 1991;303:1385-7.

3. Tresolini C, Pew Fetzer Task Force. Health professions education and Relationship-centered care. Pew Health Professions Commission. San Francisco CA 1994.

4. Blank L, Kimball H,McDonald W, Merino J. Medical professionalism in the new millennium: a physician charter 15 months later. Annals Int Med 2003;138:839-41.

5. Frenk J, Chen L, et al. Health professionals for a new century: transforming education to strengthen health systems in an interdependent world. Lancet 2010;376:1923-58.

6. Rotthoff T, Baehring T, David D, Bartnick C, et al. The value of training in communication skills for continuing medical education. Patient Educ Couns 2011; 84:170-5.

7. Silverman J. Clinical communication training in continuing medical education: Possible, do-able and done? Patient Educ Couns 2011;84:141-2.

8. Elwyn G, Edwards A, Kinnersley P. Shared decision-making in primary care: the neglected second half of the consultation. Brit J General Pract 1999;49:477-82.

9. Stewart E, Marzio D, Guggenheim D, et al. Resident Scores on a Patient Satisfaction Survey: Evidence for Maintenance of Communication Skills Throughout Residency. J Graduate Med Educ 2011;3:487-9.

10. Jenkins V, Fallowfield L, Saul J. Information needs of patients with cancer: results from a large study in UK cancer centres. Brit J Cancer 2001;84:468-72.

11. Scherger J. What patients want. J Fam Practice 2001;50:137-9.

12. Brody D, Miller S, Lerman C. et al. The relationship between patients' satisfaction with their physicians and perceptions about interventions they desired and received. Medical care 1989;27:1027-35.

13. Kravitz R, Cope D, Bhrany V. Internal medicine patients' expectations for care during office visits. J Gen Int Med 1994;9:75-81.

14. Williams C, Cantillon $\mathrm{P}$, Cochrane M. The doctor-patient relationship: from undergraduate assumptions to pre-registration reality. Med Educ 2001;35:743-747.

15. Back A, Arnold R, Baile W, et al. Faculty development to change the paradigm of communication skills teaching in oncology. J Clin Oncol 2009;27:1137-41

16. Junod P, Sommer J, Hudelson P, et al. Clinical supervisors' perceived needs for teaching communication skills in clinical practice. Med Teach 2009;31:316-22.

17. Junod P, Sommer J, Hudelson P, et al. Residents' perceived needs in communication skills training across in-and outpatient clinical settings. Educ Health 2009;22:280-94.

18. Bombeke K, Symons L, Vermeire E, et al. Medical students trained in communication skills show a decline in patient-centred attitudes: An observational study comparing two cohorts during clinical clerkships. Patient Educ Couns 2011;84:310-8.

19. Burke L, Hutchins H. Training transfer: An integrative literature review. Hum Resour Dev Rev 2007;6:263-96.

20. Fallowfield L, Jenkins V, et al. Enduring impact of communication skills training: results of a 12-month follow-up. Br J Cancer 2003;89:1445-9.

21. Lienard A, Merckaert I, Libert Y, et al. Transfer of Communication Skills to the Workplace during Clinical Rounds: Impact of a Program for Residents. PLoS ONE 2010;5:e12426.

22. Hulsman R, Ros W, Winnubst J, Bensing J. Teaching clinically experienced physicians communication skills. A review of evaluation studies. Med Educ 1999;33:655-68.

23. Henwood P, Altmaier E. Evaluating the effectiveness of communication skills training: a review of research. Clin Perform Qual Health Care 1996;4:154-8.

24. Heaven C, Clegg J, Maguire P. Transfer of communication skills training from workshop to workplace: the impact of clinical supervision. Patient Educ Couns 2006;60:313-325.

25. Madera J, Steele S, Beier M. The temporal effect of training utility perceptions on adopting a trained method: the role of perceived organizational support. Hum Resour Dev Quart 2011;22:69-86.

26. van den Eertwegh V, Dulmen S, van Dalen J, et al. Learning in context: Identifying gaps in research on the transfer of medical communication skills to the clinical workplace. Patient Educ Couns 2013;90:184-192. 
27. Gordon M. When shifting context: the role of context dynamics in educating and understanding handover. Med Educ 2013;47:438-40.

28. Pimmer C, Pachler N, Genewein U. Contextual dynamics in clinical workplaces: learning from doctordoctor consultations. Med Educ 2013;47:463-75.

29. Durning S, Artino A, Pangaro L, et al. Perspective: redefining context in the clinical encounter: implications for research and training in medical education. Acad Med 2010; 85:894-901.

30. White S, Stubbe M, Dew K, et al. Comunication between surgeon and patient in outpatient consultations. ANZ J Surgery 2013;83:307-11.

31. Essers G, van Weel-Baumgarten E, Bolhuis S. Mixed messages in learning communication skills? Students comparing role model behaviour in clerkships with formal training. Med Teach 2012;34:659-65.

32. Al Ansari A. A Comparison Study of Communication Skills between General Surgery and General Practice Residents on First-time Patient Visits. Canadian Med Educ J 2012;1:42-51.

33. Kitzinger, J. Qualitative Research: Introducing focus groups. Brit Med J 1995;311: 299-302.

34. Stewart D, Shamdasani P, Rook D. Focus Groups: Theory and Practice. Thousand Oaks, California: Sage Publications; 2007.

35. Krueger R, Casey M. Focus Groups, A Practical Guide for Applied Research (4th ed.). Thousand Oaks, California: Sage Publications; 2009.

36. Starks H, Trinidad S. Choose your method: A comparison of phenomenology, discourse analysis, and grounded theory. Qualitative Health Research 2007;17:1372-80.

37. Morse J, Field P. Qualitative research methods for health professionals. SAGE Publications, Inc 1995.

38. Barbour R. Making sense of focus groups. Med Educ 2005;39:742-50.

39. Smithson J. Using and analysing focus groups: limitations and possibilities. Int J Social Research Meth 2000;3:103-19.

40. Attride-Stirling J. Thematic networks: an analytic tool for qualitative research. Qual Research 2001;1:385405.

41. Dalen J, Bartholomeus P, Kerkhofs E, et al. Teaching and assessing communication skills in Maastricht: the first twenty years. Med Teach 2001;23:245-51.

42. Salmon P, Young B. Creativity in clinical communication: from communication skills to skilled communication. Med Educ 2011;45:217-26.

43. Epstein R, Hundert E. Defining and assessing professional competence. JAMA 2002;287:226-35.

44. Rees C, Sheard C. Undergraduate medical students' views about a reflective portfolio assessment of their communication skills learning. Med Educ 2004;38:125-8.

45. Veldhuijzen W, Ram P, van der Weijden T, et al. Characteristics of communication guidelines that facilitate or impede guideline use: a focus group study. BMC Fam Pract 2007;8:31-44.

46. Van der Vleuten C, Schuwirth L, Scheele F, et al. The assessment of professional competence: building blocks for theory development. Best Pract Research Clin Obst Gyn 2010;24:703-19.

47. Bombeke K, Symons L, Vermeire E, et al. Patient-centredness from education to practice: The'lived'impact of communication skills training. Med Teach 2012;34:338-48.

48. Van der Vleuten C, Schuwirth L, Scheele F, et al. A model for programmatic assessment fit for purpose. Med Teach 2012;34:205-14.

49. Lévesque M, Hovey R, Bedos C. Advancing patient-centered care through transformative educational leadership: a critical review of health care professional preparation for patient-centered care. $J$ Healthcare Leadership 2013;5:35-46.

50. Khanum Z. Effectiveness of reflective exercises for obstetrics and gynaecological residents. J College Physicians Surgeons 2013;23:468-71.

51. Mezirow J. Transformative learning: Theory to practice. New Dir Adult Cont Educ 1997;74:5-12.

52. Mezirow J. Transformative dimensions of adult learning. San Francisco: Jossey-Bass; 1991.

53. Mezirow J. Transformative learning as discourse. J Transform Educ 2003;1:58-63.

54. Peschl M. Triple-loop learning as foundation for profound change, individual cultivation, and radical innovation. Construction processes beyond scientific and rational knowledge. Constructivist Found 2007;2:136-45.

55. Elias M, O’Brien M, Weissberg R. Transformative leadership for social-emotional learning. Principal Leadership 2006;7:10-3.

56. Hager P, Hodkinson P. Moving beyond the metaphor of transfer of learning. British Educ Research J 2009;35:619-38. 



\section{Chapter 4}

\section{Exploring residents' communication learning process in the workplace:}

A five-phase model

Valerie van den Eertwegh

Cees van der Vleuten

Renée Stalmeijer

Jan van Dalen

Albert Scherpbier

Sandra van Dulmen

PLoS ONE 10(5): e0125958. doi:10.1371/journal.pone.0125958 


\begin{abstract}
Context: Competency-based education is a resurgent paradigm in professional medical education. However, more specific knowledge is needed about the learning process of such competencies, since they consist of complex skills. We chose to focus on the competency of skilled communication and want to further explore its learning process, since it is regarded as a main competency in medical education.

Objective: This study aims to explore in more detail the learning process that residents in general practice go through during workplace-based learning in order to become skilled communicators.

Methods: A qualitative study was conducted in which 12 GP residents were observed during their regular consultations, and were interviewed in-depth afterwards.

Results: Analysis of the data resulted in the construction of five phases and two overall conditions to describe the development toward becoming a skilled communicator: Confrontation with (un)desired behavior or clinical outcomes was the first phase. Becoming conscious of one's own behavior and changing the underlying frame of reference formed the second phase. The third phase consisted of the search for alternative behavior. In the fourth phase, personalization of the alternative behavior had to occur, this was perceived as difficult and required much time. Finally, the fifth phase concerned full internalization of the new behavior, which by then had become an integrated part of the residents' clinical repertoire. Safety and cognitive \& emotional space were labeled as overall conditions influencing this learning process.

Conclusions: Knowledge and awareness of these five phases can be used to adjust medical work and learning environments in such a way that development of skilled medical communication can come to full fruition and its benefits are more fully reaped.
\end{abstract}




\section{Introduction}

Any medical treatment is carried out within a context. How contextual factors contribute to the effectiveness of the therapy that is being administered, is a fascinating field of research [1]. The powerful effect of appropriate words and attitude, as part of this context effect, has been proven in many studies by now [2-6]. Skilled communication therefore has been included as a main competency in all major competency frameworks used in medical education, like CanMeds, ACGM and Good Medical Practice [710]. Exactly because of the generic character of communication skills, we have chosen to explore the learning process of this competency in more detail. Competencies like communication consist of complex skills and are assumed to be learned and developed most effectively in authentic professional work contexts. However when taking a closer look at the effectiveness of current communication training programs, medical students do not seem to attain professional expertise in communication [10-13]. At postgraduate level, the situation looks even more worrisome: doctors report that they are aware of the importance of adequate doctor-patient communication; however they face difficulties when trying to apply those communication skills in their actual workplace [14-17]. Continuous formal training in communication is mostly absent (in clinical specialties other than general practice) $[18,19]$ and when it is indeed offered, effectiveness studies demonstrate moderate to little effect in the long run [20-26].

This low level of effectiveness can partly be ascribed to deficiencies in the assessment methods used: it is argued, for instance, that assessment methods do not take proper account of context [27-30]. The complexity of the learning process itself could be another explanation for the reduced effectiveness of communication skills trainings. Wouda and Van de Wiel [31] used and adapted the reflective-impulsive model of social behavior in order to account for this complexity theoretically. The gist of this model is that it requires lifelong deliberate practice (in and outside the workplace) to become a skilled communicator. Previous research has aimed at the identification of barriers that residents encounter during this process of deliberate practice [32]. What the process of workplace-based learning of communication skills actually looks like in practice, however, has not yet been investigated further.

Different generic models do exist that describe the learning process of a new skill in general terms. One example of such a generic model is Maslow's well-known Four Stages of Learning Model [33]. This model describes four phases a person goes through when a new skill is acquired: moving from unconsciously incompetent to consciously incompetent, then to consciously competent, to finally become unconsciously competent. These generic phases, however, have not yet been applied to or further specified when it comes to the acquisition of communication skills in the workplace. As Salmon [34] puts it, skilled communication requires more than the mastery of communication skills. But what else is required exactly? The specific process of how a doctor acquires and develops communication skills during medical practice should therefore be investigated further to be able to adapt curricula and help doctors develop their communication and interpersonal practices more effectively [35]. 
In order to do so, a closer look is needed at the concept of skilled communicator. Over the past 40 years, this concept has evolved in such a way that a continuum between two stances gradually developed [36]. The first stance focuses on the description and measurement of physician communication behaviors and the design and testing of interventions to improve these. The second stance focuses more on the prerequisites to communication competencies, such as self-awareness, reflection, compassion and selfgrowth objectives [37]. In order to develop good communication skills, a mixture of both stances seems desirable [38-44]. Up to now, little research has specifically explored how doctors learn, develop and fine-tune this mixture of aspects during medical practice. Besides, much is assumed about the process of learning communication, but hardly anyone has used learners' own experiences for information on the learning process.

This study therefore aims to explore and describe the learning process GP residents report to go through during medical practice when they are developing the competency of skilled communicator.

\section{Methods}

\subsection{Methodology}

Because of the exploratory nature of our research question "How can the learning process that GP residents undergo in order to become skilled communicators be described?" we used qualitative research methodology. The research process was informed by several core principles of qualitative research like reflexivity [45], purposive sampling, and iterative data collection and analysis [46-48]. Furthermore because of our constructivist stance we chose to perform both systematic inductive and deductive data analysis. The latter was informed by sensitizing concepts drawn from the current literature on medical communication skills learning and -teaching, as described in the introduction. We used the Consolidated criteria for reporting qualitative research (COREQ), a 32-item checklist to make sure all important aspects were reported appropriately [49].

\subsection{Context of the study}

We chose to observe and interview residents in general practice at the Maastricht University postgraduate institute for general practice. See table 1 for an overview of the three-year training program. To put it briefly, these residents receive the kind of structural support in communication skills training Bombeke et al. [39] suggest in order to bridge the gap between theory and a personal style of context-sensitive patientcentered communication. In other words, the basic conditions for learning and developing communication are met among the participants in our study, enabling us to study the learning process itself in detail. 
Table 1: Short overview of the Maastricht postgraduate training for residents in general practice.

Residents spend the first year in a single GP practice. During the second year, they are trained in three clinical institutions such as the nursing home, emergency room or psychiatry ward. For the whole final year they are immersed in yet another GP practice.

Every week, residents in year 1 and year 3 attend a one-day follow-up program at the university's family practice department. During these meetings residents receive communication skills training through the discussion of their consultations that were videotaped during practice. These sessions are facilitated by a GP and a behavioral scientist.

In the practice settings, GP residents are supervised by GP trainers who have received special training to provide feedback and continuous individual support.

Residents are tested for their communication skills in a summative assessment at the end of each year: they need to hand in 40 video recordings of their patient consultations, of which six are used for the assessment using a validated behavioral rating scale.

\subsection{Data collection}

Previous data, collected from seven focus-group interviews among residents GP and residents surgery, revealed factors that they perceived as enabling or hindering their application of communication skills in real practice [32]. A secondary analysis on this data was used to guide the focus of the observations and set-up of the interviews in the current study.

In the next step, we used purposeful sampling [50] within an iterative process of data collection and analysis for the selection of 12 residents from general practice in order to observe and interview them during their regular consultations between April and October 2014. The selection was based on residents' progress in training, expressed in terms of years of experience. Permission was obtained from the head of the General Practice department. First-year and third-year GP residents were approached during one of their weekly sessions at the department of family practice. We did not approach $2^{\text {nd }}$ year residents since their learning and work context differed from year 1 and 3 (the $2^{\text {nd }}$ years did not stay in a GP practice and they did not have to make video recordings of consultations, see table 1). After we explained the set-up of the study, residents were invited to volunteer for participation. 14 first-year and 11 third-year residents volunteered. Out of these volunteers, we randomly chose six first-year and six thirdyear residents. The two supervisors of the weekly sessions checked the random selection of these 12 participants to make sure that the selection covered varying levels in communication skills. Their checking did not result in replacing or changing any of the randomly chosen 12 participants.

The study was approved by the Ethics Committee of the Dutch Association for Medical Education (NVMO)(file no. 345).

The first author, VvdE, visited each resident at his or her general practice to observe randomly chosen, regular patient contacts (shadowing technique). All observations 
were automatically videotaped as part of the 40 video recordings the resident has to hand in at the end of the year. After one hour of observation, an in-depth interview was conducted using the technique of stimulated recall [51]. Concrete behaviors concerning communication skills witnessed during the observation, formed an entry to the interview by asking how the resident had learned that particular behavior or skill. In case the resident did not recall what the interviewer meant, the videotape could be used to indicate concrete behaviors or skills and thereby stimulate recall.

The aim was to get an idea of the learning process going on within that resident during workplace-based learning when he or she was applying or trying to apply a communication skill. The first questions used to probe this process were: When you think back about the past hour of consultations, what communication skill did you consciously apply? How did you learn that particular skill? How did you manage to integrate that skill and make it authentic? Which mechanism(s)/ cognitive processes/ thoughts played a role in this (what did you think when doing or saying X)?

One of the first interviews was witnessed by the second author in order to make explicit and share the perspective and effect of the interviewer on the data collection process, according to the principles of reflexivity [45]. Written informed consent was obtained from each participant.

Because we used the method of iteration $[47,48]$ we subjected new data to analysis as soon as they were collected in order to refine subsequent data collection. This enabled us to confirm, elaborate, or refute the main insights in a stepwise manner. The final interviews revealed no new information anymore and it was decided to complete data collection after 12 interviews since saturation was achieved [50].

\subsection{Analysis}

With the participants' written consent, all interviews were audiotaped and transcribed verbatim. Each participant was asked for consent with the content of the transcripts. VvdE and JvD independently analyzed and coded the transcripts. Using principles of constant comparison [46] and the immersion/ crystallization analysis style as described by Miller and Crabtree [52] the researchers analyzed the coded data, clustered these into coherent categories and refined the categories by systematically checking them against incoming data. This analysis involved decontextualization (to allow parts of the data to be lifted out and investigated more closely) and recontextualization (to make sure the categories still agreed with the context from which they were collected) of the data. During this process VvdE and JvD took notice of and shared the effect of their own frame of reference (reflexivity) on the process of analysis [45]. Final consensus was reached about the construction of five specific phases and two overall conditions to describe the learning process. All co-authors discussed and agreed on the five main phases and two conditions. This procedure, known as researcher triangulation, ensures an objective or fair image of the data. 


\section{$3 \quad$ Results}

Analysis of the data resulted in the construction and description of five phases that characterized the learning process of communication skills for our particular group of GP residents during medical practice (see table 2). All participants gave examples of the fact that their learning process was influenced by the safety of their relationship with their supervisor and by the amount of cognitive and emotional space they experienced during the workplace-based learning of their communication skills. We captured these influencing factors and labeled them as two overall conditions for learning: cognitive \& emotional space and safety (see table 2). This paragraph will provide a description of each of the phases, illustrated by quotes drawn from the interviews, and will end with a brief description of the two overall conditions.

Table 2: The five phases and two overall conditions in GP residents' learning process of communication.

\begin{tabular}{lllll}
\hline \multicolumn{4}{c}{ COGNITIVE AND EMOTIONAL SPACE } \\
$\begin{array}{llll}\text { Phase 1 } \\
\begin{array}{l}\text { Confrontation with } \\
\text { the effect of certain } \\
\text { behavior }\end{array}\end{array}$ & $\begin{array}{l}\text { Phase 2 } \\
\text { Becoming conscious } \\
\text { of own behavior }\end{array}$ & $\begin{array}{l}\text { Phase 3 } \\
\text { Searching for } \\
\text { alternative behavior }\end{array}$ & $\begin{array}{l}\text { Phase 4 } \\
\text { Personalization } \\
\text { of new behavior }\end{array}$ & $\begin{array}{l}\text { Internalization and } \\
\text { clinical integration }\end{array}$ \\
\hline & & SAFETY & \\
\hline
\end{tabular}

\subsection{Phase 1: Confrontation with the effect of a behavior}

The very first step in the learning process of communication skills appeared to be confrontation with a positive or negative effect of one's own behavior. This confrontation could occur during diverse work or personal situations; such as a very effective or ineffective consultation, by watching and discussing video recordings of consultations, or in the form of feedback during real observations. Life events, such as getting married, getting children, or illness among themselves or their family, formed a fourth important source of confrontation. In all cases, the unexpected effect or a feeling of (dis)satisfaction with the situation was the trigger to change one's own view or way of doing.

"I didn't check the auxiliary question and at the end of the consultation I discovered that the parents did not necessarily require a photo too. This negative outcome really bothered me. My supervisor had told me before about the importance of consciously asking questions, but this confrontation made me all of a sudden realize what he meant. It made me become aware of my own blind spot." Rgp 7 
"When my father was in intensive care and I spoke to a resident on duty, I realized how much my emotions gained the upper hand and for the first time I was being confronted with the feeling of how it is to be a patient ('s relative). This experience really changed my way of looking at communication. The importance I attach to good communication has really increased due to this confrontation."Rgp 11

\subsection{Phase 2: Becoming conscious of own behavior}

The second step in the learning process consisted of reflecting upon and becoming conscious of one's own particular behavior and its underlying mechanism or reason. Understanding the need to change that particular behavior also appeared crucial in this phase. A typical consequence of becoming conscious of and reflecting upon one's own behavior was the automatic change in the resident's frame of reference. These made him or her look at a situation or interaction from a different angle, and see his or her own share in the process.

Residents mentioned that life events had the deepest impact and brought about the most profound changes in their frames of reference. These changes almost always led to an improvement of their ability to empathize with patients and made them more open to other points of view.

"My husband's sudden illness and a personal life event have really influenced my frame of reference. I became more aware of many subtle aspects in the non-verbal communication related to patients' fears and uncertainties. Due to this increased awareness, I now communicate with patients differently: I pay much more attention to the patient's possible concerns. This increased awareness is a consequence of my own confrontation with suffering and illness." Rgp 10

"I have become conscious of the three layers that are inherent to a consultation: first there is medical knowledge; on top of that comes the layer to make it a pleasant and smooth consultation, which is followed by a layer of my own feelings during a consultation that I should put to effective use. This way of looking has really influenced my communication." Rgp 2

\subsection{Phase 3: Searching and receiving alternative behavior}

As a third step in the learning process it appeared necessary to guide the resident in making the transition from awareness of the need to change to application of new behavior in real practice. Key in this was the availability of concrete alternative behavior. Residents used many sources to search or receive suggestions for alternative behavior: they discussed feedback with the behavioral scientist /clinical trainer until they had crystalized out concrete examples of sentences they could try out in practice; they watched video recordings of peers, or observed their supervisor as role model during real observations and distilled practical alternative sentences or ways of behaving; some of them read books on communication containing tips or alternative behavior; 
and most of them also discussed issues in private sphere with their partner, peers, friends, family, or relatives to receive alternative tips or ideas. The range of practical alternatives did not feel as "theirs" yet and needed to be tried out, as explained in the next phase.

"Actually there is a big difference between acknowledging the need to change and knowing how to change. I really need concrete tips or alternatives to make it practical and to know what I can do differently." Rgp 1

"Once I have become aware of a specific behavior (and I realize that I want/ need to change it) it becomes important to have concrete alternatives ....in order to get such concrete alternatives I often talk about it with other people among my acquaintances. A friend of mine, for instance, is a psychologist, and with her I exchange tips and experiences. Her tips are always very concrete and I can try it out during new consultations to see what fits me best." Rgp 3

"Because we discuss it extensively at the follow-up day and I then also get to see and hear other people's reactions through the discussion of our videotaped consultations, I often return with a few alternative phrases that I can try out in my own practice to see which one works best for me." Rgp 6

\subsection{Phase 4: Personalization}

In this phase the resident searched for situations in his or her daily practice in which the new or alternative behaviors could be tried out. Typical in this phase were the many attempts needed to find out which alternatives suited the resident best. To achieve this, learning by trial and error turned out to be the most important approach in which, moreover, the resident's own feeling was leading. In this experiential phase, most residents reported that they had to consciously step outside of their comfort zone. Residents therefore perceived this as difficult, needing much time. The patient's reaction or response formed an important source of information: when the patient's reaction was negative, the resident either stopped or tried alternative ways of formulating or behaving, depending on his or her level of self-confidence and the context of the consultation. When the patient's reaction was positive, this reassured the resident and encouraged him to try out the new behavior also in other situations. This fine-tuning and personalization was only tried out when a consultation was suitable, since each consultation differed in context and with regard to the personality of the patient.

An important characteristic all residents reported was to "be able to be myself during a consultation", in other words "to stay authentic". The more a new behavior was in line with their personality the easier it was to find "the right way of formulating". In other words: "the right way of formulating" appeared to be that formulation that suited their own personality. To enlarge their repertoire, they repeatedly turned back to phase three until they found "a way of formulating" that felt right. 
When a new skill didn't produce a desirable effect or didn't feel right after a few trial sessions, most residents abandoned the new skill, because staying authentic was more important.

A final characteristic of this phase was the long time it took to personalize a new skill. Repetition and rehearsal turned out to be crucial.

"At first I did things in order to pass a test, but now I first consciously decide whether or not I am in harmony with it. In the process of acquiring communication skills, I am consciously trying to stay true to myself. In the past period I have gained a certain level of self-confidence, which gives me the COURAGE to stay true to myself. This implies that I do not randomly incorporate all feedback I get during our meetings at the institute. Instead I discuss or search until I get a few alternatives that match my personality and then I go and try out these alternatives in real consultations and I continue just as long until one of them feels natural or authentic." Rgp 8

"What matters the most to me is that a new tip or behavior feels in line with who I am as a person; only then will I continue to try it out, make it authentic and part of my clinical repertoire. My frame of reference determines whether or not something fits me and how it makes me feel. My feelings are my most important counselor in trying out new communication skills." Rgp 9

\subsection{Phase 5: Internalization and integration}

When the phase of personalization had continued for a sufficient amount of time, residents reported the new skill to have become part of their regular repertoire and they applied it subconsciously. This final phase was entered when they felt the new skill had become an integrated part of themselves (internalization) and of their way of doing a consultation (integration). Characteristic of the internalization was the fact that the resident reported the feeling of having become more mature as a person. A natural result of this feeling was the fact that all participants reported that communication skills development and personal growth could not be seen as two independent things, but instead are integrated and should be treated as such.

Characteristic of the integration was the flexibility with which the skill was used: the skill was no longer used in each consultation as a goal in itself to discover its potential added value, but instead the skill was applied only when it seemed clinically or medically relevant within a specific consultation. In other words, the skill had been integrated in the clinical repertoire of the resident.

"There's a clear difference between the trial and error phase where I consciously try out and apply a specific skill to make myself familiar with it and make it personal or authentic; and the next step when the skill has become fully integrated. In this latter step I no longer apply the skill to each consultation, but only when necessary. By this I mean to say that in the end I really apply it autonomously and I SENSE it when it is needed." Rgp 5 
"Personal growth and communication skill development run parallel to each other and cannot be separated. This is precisely because you develop as a human being, also in other spheres. You cannot regard these things separately. A new behavior feels authentic and not just a trick only when it has become an integrated part of whom you are as a person." Rgp 4

\subsection{Two overall conditions influencing the learning process}

All participants gave examples of factors that influenced their learning process. We clustered these factors and labeled them as two overall conditions influencing the learning process.

First of all, a relationship with their supervisors in which the residents felt safe was perceived as important. This safety was experienced when supervisors gave much personal attention, when issues were discussed in a non-judging manner and when the relationship was perceived as equal (as opposed to hierarchical) and reciprocal in learning. This safety was perceived important because residents felt vulnerable when they had to let go of old behavior and try out new behavior. It takes some courage to try out new behavior in real practice. Being assessed on their communication behavior was perceived as inconsistent with this need for a safe learning environment.

"I can search and try out new behavior because I'm in a controlled environment where I'm allowed to learn and try out. This feeling of safety is very important to me." Rgp1

"What I really like about the conversations I have with my supervisor, is that we exchange our experiences and this feels like a reciprocal relationship in which I feel safe enough to be myself and develop myself." Rgp 12

"A safe climate is important to me when I am trying out new communication skills. And I feel unsafe when I am being judged for trying out. So assessment really works counterproductive."Rg $p 4$

A second overall condition all residents gave examples of was labeled as "having cognitive and emotional space". Having cognitive space means that residents felt confident with regard to the medical content or were no longer preoccupied with the medical content and this enabled them to have enough space to focus on the patient and his or her non-verbal signals. Five third-year participants mentioned explicitly that their increased knowledge and confidence with regard to medical content made it possible to focus more on fine-tuning communicational aspects.

Having emotional space means the absence of emotional stressors like little sleep, bad day, personal conflicts, feelings of uncertainty, busy schedules, not enough support from their supervisor, intensive use of computer, etc. Experiencing enough emotional 
space was also reported as an important condition to be really able to pay undivided attention to themselves and the interaction with their patient.

"Because I had to work for a while with patients who did not require complex medical knowledge, I had room in my head for the refinement of my communication skills." Rgp 2

"When I am tired or not feeling very well myself or when I am stressed because the consultations are overrunning too much, then I don't pay attention to the (more subtle) non-verbal signs of the patient anymore and I don't have the energy to try out new communication skills." Rgp 3

\section{Discussion}

\subsection{Discussion}

This study gives more insight into the process of how residents in general practice learn, develop and fine-tune their communication during medical practice. We choose to focus on communication as complex skill, because communication is one of the generic competencies in all major competency frameworks. The five phases and two overall conditions we found show what it takes to personalize, internalize and integrate a new communication skill. Maslow's general phases (moving from unconscious incompetence to unconscious competence) are acknowledged in this regard, as might be the case for other existing generic models on learning, but the added value of our phases is a more detailed description of the specific processes that take place when workplace-based communication learning is concerned.

In general, the assumption that residents or doctors will learn a communication skill if you "just" give them good feedback, appears to not cover the full picture. Personalization and internalization seem crucial "extra" steps in the learning process to make the new behavior authentic and effective in the long run.

The five phases might provide an additional explanation of earlier findings [53,54], stating that longitudinal training in communication skills is more effective compared to single or isolated training moments. In light of our phases, longitudinal training might increase the chance for the learner to also complete the final two phases of personalization and internalization \& integration; provided that (s)he is given the opportunity and support to practice. In a study by Eertwegh et al. [32], residents in surgery for instance attained once a year an off-site communication training of maximum one day. Back on the work floor they reported the newly acquired skills or tips to evaporate quickly, since they received no support or opportunity to practice and no follow-up was given on the attended training. It might be interesting to find out whether this indeed can be ascribed to the fact that these residents were not fully able to pass through the phases 
of personalization, internalization and integration. If so, it would be interesting to explore and evaluate how knowledge of the five phases reported in this study can be used to influence clinical workplace-based learning programs to improve long-term development of skilled medical communication. We do realize however that implementing such continuous learning in clinical work environments other than general practice, requires substantial change at the institutional/hospital level.

More generally, we advocate increased awareness among doctors of the therapeutic effect of good communication [1,55]. As Bensing [55] pointed out, it is a pity that doctors do not make more conscious use of this therapeutic effect for the benefit of increased health outcomes and reduced costs. We do underline this need and we think the five phases lend themselves well to develop and fine-tune workplace-based learning programs that foster an increased awareness and active use of the therapeutic effect of good communication among residents and doctors.

Limitations of the study: We limited ourselves to residents general practice because they met the basic conditions for learning and developing communication skills. To increase representativeness of the findings, it would be interesting to further investigate whether residents in other specialties also recognize these five phases and overall conditions in their communication learning process.

Our sample size was limited to 12 participants. Although this might seem a rather small sample size to draw general conclusions from, the patterns and final five phases that resulted from this sample contain important information representing underlying patterns $[45,50]$. Our findings should be thought of as descriptions and notions applicable within our specified setting of GP residents [45]. Future research based on larger sample sizes might further generalize our findings.

\subsection{Practice implications}

The five distinct phases and two overall conditions in the acquisition of communication skills by GP residents show what it takes to learn and develop communication skills effectively. This knowledge could inspire organizers of communication skills courses from other disciplines than general practice to pay attention to other necessary components of teaching.

The focus of the current research is on communication, since it is an important competency in all competency frameworks [7-10]. The question rises whether the way communication is learned is representative for other complex skills, for example such as professionalism, interprofessional practice or leadership skills. Further research needs to address the generality of the current model for other complex skills. If it is, then this may have serious consequences for the design of longitudinal and continuous postgraduate training programs. 
Acknowledgment: A special thanks to all eight participants of this study for their time and their openness. Another thanks goes to Jean Muris and the supervisors at the Department of General Practice in Maastricht University for enabling us to perform our data collection.

Conflict of interest: The authors report no conflict of interest.

Role of funding: The authors did not receive any funding for preparing and conducting this research. 


\section{References}

1. Benedetti F. How the doctor's words affect the patient's brain. Eval Health Prof 2002;25:369-386.

2. Egbert L, Battit G, Welch C, Bartlett M. Reduction of postoperative pain by encouragement and instruction of patients. A study of doctor-patient rapport. New Engl J Med 1964;270:825-7.

3. Egbert L, \& Jackson S. Therapeutic benefit of the anesthesiologist-patient relationship. Anesthesiology 2013;119:1465-8.

4. Stewart M. Effective physician-patient communication and health outcomes: a review. Can Med Assoc J 1995;152:1423-33.

5. Street R, Cox V, Kallen M, Suarez-Almazor M. Exploring communication pathways to better health: clinician communication of expectations for acupuncture effectiveness. Patient Educ Couns 2012;89:245-251.

6. Rakel D, Barrett B, Zhang Z, Hoeft T, Chewning B, Marchand L, Scheder J. Perception of empathy in the therapeutic encounter: Effects on the common cold. Patient Educ Couns 2011;85:390-397.

7. Frank J, Snell L, Cate O, Holmboe E, Carraccio C, Swing S, Harris K. Competency-based medical education: theory to practice. Med Teach 2010;32:638-645.

8. Swing S. The ACGME outcome project: retrospective and prospective. Med Teach 2007;29:648-54.

9. Swing, S. Assessing the ACGME general competencies: general considerations and assessment methods. Acad Emergency Med 2002;9:1278-88.

10. Good Medical Practice. General Medical Council 2013. www.gmc-uk.org/guidance.

11. Aspegren K, Lonberg-Madsen P. Which basic communication skills in medicine are learnt spontaneously and which need to be taught and trained? Med Teach 2005;27:539-43.

12. Hook K, Pfeiffer C. Impact of a new curriculum on medical students' interpersonal and interviewing skills. Med Educ 2007;41:154-9.

13. Williams C, Cantillon $\mathrm{P}$, Cochrane M. The doctor-patient relationship: from undergraduate assumptions to pre-registration reality. Med Educ 2001;35:743-7.

14. Back A, Arnold R, Baile W, Tulsky J, Barley G, Pea R, et al. Faculty development to change the paradigm of communication skills teaching in oncology. J Clin Onco 2009;27:1137-41.

15. Junod P, Sommer J, Hudelson P, Demaurex F, Luthy C, Louis-Simonet M, et al. Clinical supervisors' perceived needs for teaching communication skills in clinical practice. Med Teach 2009;31:316-22.

16. Junod P, Sommer J, Hudelson P, Demaurex F, Luthy C, Louis-Simonet M, et al. Residents' perceived needs in communication skills training across in- and outpatient clinical settings. Educ Health 2009;22:280-94.

17. Lundberg k. What Are Internal Medicine Residents Missing? A communication needs assessment of outpatient clinical encounters. Patient Educ Couns 2014;DOI: 10.1016/2014.07.015.

18. Rotthoff T, Baehring T, David D, Bartnick C, Linde F, Willers R, et al. The value of training in communication skills for continuing medical education. Patient Educ Couns 2011;84:170-5.

19. Silverman J. Clinical communication training in continuing medical education: possible, do-able and done. Patient Educ Couns 2011;84:141-2.

20. Barth J, Lannen P. Efficacy of communication skills training in oncology: a systematic review and metaanalysis. Ann Oncol 2011;22:1030-40.

21. Fellowes D, Wilkinson S, Moore P. Communication skills training for health care professionals working with cancer patients, their families and/or carers. Cochrane Database Syst Rev 2004;2:CD003751.

22. Gysels M, Richardson A, Higginson IJ. Communication training for health professionals who care for patients with cancer: a systematic review of effectiveness. Support Care Cancer 2004;12:692-700.

23. Kramer A, Dusman H, Tan L, Jansen J, Grol R, van der Vleuten C. Acquisition of communication skills in postgraduate training for general practice. Med Educ 2004;38:158-67.

24. Betz Brown J, Boles M, Mullooly J, Levinson W. Effects of clinician communication skills training on patient satisfaction. Ann Intern Med 1999;131:822-9.

25. Fossli Jensen B, Gulbrandsen P, Dahl F, Krupat E, Frankel R, Finset A. Effectiveness of a short course in clinical communication skills for hospital doctors: results of a crossover randomized controlled trial. $\mathrm{Pa}$ tient Educ Couns 2011;84:163-9.

26. Uitterhoeve R, Bensing J, Grop R, Demulder P, van Achterberg T. The effect of communication skills training on patient outcomes in cancer care: a systematic review of the literature. Eur J Cancer Care 2009;19:442-57. 
27. Essers G, van Dulmen S, van Weel C, van der Vleuten C, Kramer A. Identifying context factors explaining physician's low performance in communication assessment: an explorative study in general practice. BMC family practice 2011;12:138-46.

28. Hulsman R, Ros W, Winnubst J, Bensing J. Teaching clinically experienced physicians communication skills. A review of evaluation studies. Med Educ 1999;33:655-68.

29. Bensing J, van Dulmen S, Tates K. Communication in context: new directions in communication research. Patient Educ Couns 2003;50:27-32.

30. Van Nuland M, Thijs G, Van Royen P, Van den Noortgate W, Goedhuys J. Vocational trainees' views and experiences regarding the learning and teaching of communication skills in general practice. Patient Educ Couns 2010;78:65-71.

31. Wouda J, van de Wiel H. The communication competency of medical students, residents and consultants. Patient Educ Couns 2012;86:57-62.

32. van den Eertwegh V, van Dalen J, van Dulmen S, van der Vleuten C, Scherpbier A. Residents' perceived barriers to communication skills learning: Comparing two medical working contexts in postgraduate training. Patient Educ Couns 2014;95:91-97.

33. Maslow A.H. Motivation and personality. New York: Harper \& Brothers 1954.

34. Salmon P, Young B. Creativity in clinical communication: from communication skills to skilled communication. Med Educ 2011;45:217-26.

35. Furber L, Murphy R, Cox K, Steward W. Enhancing communication in oncology outpatient consultations: critical reflections from doctors. Int J Med Educ 2011;2:159-169.

36. Clarke A. Teaching Physicians Communication Skills: Where We Are, How We Got Here. Research Project Submitted In Partial Fulfillment of the Requirements for the Degree of Master of Education. Simon Fraser University 2013.

37. Tresolini C, Pew-Fetzer Task Force. Health Professions Education and Relationship-Centered Care: Report of the Pew-Fetzer Task Force on Advancing Psychosocial Education. San Francisco, California: Pew Health Professions Commission 2014. Available: http://futurehealth.ucsf.edu.

38. Levesque M, Hovey R, Bedos C. Advancing patient-centered care through transformative educational leadership: a critical review of health care professional preparation for patient-centered care. J Healthcare Leadership 2013;5:35-46.

39. Bombeke K, Symons L, Vermeire E, Debaene L, Schol S, de Winter B. Patientcentredness from education to practice: the 'lived' impact of communication skills training. Med Teach 2012;34:338-48.

40. Salmon P, Young B. Core assumptions and research opportunities in clinical communication. Patient Educ Couns 2005;58:225-34.

41. Riess H, Kraft-Todd G. EMPATHY: A tool to enhance nonverbal communication between clinicians and their patients. Acad Med: $j$ Assoc Americ Med Coll 2014;89:1108-12.

42. van Es M, Wieringa-de Waard J, Visser M. Differential growth in doctor-patient communications skills. Med Educ 2013;47:691-700.

43. Blanco M, Maderer A, Price L, Epstein S, Summergrad P. Efficiency is not enough; you have to prove that you care: Role modelling of compassionate care in an innovative resident-as-teacher initiative. Educ for Health 2013;26:60-5.

44. Khanum Z. Effectiveness of reflective exercises for obstetrics and gynaecological residents. J Coll Phys Surg 2013;23:468-71.

45. Malterud K. Qualitative research: standards, challenges, and guidelines. The lancet 2001;58:483-8.

46. Watling C, Lingard L. Grounded theory in medical education research: AMEE Guide No. 70. Med Teach 2012;34:850-861.

47. Lingard. When I say grounded theory. Med Educ 2014;48:748-9.

48. Charmaz K. Constructing grounded theory: A practical guide through qualitative analysis. Thousand Oaks, CA: Sage publications 2012.

49. Tong A, Sainsbury P, Craig J. Consolidated criteria for reporting qualitative research (COREQ): a 32-item checklist for interviews and focus groups. Int J Quality Health Care 2007;19:349-357.

50. Patton M. Qualitative evaluation and research methods. Thousand oaks, CA: Sage Publications 1990.

51. Calderhead J. Stimulated recall: A method for research on teaching. Brit J Educ Psychology 1981;51:211217. 
52. Miller W, Crabtree B. Clinical research: a multimethod typology and qualitative roadmap. In: Crabtree B, Miller W, eds. Doing qualitative research, 2nd edn. Thousand Oaks: Sage Publications 1999;3-30.

53. Van Dalen J, Kerkhofs E, van Knippenberg-Van Den Berg B, van Den Hout H, Scherpbier A, Van Der Vleuten C. Longitudinal and concentrated communication skills programmes: two Dutch medical schools compared. Adv Health Sciences Educ 2002;7:29-40.

54. Stein T, Frankel R, Krupat E. Enhancing clinician communication skills in a large healthcare organization: a longitudinal case study. Patient Educ Couns 2005;58:4-12.

55. Bensing J, Verheul W. The silent healer: the role of communication in placebo effects. Patient Educ Couns 2010;80:293-9. 



\title{
Chapter 5
}

\section{Transformative learning in clinical communication: Creating the opportunity to know thyself}

\author{
V. van den Eertwegh \\ C. van der Vleuten \\ J. van Dalen \\ A. Scherpbier \\ S. van Dulmen \\ R. Stalmeijer
}

Submitted (Status: accepted with revision) 


\begin{abstract}
Context: Improving communication in health care continues to be a fundamental challenge as attempts at improvement meet with stiff resistance. Attention should be diverted to the question of how communication can be learned in a more transformative, and, consequently, more effective, manner.

Objective: To elicit clinical residents' introspective accounts in order to explore how communication can be learned in a more effective (transformative) manner, and which factors in residents' daily work environment support this process of transformative learning.

Methods: We used a qualitative research methodology based on 12 in-depth interviews with residents from ten different clinical departments. The research process was informed by several core principles of qualitative research, such as reflexivity, purposive sampling, and iterative data collection and analysis.

Results: In order to reach transformative or effective communication learning with lasting consequences, it appeared necessary for learners to be confronted with their personal behavior. Time needed to be allowed to digest such confrontations, the success of which depended on one's level of self-awareness. Residents identified five factors that helped them increase their level of self-awareness and render their learning of communication more transformative: receipt of more feedback (especially positive), sensitive role models and personal attention, safety and vulnerability, independent coaching / supervision and departmental awareness.

Conclusions: Learning communication (skills) should become part of learners' lifelong personal development. Our findings highlight the importance of continuous coaching or group sessions in residency training which offers a viable opportunity to support this personal learning process.
\end{abstract}




\section{Introduction}

All learners construct knowledge from an inner scaffolding of their individual and social experiences, emotions, will, aptitudes, beliefs, values, self-awareness, purpose, and more.... If you are learning, what you understand is determined by how you understand things, who you are and what you already know.

Peter Senge (founder Society for Organizational Learning, Massachusetts Institute of Technology).

The fact that communication plays an important role in improving health care is indisputable [1-5]. Communication in health care contexts, moreover, is a topic that has been widely studied, and there have been repeated attempts to improve communication in a variety of settings. In spite of these efforts, improving communication in health care continues to be a fundamental challenge as attempts at improvement meet with stiff resistance: postgraduate programs that offer continuous training in communication skills are still scant [6,7], and when they do provide them, they linger in lack of transfer and long-term effectiveness [8-11]. This concern about the impact of communication programs has been raised by many authors [12-17]. Frenk et al., and more recently Ruben, therefore argued that attention should be diverted to the fundamental question of how communication skills are learned, translated, and applied in health communication education and practice $[16,12]$.

To answer this fundamental question, Lévesque et al., Khanum and Eertwegh et al. [18-20] proposed using the underpinnings of transformative learning theory to improve the learning of and training in medical communication skills. Moreover one should regard the learning and development of communication at a broader level than skills only. In this article we refer to communication learning, instead of communication skills learning. Transformative learning is based on the perspective that learning is influenced by, and in turn shapes our experiences in life [21]. Instead of focusing on cognition only, it adds an affective component to learning, resulting in deeper, more effective learning. It is based on neuroscientific insights revealing that emotion is more intimately related and important to cognitive processing than was previously thought: learning is a constant dynamic interplay between emotion and cognition, rather than a hierarchical relationship in which cognition predominates [22]. Mezirow and Taylor described transformative learning as a learning process that requires people not only to question their understanding of an experience, but also to actively process this information $[21,23]$. This type of learning is more likely to lead to a permanent change in behavior, because it leaves an imprint on the person's underlying frame of reference. As a result, new behavior becomes better integrated or consolidated within the person. Since the aspired goal is to accomplish a permanent change in communicative behavior in terms of transfer or lasting effectiveness, it seems expedient to approach communication from a transformative learning perspective. Transformative learning can be reached through experiential learning [24], provided reflection on the experience is 
made possible. Hence, reflection and self-awareness are essential skills if one wants to make the learning of communication more effective or transformative.

The importance of reflection and self-awareness as prerequisites for the development of effective communication is also emphasized by educational policymakers such as the Pew-Fetzer taskforce (a taskforce that aims to reinforce relationship-centered care) [25]. What is still lacking, however, are concrete guidelines as to how these skills can be developed. In other words, little is known, if anything, about whether and how reflection and self-awareness in relation to transformative learning of communication can be integrated into real medical practice.

What we do know, however, is that several authors have pointed to difficulties in implementing reflection and self-awareness in daily clinical practice. Ahrweiler et al. [26], for instance, recently posited that students are not supported enough in their endeavor to forge therapeutic relationships with patients and simultaneously cope with their own feelings and attitudes. They concluded that more training is needed to promote self-awareness. Schenck \& Churchill [27] went even further by stating that the relationship with a patient hinges on the doctor's level of self-awareness. Their contention, which was echoed by Novack et al. [28] and Dobie [29], was that improvements in medical education should include a deliberate effort to deepen understanding among medical students and doctors about how their personal attitudes, emotions and relational skills (or lack of them) affect their clinical abilities.

The assertion that reflection and self-awareness are important finds similar resonance in the work of Jarvis-Selinger et al. [30] and Pinar [31] who introduced insights from another field of research. These authors called into question the narrow focus on "doing" in today's competency-based education. As a counterweight, they suggested that more attention be paid to the dimension of identity formation when training and working with the next generation of physicians [30]. Identity formation is a process whereby a person moves through a series of developmental stages [32, 33]; the transition from stage to stage does not occur gradually, but is rather marked by sudden discontinuities (or sometimes crises). These discontinuities represent a crucial period of increased vulnerability and heightened potential, however, they will only signal turning points if effective reflection on the discontinuity ensues. Hence, in education it is crucial that the focus of attention be diverted such that learners are supported in the effective management of and reflection on their problems or discontinuities (and accompanying emotions) [29,30].

In order for reflection, self-awareness and/or professional identity formation to become points of attention in postgraduate medical education, general acknowledgment of their importance is a prerequisite. The question that arises next is whether this need to pay more attention to reflection and self-awareness is actually acknowledged by doctors in real medical practice themselves. Van den Eertwegh et al. [34] investigated 
the process whereby trainees in general practice learned communication and identified five phases along which these residents honed such skills. Confrontation, reflection and self-awareness indeed appeared to be crucial. It should be called to mind, however, that these trainees received continuous (that is, weekly) support in the form of a specific training program and supervision. What leaves one to wonder, then, is how clinical residents who do not receive such continuous support learn and hone their communication. This question has yet to be answered. The present study therefore seeks to elicit clinical residents' introspective accounts in order to explore how they effectively learn and improve their communication and which factors in their daily work environment support the process of transformative learning.

\section{Methods}

The study was approved by the Ethics Committee of the Netherlands Association for Medical Education (NVMO file no. 432).

\subsection{Methodology}

Because of the exploratory nature of our research question "What makes residents' communication learning transformative and which factors support this process?" we used a qualitative research methodology. The research process was informed by several core principles of qualitative research, such as reflexivity [35], purposive sampling, and iterative data collection and analysis [36-38]. The principle of reflexivity presupposes that research is inherently structured by the subjectivity of the researcher. We took several measures to recognize and address this bias, such as reflexive journaling and member-check procedures. The backgrounds of the researchers within our research team ranged from psychology (CvdV, SvD, JvD), educational sciences (RS), and medicine (AS), to change management and organization (VvdE). The blend or interplay between these disciplines has influenced our inductive approach. More specifically, as adherents of the constructivist stance, we believe that knowledge is constructed by way of interactions between researcher and participants. We therefore chose to perform an inductive as well as a deductive data analysis $[39,40]$. The deductive analysis was informed by a synthesis of concepts drawn from current literature on the learning and teaching of medical communication skills and by principles from transformative learning and identity theory, as described in the introduction. Our inductive approach built on these constructs by attempting to recognize, understand and contrast existing concepts and develop new ones through dialog [41]. 


\subsection{Data collection}

\section{Participants}

We chose to interview residents from different specialties at the Maastricht University Medical Centere (MUMC+), either working at the MUMC+ or having an internship at another hospital in the southern part of the Netherlands. For the selection of residents we used purposive sampling [39] within an iterative process of data collection and analysis so as to be able to conduct in-depth interviews in the period spanning September to December 2014. We approached participants via email and explained the set-up and purpose of the study. Participants came from an array of specialties and years of training, and their communication was developed to varying degrees. We sampled until saturation [39] was met, which occurred after 12 residents had been interviewed. These 12 residents were working in 10 different departments: psychiatry, pediatrics, gynecology, neuro-surgery, neurology, ophthalmology, anesthesiology, surgery, clinical genetics and dermatology. Their mean age was 28 years and eight of them were female.

\section{Data collection}

The first author (VvdE) visited each resident in their department at an agreed date and time to conduct an in-depth interview of one hour. The aim of the interview was to explore which aspects made their learning of communication transformative/have lasting effects. The two central questions were: "When you are working and learning on the job, what is it that inspires you or makes you decide to hone your communication?" and "When you decide to hone your communication, how is this process rendered transformational?". When asked, the term 'transformative' was defined as leading to a permanent change in behavior that felt authentic. The first follow-up questions used to probe were: Do you remember a moment during your work in which your communication came to your attention? What made you reflect on them and incentivized you to improve your communication? How did this process become transformative/have lasting effects? Which elements in your daily work environment accelerated or facilitated this process? Which elements disturbed this process? What aspects would you wish to introduce in your department to facilitate this process of transformative learning?

The first interviews were witnessed by another member of the research team in order to check for unwanted bias, according to the principles of reflexivity [35]. Written informed consent was obtained from each participant. All interviews were audiotaped and transcribed verbatim. Each participant also gave written consent for the content of the transcripts that ensued.

\subsection{Analysis}

Four of the six authors independently analyzed and coded the transcripts. Our iterative approach $[37,38]$ entailed that we subjected new data to analysis as soon as they were collected in order to refine subsequent data collection. This enabled us to confirm, 
elaborate, or refute the main insights in a stepwise manner. Using principles of constant comparison [36] and the immersion/ crystallization analysis style as described by Miller and Crabtree [40], the researchers analyzed the coded data, clustered these into coherent categories and refined the categories by systematically checking them against incoming data. This analysis involved decontextualization (to allow parts of the data to be lifted out and investigated more closely) and recontextualization (to make sure the categories still agreed with the context from which they were collected) of the data. How all co-authors reached final consensus about the findings will be described in the results section of this article.

\section{Results}

This results section is structured into two parts, in conformity with our research question: whereas part 1 will detail the process of transformative learning itself, part 2 will describe the five factors in the learning environment that, in residents' view, helped render their communication learning transformative. In general, when talking about developing their communication, the residents automatically linked this to the concept of personal development: they considered effective communication learning to be a dimension of both their personal and professional development. The concepts of "learning communication" and "personal development" are therefore used interchangeably throughout this results section.

\subsection{The process}

The 12 residents all mentioned confrontation as a necessary precondition for deciding to improve their communication.

"A structural change in my behavior almost always comes about because of a confrontation or something undesirable that I really wish to change." $R 1$

Since none of them received continuous formal communication training or support during their residency, this confrontation occurred during regular work situations for one of three reasons: because a conversation with a patient or a colleague had an undesirable or even positive effect; because they had witnessed a colleague or staff member behave in a certain way that deviated from their own; or because they had received direct feedback on their communication. Most residents, however, mentioned that this latter form of confrontation rarely occurred, since the feedback they received from staff or other residents was almost always focused on medical content. For all three forms of confrontation it appeared important that they derived from authentic real-life situations: simulations or fabricated case descriptions did not have as much confrontational capacity as authentic situations had. 
Confrontations, however, did not automatically elicit reflection on one's communication. On closer inspection two factors appeared to be of paramount importance: the level of self-awareness and openness. Residents immersed themselves in the confrontation and experienced it as a transformative moment of learning only when they were aware that their behavior was ineffective and when they were willing to change. Some of the residents explained this level of openness or self-awareness in terms of recognizing feedback (or recognizing the problem) and acknowledging that something in their behavior had to change.

"It is very important to make things explicit: when someone helps me to spell out exactly what happened or what I can do differently, then I really become aware of myself and this is conducive to change." $R 5$

"Only when I have become aware of myself / my share, I can take control and change something permanently." $R 4$

Because it was a recurrent theme, we explored the concept of self-awareness in more detail during the interviews. In essence, our residents reported that the key to achieving a permanent change in their communication behavior was to make an unconscious aspect of their behavior conscious and thus increase their self-awareness.

"When the change is lasting (that is, transformative), something else inside of me that goes beyond behavior has changed too. In other words, I cannot fully internalize a change in my way of communicating if I do not make myself aware of something I was not previously aware of. I transform by rendering the unconscious conscious." $R 9$

"The entire development of my communication is actually grounded in awareness. Each day I am aware of the interplay between my personal development on the one hand, and my learning and working on the other; to me, these two are inextricably linked." R12

Residents reported that the ability to use and increase one's self-awareness and the time needed to accomplish this differed considerably between fellow residents. While some reported to be able to go through this process alone, most residents indicated that they highly valued having somebody who helped them become more aware of a particular aspect.

"To me it is of enormous help when someone holds a mirror up to my face: if I do not talk about it or no-one points it out to me, I keep being stuck in my own reality." $R 7$

Another aspect of self-awareness that residents pointed out was the fact that it was perceived as a personal, lifelong point of attention. 
"To me, transformative learning is a process I have been going through all of my life and that is fueled by the level of my awareness." R3

Residents also reported it to be a laborious task that depended very much on their own emotional and physical condition. When it was too busy during a work day to reflect upon a confrontation, residents reported they postponed reflection - either deliberately or unconsciously - until they felt they had enough time to think about it and/or discuss it with others. Two residents, one in the first and one in the fourth year of residency training, reported they were under such constant stress at work (due to planning and support problems in the department) that they had no opportunity whatsoever to hone their communication .

"It takes energy to develop your communication and behavior and my fitness really affects the extent to which I can engage myself in this process." $R 12$

"In our department it is just too busy to be able to delve into my communication skills at all. Although I know I need it, I just don't get round to it because of the continuous stress the fully planned and overrunning outpatient consultations put me under. Other residents in our department recognize this very experience." $R 4$

A final factor at play was self-confidence. A reported difference in self-confidence between junior and senior residents was apparent: junior residents reported to be much more dependent on their supervisors, as a result of which they literally copied specific communication skills and behavior; senior residents, by contrast, had gained more selfconfidence and this went hand in hand with an increased level of self-awareness and a more personal communication style. Senior residents regarded "being authentic" as an important characteristic of a good clinician.

"I now have a lot more courage to stand for myself than I had at the start of my program."R11

"Because I am now more self-confident, I find the courage to be me more easily, that is, I dare to spend more time on my personal development. This is because I realize more and more that this is how doctors can really make a difference." $R 3$

\subsection{Scaffolds in the learning and work environment}

The following five factors were considered to effectively support residents in increasing their level of self-awareness and making their communication learning more transformative. 


\subsubsection{Receiving more feedback (especially positive)}

First of all, residents reported they would like to receive more feedback on their communication, since this confronted them with their way of doing and made them aware of hidden aspects of their behavior. Residents also reported that most of the staff were not used to talking about communicational issues. Moreover, they expressed the need to give and receive more positive feedback, since most staff were used to commenting only on things that needed improvement. Reinforcing positive behavior would help them build self-confidence and would add to a more positive working atmosphere.

"Staff hardly ever confronts us with feedback, because it doesn't occur to them. When you take the initiative to solicit feedback, if ever, it often does not result in anything concrete." R8

"We actually need positive feedback: it happens all too infrequently that good behavior is being confirmed." $R 2$

\subsubsection{Sensitive role models and personal attention}

A second factor concerned the staff as role models. Residents perceived support the most effective when received from those staff members who themselves were sensitive to communication issues and personal development issues. More specifically, they reported that these staff members dedicated more time or moments of full attention to giving feedback and discussing issues in a more personal or sensitive way.

"The best role models are those staff members who themselves are also the most sensitive and personally aware." $R 8$

"When a staff member really takes time for me, my learning curve is rocketing." R10

\section{$\underline{\text { 3.2.3 }}$ Safety and vulnerability}

Residents reported safety as a crucial factor. Only when they felt safe enough, did they become willing to open up to feedback and reflect on their own behavior. The hierarchical relationships ensuing from a postgraduate system that requires staff members to judge residents' performance during residency, often conflicted with residents' perceived sense of safety.

"Whether I will speak my mind about something or not very much depends on my sense of safety." $R 1$

"As supervisors also judge you because you are in training, you are careful about showing your vulnerability. This is not conducive to transformative learning." $R 5$ 


\subsubsection{Independent coaching/ supervision}

Three out of the ten departments in which the participants were situated offered their residents a form of continuous coaching or group sessions with an independent coach to deal with issues related to communication and personal effectiveness. The residents involved appreciated this as a highly valuable and rewarding investment. The presence of an independent coach (as opposed to staff) warranted a safe learning environment: as an outsider to the hierarchy, the coach did not assess the residents' overall functioning. Residents who did not receive this kind of continuous support, all expressed the wish or need to arrange this in their department.

"Two hours a month we have peer-to-peer coaching. We all really consider this the icing on the cake: during this time we discuss just about everything that's personal. Ideally, this session would be guided by an independent coach who knows how to cope with our personal troubles effectively." 66

"Within our department we really should talk more and more openly about poignant events, such as the decease of (young) people, incidents or complaints... people generally don't talk that much to each other about how it affects you." $R 9$

\subsubsection{Departmental awareness}

A fifth point, which actually springs from the previous factors, relates to the workplace culture in the department. More specifically, it was mentioned that individual transformative learning of communication can only truly set in if the whole department recognizes the importance of communication. A more communication-conscious workplace culture would encourage individuals to take and share more responsibility in this regard.

"I would like to work in a team in which everybody has a conscious approach toward communication and all members dare to continuously call each other to account. When everybody realizes that this affects the quality of action, you automatically create a safer environment that is conducive to behavioral change." R2

\section{Discussion}

The residents in our study emphasized the importance of confrontation and reflection in bolstering self-awareness, which, in turn, was perceived as indispensable to the continuous development of their communication. This is in line with transformative learning and identity theory in which discontinuities and confrontations (sometimes resulting in crises) are seen as prerequisites for a person's reflection on his or her inner self and growth in their role as person and professional. In this regard, communication learning should be 
seen or treated more as a form of personal development. When looking at communication learning this way, some important lessons for education can be derived. First and foremost, communication learning should be interwoven with the curriculum in such a way that practitioners become incentivized to hone their communication in their own, personal way, instead of designing isolated training programs in which practitioners should acquire the same set of predefined communication "skills" [42].

Another lesson that was already pointed out by Jarvis-Selinger is that learners should receive continuous support as to how to manage their confrontations and reflect on them effectively [30]. Our residents indeed perceived it as crucial to receive support in reflecting on their behavior to become more aware of themselves and their communication. They also reported that the process of reflection and transformation took time and effort and could only be effected when they had enough energy or "emotional space" for it. Wear et al. [43] as well as Kumagai et al. [44] confirm in this regard that the ability to "reflect-while-practicing" needs time and space to develop. They suggest that dedicated, intentional pauses in daily activities must be created and, at least during the years of education, separated from clinical care to facilitate the development of fully reflective mindful clinical practice. This time taken to reflect offers budding physicians the opportunity to more fully incorporate their experiences into a professional identity that embodies critical awareness, cultural humility, and empathy. The authors suggest that these curricular spaces must be created in a very deliberate manner, even on busy wards services, throughout the education of physicians. In order to accommodate such curricular spaces, they recommend that the following four teaching methods be implemented: experiential learning, critical reflection, a supportive group process and a curriculum that fosters continuity [44].

A previous study by Eertwegh et al. [34] among GP residents confirmed that weekly meetings (in which residents discussed video recordings of their patient consultations) offered the space to reflect on their behavior and increase their self-awareness. The added value of our current study is more insight into the learning process of clinical residents who do not receive continuous support in communication learning. The residents from ten different disciplines who participated in this study once again confirm the need for continuous support to increase their reflection and self-awareness to hone their communication.

As a third lesson that can be derived from the study at hand, we would like to stress the importance of using authentic confrontations brought forward by the learner him- or herself. We believe reflection doesn't work if it is imposed on learners in the absence of authentic confrontations. If it is cultivated too much or too early in a curriculum when there are no real confrontations (with patients or otherwise), imposed reflection might even trigger resistance [45].

A final point concerns the importance of feedback. Feedback is widely recognized as an essential element in clinical education, and yet it is an area in which we continue to fall short. Weinstein [46] points to the fact that most medical education programs are not 
designed in a way that supports educational alliances in clinical settings to make the environment safe enough to increase giving and receiving of feedback. Rather, they are organized according to the medical needs of the organization. It is our contention that this Gordian knot can be disentangled by giving more positive feedback, as the residents in this study suggested. One of the main reasons for not giving feedback is the fear to disturb the relationship. But when we start to make more explicit what goes well, this enhances the relationship and will automatically have a positive impact on the work climate in general, leading to increased departmental awareness, a more positive or personal way of working together and more safety [47]. These three very factors were spontaneously mentioned by the residents in our study as enhancing transformative learning. Appreciative Inquiry is a practical change management approach that builds on this principle of positivity [48]. The basic tenet is that an organization will grow in whichever direction that people in the organization focus their attention on. Hence, focusing on identifying what is working well, analyzing why it is working well and then doing it more often, will most effectively set in train desired changes [48].

Limitations of the study: The 12 participants in our study were working in the same academic hospital, MUMC+. The other two participants had their internship in two different hospitals, an academic one and a peripheral hospital, both located in the southern part of the Netherlands. Since our aim was not to generalize findings, but to provide insights that might inform future research, we recommend future studies to be conducted in other hospitals and also in other countries, to investigate possible contextual factors of influence and to see whether our findings can be extrapolated. Because our deductive analysis was informed by synthesizing concepts drawn from literature on transformative learning and identity theory, we are aware of the potential risk of a self-fulfilling prophecy. To minimize this risk, we engaged multiple researchers in the interpretation and analysis of the data which only ended when all authors had reached consensus. Finally, this study design is based on participants' introspection. These introspective accounts provide data about needs, beliefs and personal experiences, which fits the exploratory nature of our study. Introspective accounts, however, do not provide data about real behavior. We therefore recommend adding other forms of data collection, such as observational research in which residents are followed through time to observe in more detail the process whereby they learn and hone their communication and possibly observe their actual behavior.

\section{Implications for practice}

In the hectic reality of medical practice, the above suggestions might seem far-fetched or unattainable. However, in order to render communication learning truly transformative or effective in the long run, it appears necessary to pay continuous attention to it and incorporate enough moments of confrontation, reflection and support to increase one's level of self-awareness. 
As Papastamatist et al. [49] state, for effective transformative learning to take place, cognitive, physical, emotional and spiritual dimensions are closely interrelated and need to be given attention. This study has demonstrated that continuous coaching or group sessions offer a viable opportunity to pay attention to these cognitive, physical, emotional and spiritual dimensions. Driessen et al. [50] already pointed out the advantages of coaching or mentoring to help increase clinical competency, productivity, well-being and reduce burnout. Cole [51] puts it even more clearly when he states that humanizing medicine also depends on recovering the humanity of physicians themselves: self-care must be seen not as an option but as an obligation to doctors. To do so, institutions must provide avenues for dialog that allow renewal, self-care, mutual support and reflection.

Continuous coaching or group sessions are one such avenue and are relatively easy to organize and implement within a department, on a monthly basis for instance. Participants' own experiences from daily practice form the input. Besides, video recordings of regular consultations can be made and can be used to discuss during the sessions, an approach coined video enhanced reflective practice [52]. In his recent article, Branch [53] provides a practical approach and framework for curriculum planners to implement such continuous coaching sessions in a scattered way throughout the curriculum.

The product of such continuous coaching sessions, then, is not just knowledge (facts) or skills; rather, it is the development of personal values and an orientation toward oneself, others, and the world- it is understanding, which may be defined as a deep and abiding engagement with the human aspects of illness and medical care. It is this understanding which fosters empathy and awareness, as essential ingredients for effective communication.

Acknowledgment: A special thanks to all the participants of this study for their time and their openness. Another thanks goes to Angelique van de Heuvel for her revision of English spelling and grammar.

Conflict of interest: The authors report no conflict of interest.

Role of funding: The authors did not receive any funding for preparing and conducting this research. 


\section{References}

1. Epstein R, \& Street Jr R. Patient-centered communication in cancer care: promoting healing and reducing suffering. Nat Cancer Institute, NIH Publication 2007;07: 6225.

2. Kaplan S, Greenfield S, \& Ware J. Assessing the effects of physician-patient interactions on the outcomes of chronic disease. Med Care 1989;27:110-27.

3. Silverman J, Kurtz S, \& Draper J. Skills for communicating with patients. Third edition. Radcliff medical press 2013.

4. Stewart M. Effective physician-patient communication and health outcomes: a review. Canadian Med Assoc J 1995;152:1423-33.

5. Street Jr R, Makoul G, Arora N, \& Epstein R. How does communication heal? Pathways linking clinicianpatient communication to health outcomes. Patient Educ Couns 2009;74:295-301.

6. Rotthoff T, Baehring T, David D, Bartnick, C, Linde F, Willers R, et al. The value of training in communication skills for continuing medical education. Patient Educ Couns 2011;84:170-5.

7. Silverman J. Clinical communication training in continuing medical education: possible, do-able and done. Patient Educ Couns 2011;84:141-2.

8. Shilling V, Jenkins V, \& Fallowfield L. Factors affecting patient and clinician satisfaction with the clinical consultation: can communication skills training for clinicians improve satisfaction? Psycho-oncology 2003;12:599-611.

9. Fallowfield L, Jenkins V, Farewell V, \& Solis-Trapala I. Enduring impact of communication skills training: results of a 12-month follow-up. Brit J Cancer 2003;89:1445-9.

10. Lienard A, Merckaert I, Libert Y, Bragard I, Delvaux N, Etienne A, et al. Transfer of communication skills to the workplace during clinical rounds: impact of a program for residents. PLoS One 2010;5:e12426.

11. van den Eertwegh V, Dulmen S, van Dalen J, Scherpbier A, \& van der Vleuten C. Learning in context: identifying gaps in research on the transfer of medical communication skills to the clinical workplace. $P a$ tient Educ Couns 2013;90:184-92.

12. Ruben B. Communication Theory and Health Communication Practice: The More Things Change, the More They Stay the Same. Health communication 2014 ahead-of-print;1:11.

13. Parrott R. Emphasizing communication in health communication. J Communicationn2004;54:751-87.

14. Tresolini C, Pew Fetzer Task Force. Health professions education and relationship-centered care. San Francisco, CA: Pew Health Professions Commission 1994.

15. Blank L, Kimball H, McDonald W,\& Merino J. Medical professionalism in the new millennium: a physician charter 15 months later. Ann Int Med 2003;138:39-41.

16. Frenk J, Chen L, Bhutta Z, Cohen J, Crisp N, Evans T. et al. Health professionals for a new century: transforming education to strengthen health systems in an interdependent world. The Lancet 2010;376:192358.

17. Thompson T, Parrott R, \& Nussbaum J. Why is it so difficult to talk about impact? Health Communication 2010;25:560-2

18. Levesque M, Hovey R, \& Bedos C. Advancing patient-centered care through transformative educational leadership: a critical review of health care professional preparation for patient-centered care. $J$ Healthcare Leadership 2013;5:35-46.

19. Khanum Z. Effectiveness of reflective exercises for obstetrics and gynaecological residents. J Coll Phys Surg 2013;23:468-71.

20. van den Eertwegh V, van Dalen J, van Dulmen S, van der Vleuten C, \& Scherpbier A. Residents' perceived barriers to communication skills learning: Comparing two medical working contexts in postgraduate training. Patient Educ Couns 2014;95:91-97.

21. Mezirow J. Transformative learning: theory to practice. New Dir Adult Contin Educ 1997;74:5-12.

22. Salzman C, \& Fusi S. Emotion, cognition, and mental state representation in amygdala and prefrontal cortex. Ann Rev Neuroscience 2010;33:173-202. 
23. Taylor E. Analyzing research on transformative learning theory. In: J Mezirow \& Associates, editors. Learning as transformation: critical perspectives on a theory in progress. San Fransisco: Jossey-Bass 2000;285-328.

24. Kolb D, Boyatzis R, \& Mainemelis C. Experiential learning theory: Previous research and new directions. Perspectives on thinking, learning, and cognitive styles 2001;1:227-47.

25. Tresolini C, Pew-Fetzer Task Force. Health Professions Education and Relationship-Centered Care: Report of the Pew-Fetzer Task Force on Advancing Psychosocial Education. San Francisco, California: Pew Health Professions Commission 2014. http://futurehealth.ucsf.edu (accessed on 17 October 2014]

26. Ahrweiler F, Scheffer C, Goldblatt H, Hahn E, \& Neumann M. Clinical practice and self-awareness as determinants of empathy in undergraduate education: A qualitative short survey at three medical schools in Germany. GMS Z Medizin Ausbild 2014;31(4),Doc46. DOI:10.3205/zma000938.

27. Schenck D, \& Churchill L. Healers: Extraordinary clinicians at work. Oxford University Press 2011.

28. Novack D, Epstein R, \& Paulsen R. Toward creating physician-healers: fostering medical students' selfawareness, personal growth, and well-being. Acad Med 1999;74:516-20.

29. Dobie S. Reflections on a well-travelled path: self-awareness, mindful practice, and relationship-centered care as foundations for medical education. Acad Med 2007;82:422-27.

30. Jarvis-Selinger S, Pratt D, \& Regehr G. Competency is not enough: integrating identity formation into the medical education discourse. Acad Med 2012;87:1185-90.

31. Pinar W. Understanding curriculum as phenomenological text. In: Pinar WF, ed. Understanding Curriculum: An introduction to the study of Historical and contemporary Curriculum Discourses. New York, NY:P.Lang 1995;404-46.

32. Kegan R. The evolving self: Problems and process in human development. Cambridge, Mass: Harvard University Press 1982.

33. Erikson E. The life cycle completed. New York, NY: Norton 1982.

34. van den Eertwegh V, van der Vleuten C, Stalmeijer R, van Dalen J, Scherpbier A, \& van Dulmen S. Exploring residents' communication learning process in the workplace: a five-stage model. PlosOne 2015;10(5): e0125958. doi:10.1371/journal.pone.0125958

35. Malterud K. Qualitative research: standards, challenges, and guidelines. The lancet 2001;358:483-8.

36. Watling C, \& Lingard,L. Grounded theory in medical education research: AMEE Guide No. 70. Med Teach 2012;34:850-61.

37. Lingard L. When I say grounded theory. Med Educ 2014;48:748-9.

38. Charmaz K. Constructing grounded theory: A practical guide through qualitative analysis. Thousand Oaks, CA: Sage publications 2012.

39. Patton M. Qualitative evaluation and research methods. Thousand oaks, CA: Sage Publications 1990.

40. Miller W, \& Crabtree B. Clinical research: a multimethod typology and qualitative roadmap. In: Crabtree B, Miller W, eds. Doing qualitative research, 2nd edn. Thousand Oaks: Sage Publications 1999;3-30.

41. Frambach J, van der Vleuten C, \& Durning S. AM Last Page: Quality criteria in qualitative and quantitative research. Acad Med 2013;88:552.

42. Mendick N, Young B, Holcombe C, \& Salmon P. How do surgeons think they learn about communication? A qualitative study. Med Educ 2015;49:408-16.

43. Wear D, Zarconi J, Kumagai, A, \& Cole-Kelly K. Slow Medical Education. Acad Med 2015;90:289-93.

44. Kumagai A,\&Thirusha N. Reflection, dialogue, and the possibilities of space. Acad Med 2015;90:283-288.

45. Driessen E, van Tartwijk J, van der Vleuten C, \& Wass V. Portfolios in medical education : why do they meet with mixed success? A systematic review. Med Educ 2007;41:1224-33

46. Weinstein D. Feedback in Clinical Education: Untying the Gordian Knot. Acad Med 2015; doi: 10.1097/ACM.

47. Iedema R, Mesman J, \& Carroll K. Visualising Health Care Improvement. Radcliffe Publishing Ltd. London. 2013.

48. Cooperrider D. \& Whitney D. Appreciative inquiry: A positive revolution in change. Berrett-Koehler Publishers 2005.

49. Papastamatist, A. \& Panitsides, E. Transformative Learning: Advocating for a Holistic Approach. Review Eur Studies 2014;6:74.

50. Driessen E. \& Overeem K. Mentoring. In K. Walsh (Ed.), Oxford Textbook of Medical Education (pp. 265284). Oxford: Oxford University Press 2013. 
51. Cole T. The suffering of physicians. The Lancet 2009;374:1414-15.

52. Kennedy H, Landor,M. \& Todd L. Video Enhanced Reflective Practice: Professional Development through Attuned Interaction. London, Jessica Kingsley 2015.

53. Branch. Teaching professional and humanistic values: suggestions for a practical and theoretical model. Patient Educ Couns 2015;98:162-7 

Chapter 6

Discussion 



\section{Background}

The two main research questions (RQ) introduced in chapter 1 of this dissertation were: "What factors influence the weak transfer of medical communication skills from postgraduate training to medical practice?" and "What does the process of learning medical communication look like and what do residents need in order to render this process effective/transferable?". These two questions are inherently linked to the present discussion on communication skills teaching and acquisition in which two stances hold sway: at the one end we find those seeking to describe and measure physician communication behaviors, whereas at the other researchers lean toward the prerequisites for communication competencies, such as self-awareness, reflection, compassion, and self-growth objectives [1]. Effective communication learning (and transfer) seems to require a mixture of both [2]. Yet, we still do not know what this mixture should look like and how it should be translated into medical curricula to increase effectiveness (and transfer) of medical communication training programs. The findings reported in this dissertation provide preliminary answers to these fundamental questions. More specifically, the present dissertation has contributed to a further clarification of the factors that influence the weak effectiveness (or transfer) of postgraduate communication skills training programs (RQ 1) and has unraveled the communication learning process and learners' associated needs (RQ 2). The next paragraphs will discuss the main results ensuing from this dissertation in light of the existing gaps in the literature on effectiveness of medical communication teaching and learning. This will be followed by suggestions for improvement, limitations, and implications for future research.

Most often the term "communication learning" is used instead of "communication skills learning", to emphasize that there is more to communication than the level of skills, as will be further explained in section 3.1.

\section{Main results in relation to existing research gaps}

Five important research gaps and an attempt to fill these provided impetus to the present dissertation. First, as discussed in chapter 2, we found that there was a paucity of studies focusing on effectiveness in terms of transfer of learned skills to different specific clinical situations and long-term retention [3]. Second, we observed that research had hitherto obscured the factors that inhibit or facilitate physicians' application of skills in real, daily practice [4]. In order to improve the effectiveness of training, more insight into these factors would be foundational, because interactions between factors at multiple levels can either make or break quality improvement interventions $[5,6]$. The studies included in this dissertation help fill these two gaps outright, because they unveiled the factors that can bolster effectiveness and transfer of communication skills training and acquisition. Sensitivity to context appeared crucial in understanding better the interactions between factors. More specifically, it transpired that there are four contextual factors at play that directly enhance effectiveness or transfer over time: 
encouragement of deliberate practice in the work environment, recognition of the value of communication skills, institutionalized support, and appropriate feedback from role models. Non-contextual assessments based on checklists emerged as an important factor to inhibit the acquisition of communication skills. In our last study, we explored these factors more deeply, which yielded further insight into the learning process behind the factors. According to residents in the clinic, acquisition of communication skills was a function of their level of self-awareness, which should be raised to achieve higher effectiveness. Hence, confrontation with their personal behavior was a precondition for initiating the learning process. Additionally, time and space was needed to digest such confrontations, the success of which depended on one's level of selfawareness. The clinical residents identified five factors that helped them increase their level of self-awareness and render their learning of communication more effective: receipt of more feedback (especially positive), sensitive role models and personal attention, safety and vulnerability, independent coaching / supervision, and departmental awareness. We believe that in order to truly make communication learning effective in the long run, it is important that departments pay more attention to these contextual factors. In section 3 we will elaborate on how this can be operationalized in the hectic reality of the medical work environment.

The revelation that systematic implementation of communication skills trainings at the organizational or departmental level is often poorly developed or missing altogether [7-12], constituted the third research gap to inspire our investigation. Three of our studies (chapters 3, 4, and 5) unveiled that continuous attention at departmental level is essential. Without a nurturing environment and integration, improvements from communication skills trainings are often likely to flounder in the face of workload pressures, time constraints, inappropriate modeling, and apparent failure to recognize the value of this pivotal clinical skill [13]. The participants in our studies from those departments that did offer continuous training or support in communication skills (the general practice department, for instance, organized weekly sessions in which video recordings of real patient consultations were discussed, whereas some departments offered their residents monthly workplace-based coaching/supervision sessions with an independent coach) stated that only by the recurrence of sessions could space and a safe learning climate be created and, consequently, could their learning be truly supported in the long run. In summary, the three studies confirm that, in order for continuing medical education activities to reach their greatest potential, they must be truly continuing rather than causal, sporadic, or opportunistic [14].

The fourth research gap concerned the observation that communication skills assessments often do not take proper account of context. This assertion received more backing from our studies that revealed that the use of behavioral checklists in the assessment of communication skills was often regarded as subjective. There is more to the communication process than the merely perceptible skills such checklists capture. In other words, these checklists are reductionist to the extent that they do not take proper 
account of the hidden aspects of communication and the context in which the communication occurred. Another issue of concern raised was the fact that the assessment was summative for GP residents, which, they felt, thwarted the learning process. Passing the assessment became a goal in itself rather than an instrument for skills improvement. This summative character even fueled the residents to display unauthentic communication behavior, only to pass the assessment. These insights help explain why many doctors are skeptic about communication skills training and assessment.

Finally, we detected a fifth gap in research, notably an underrepresentation of clarification research and conceptual models to advance the science of medical communication skills education. Moreover, we observed that research on transfer to date had made limited use of qualitative methods [15]. Since we aspired to keep our research questions as exploratory in focus as possible, the choice to use qualitative research methodology was obvious. Our exploratory approach enabled us to investigate, unravel and clarify the process of medical communication acquisition. This venture resulted in the development of a five-phase model and two overall conditions describing the development toward becoming a skilled communicator (see table 1 below).

Table 1: The five phases and two overall conditions in residents' learning process of communication.

\begin{tabular}{lllll}
\hline \multicolumn{4}{c}{ COGNITIVE AND EMOTIONAL SPACE } \\
\hline $\begin{array}{l}\text { Phase 1 } \\
\begin{array}{l}\text { Confrontation with } \\
\text { the effect of certain } \\
\text { behavior }\end{array}\end{array}$ & $\begin{array}{l}\text { Phase 2 } \\
\text { Becoming conscious } \\
\text { of own behavior }\end{array}$ & $\begin{array}{l}\text { Phase 3 } \\
\text { Searching for } \\
\text { alternative behavior }\end{array}$ & $\begin{array}{l}\text { Phase 4 } \\
\text { Personalization } \\
\text { of new behavior }\end{array}$ & $\begin{array}{l}\text { Internalization and } \\
\text { clinical integration }\end{array}$ \\
\hline & SAFETY & \\
\hline
\end{tabular}

This model demonstrates that the process of learning and improving communication requires more than the simple provision and receipt of feedback. To ensure learning is really effective or transformational, the learner must first become conscious of a blind spot and be able to reflect on it in such a way that self-awareness increases and that new alternative behavior can be tried out safely in practice to make it personal and internalize it.

Our choice to interpret findings in light of the principles of transformative learning theory proved instrumental in that they confirmed that confrontations are prerequisites for a person's reflection on and change of his or her frames of reference and are therefore necessary for personal and professional development.

\section{Synthesis of results}

The above insights into the process of communication learning complement existing theory, since the five-phase model unifies elements of both extremes on the communi- 
cation skills development continuum (focus on both behavior and prerequisites to learning), providing a new, integrated perspective on how communication should best be learned. Where phases 1 and 2 focus on the prerequisites to learning, demonstrating the importance of reflection and awareness, phase 3 emphasizes the need to find and practice concrete alternative behavior(s) (know-how/ skills). Phases 4 and 5 concentrate on elements of both stances, with personalization and internalization involving trial and error in real practice (behavior), such that in the end the new behavior feels authentic and the person experiences self-growth (prerequisites). Hence, the fivephase model contributes to a current central theme in the field of communication skills learning and teaching by showing what process is needed to increase effectiveness and transfer of postgraduate communication skills teaching.

The five-phase model also has implications for our conception of "transfer". It transpired that effective learning (or transfer to the medical workplace) of communication does not automatically ensue from communication skills training, especially not so when training is decontextualized or offered off-site. Rather, as the respondents in our study pointed out, it is contingent on the availability of a safe learning environment that pays continuous attention to communication, thus embedding it in the daily work context and ensuring departmental support. Only then will the learner feel safe enough to allow reflection on current behavior, to adapt, practice, personalize, and internalize new behavior. In fact, when the learner has internalized the new behavior, transfer of the new skill or behavior to other situations follows naturally, most likely because the new behavior or skill has become an authentic part of the learner. In other words, the five-phase model visualizes the process that is needed for transfer to occur. This process of deep learning resulting in transfer is what we call "transformational learning".

\section{Suggestions for improvement}

\subsection{What is needed at departmental level}

When translating the above results into everyday medical practice, we think it is important that medical educators and policymakers start realizing that the five phases of the communication learning process can only occur successfully if the learner experiences enough emotional and cognitive space and safety, the two main conditions for learning mentioned in our model. This section discusses what is needed within clinical departments to create such space and safety, and how this can be operationalized.

Evidence of recent years suggests that not only patients, but also physicians suffer from the dehumanization of modern medicine [16]. There are many signs that being a physician today is not good for your health: rates of anxiety, depression, addictions, and

suicide are higher among physicians than in the general population [16]. Doctors must seek-and institutions must provide-avenues for dialog that allow renewal, self-care, 
mutual support, and reflection [16]. Professional associations and institutions must create better working conditions and provide programs that support stress-reduction, healthy lifestyle choices, personal reflection, and self-care. In turn, self-care must be seen not as an option but as an obligation. The obligation to care for the patient entails the obligation to care for the self, for, when the health of the physician is compromised, is not the quality of patients' care compromised too? Cole and Carlin conclude that we are just beginning to realize that humanizing medicine depends in no small part on recovering the humanity of physicians themselves [16]. Residents in our studies confirmed this need for space and mutual support to reflect on communication and develop their professional identity. In our study, continuous sessions or peer-to-peer coaching at departmental level worked well to provide such space and support.

What's more, the current focus on competency-based education does not automatically prompt residents to pay attention to personal emotions, for instance, by asking themselves "what does this patient or situation do to me?". By disregarding emotions, the work culture (and role models) invokes the implicit message that personal emotions are not professional and are best ignored. The residents in our studies, however, stated that emotion did play a key role in their communication learning process and should not be ignored. Recent findings in neuroscience indeed reveal and confirm that emotions are more intimately related and important to cognitive processing than was previously thought [17]. In fact, there is a constant dynamic interplay between emotion and cognition, rather than a hierarchical relationship in which cognition predominates [18]. If emotions do play such a pivotal role in the process of communication) learning, then this adds another argument to our plea for more space and support within medical departments for reflection on communication issues and personal development.

We have explicitly bracketed the concepts "communication learning" and "personal development" together, because studies 3 and 4 showed that residents consider these two to be inherently linked (they considered communication learning a form of personal development). The belief that communication learning is a form of personal lifelong development is an important one. It is also embraced by transformative learning theory [19] the theoretical framework for this dissertation, and shared by others like Korthagen [20] who contended that personal development is the key to professional development. His model coined "the Onion" is an adaptation of what in the literature is often referred to as "Bateson's model". The model distinguishes six different layers of learning, confirming that learning occurs simultaneously at different (cognitive and emotional) levels within a person. The layers are (from outside to inside): a person's exchange with his environment, his behavior, his competences, his beliefs and convictions, his identity or self-image, and at the deepest level his commitment to contribute to the world. Korthagen states that when the learning of competencies is based on a person's inner qualities (the inner or more deeper levels), a more effective form of learning occurs. Korthagen argued that when competencies are learned on the basis of a person's inner qualities (the inner layers of the onion), learning becomes more effec- 
tive. His model is generic and not accommodated to the learning of medical communication. Our five-phase model, by contrast, is specifically keyed to the learning of medical communication and confirms that new behavior or learning should be personalized and internalized (Korthagen's inner layers of the onion) to make it authentic and effective (transformational). One could argue, by extension, that these five phases possibly also apply to the acquisition of other CanMEDS competencies, such as professional behavior or collaboration.

The conception that learning is equivalent to lifelong personal development has important implications for practice and for the established model of competency-based education. It confronts us with the fact that a curriculum which is purely based on competencies and which seeks to strictly atomize the art of being a good doctor into behavioral skills and subskills is not conducive to integrated learning. Education based solely on competencies leads to an excessive concern with the need to provide a precise definition of all skills/competencies and subskills/sub-competencies involved, thereby automatically gravitating too much toward assessment issues [21]. This suggests that becoming a skilled communicator is a matter of acquiring the right behavioral skills/competencies. Yet, there is more to effective communication than mere skills [22], as our five-phase model confirms. We therefore hope this dissertation will contribute to a shift in the way communication learning is envisioned. A shift toward viewing it more as a holistic and personal lifelong process of learning whereby medical work and learning environments can and should be adjusted accordingly to foster this learning process. We therefore prefer to speak of "communication learning", as opposed to "communication skills learning", to capture the fact that there is more to communication than only the level of skills.

By extension, we suggest supplementing competency-based education programs with structured time for residents to pay attention to communication issues and the deeper levels of learning as part of their personal and professional development, instead of focusing on isolated training programs and lists of rules and behaviors to capture the CanMEDS competency of communication skills.

The residents in our studies are not the only ones who have expressed a need to dedicate structured time to communication and personal issues at departmental level. Pulmonologist Koster wrote in 2013 that doctors are left to their own devices when it comes to dealing with difficult communication and emotional situations, such as death, severe illness, medical malpractices, difficult patients, etc. [23]. Firemen, to name an example, receive professional support when they have to deal with emotions in stressful situations. Doctors, by contrast, who are often in equally stressful situations, do not receive anything similar. Consequently, it is commonplace for residents or specialists to shrug off these emotions instead of taking them more seriously. This often leads to burnout and emotional distancing from patients (and colleagues) with repercussions on the quality of care. Koster's article received many reactions from other doctors confirming the need for a paradigm shift [24]. This paradigm shift entails a move toward a 
medical work culture in which it becomes normal to talk about how the profession affects you as a person and in which colleagues emotionally support each other more openly when needed. The practical solution most often mentioned in all reactions was to start implementing regular sessions (peer-to-peer coaching) at the departmental level with non-committal participation. These sessions then offer space and support to discuss communication/emotional issues, such that doctors or residents feel less solitary and have the possibility to ask for tips or support when needed. The Dutch Association of Medical Specialists has promised to take this signal seriously and integrate this need for recurrent peer sessions in their policymaking [24].

\subsection{How to operationalize}

Our central plea for more continuous attention and support at departmental level automatically leads to the question of implementation: How can we effectively operationalize and scaffold the pivotal reflective learning and work environment that is required to sustain the development of skilled medical communicators? As stated above, coaching or group sessions in residency training offer a viable opportunity to support the personal lifelong communication learning process. There are several conditions or key points that need to be taken into account in order to increase its effectiveness.

First of all, the implementation of such sessions should be embedded and supported by all staff members in the department. Only then will residents feel safe enough to open up and use confrontations as an incentive to learning.

Second, we suggest making use of real/authentic confrontations or clinical situations brought forward by the participants themselves. This allows learning of communication to become integrated with the daily medical work context, which is important because it ensures that the group sessions will keep serving their original purpose, that is, to help students become a better doctor (instead of becoming "another goal in itself" within postgraduate education). Another advantage of using personal situations brought forward by the participants themselves is that the learning process becomes learner-centered and experiential (what does this specific resident need at this moment in time to develop into a skilled communicator). Learner-centeredness is necessary to enable personalization and internalization of new behavior. In case a resident lacks specific confrontations to initiate his or her learning process, collecting feedback from real patients (or colleagues, or nurses) can be powerful because of its authenticity [25]. Another suggestion is to install a video camera in one or more consulting rooms within the department to be able to make recordings of real patient consultations. These video recordings are another effective form of authentic material to be used as input during the peer sessions to enhance reflective practice (as confirmed by the residents in our first study). These suggestions are also in keeping with the recent increase in attention to personalized learning. 
A third important point is to have confidence in learners' motivation to take responsibility for their own development. Making these sessions compulsory would counteract this process, because learning through coercion does not work as effectively as learning through intrinsic motivation. Luken [26] clearly points at this issue by stating the negative effects of forced reflection without inner motivation. If reflection is imposed upon a learner while he or she does not see or feel the need to reflect or change, then the first step or precondition for learning (phase 1 in our model) is not met. When too much emphasis is put on reflection as a goal in itself (that is, in the absence of authentic situations or confrontations) it will spawn resistance. By the same token, we suggest that it would help to replace summative assessment of communication skills by formative assessment focused on concrete feedback and driven by personal learning goals. Such type of formative assessment would better emphasize the supportive character which residents in our study preferred communication learning and assessment to be.

A fourth point to consider is the availability of sufficient departmental staff who are sensitive to communication issues themselves to serve as role models. Perron [27] already pointed at clinical supervisors' perceived lack of competence to identify communication skills and give effective feedback. Staff training or faculty development is needed in this regard. Because it takes time to cultivate competence among staff, a practical interim solution might be to have the peer sessions guided by an independent person who has experience in supervising communication and socio-emotional issues. A positive corollary to this solution is that such a person is not part of the hierarchical system and does not need to assess residents' general performance. This adds to the perceived safety of such peer sessions.

\section{$4 \quad$ Strengths and limitations}

A first limitation of this dissertation is that it was impossible within its scope to translate our findings into practice by conducting for instance an interventional study. Another limitation is that, due to the qualitative nature of our studies, we should be careful to generalize our results. Our main intention, however, was to explore. In this regard, the innovative character of this dissertation is a strength and its accompanying findings should be considered as new insights into the process of learning which can animate future research attempts to generalize findings. A third limitation concerns the fact that all three of our studies are based on residents' self-reports. Although our results were triangulated with existing literature, this might reduce the transferability of our findings. The fact that our participants were all residents from a single center, reducing transferability, constitutes a fourth limitation. 


\section{Implications for future research}

Future research could first of all focus on validation and refinement of our suggestions for improvement. Another implication for future research, resulting from our limitations, is to conduct interventional studies and/or studies based on other methods than focus-group interviews and in-depth interviews. This might make generalization and transferability of our findings possible. Another implication for future research derives from the fact that context appeared to play such a crucial role in the process of learning. Hence, we suggest that future research be conducted in other work contexts, that is, in other hospitals as well as other countries and cultures. It would be interesting to investigate whether these other contexts would reveal differences with regard to the five phases and accompanying needs in the process of learning medical communication. A final recommendation for future research concerns the generalizability of our five-phase model to competencies other than communication. This dissertation unraveled the process of learning how to become a skilled medical communicator. But what does the learning process look like for the other CanMEDS roles, being: learning to become a manager, a health advocate, a collaborator, a scholar, a professional, and a medical expert [28]? Each of these competencies equally entails a lifelong process of learning and personal development. More insight into the possible parallels between these learning processes can excite the implementation and modernization of postgraduate medical education programs.

Ultimately, the suggestions in this dissertation can boost the development of medical work and learning climates that provide a healthy breeding ground for doctors' development into skilled communicators. Only then will we put into practice the essence captured in the following quote by Maharshi "A doctor's own self-realization is the greatest service he/she can render the world". 


\section{References}

1. Clarke A. Teaching Physicians Communication Skills: Where We Are, How We Got Here. Research Project Submitted In Partial Fulfillment of the Requirements for the Degree of Master of Education. Simon Fraser University 2013.

2. Jarvis-Selinger S, Pratt D, \& Regehr G. Competency is not enough: integrating identity formation into the medical education discourse. Acad Med 2012;87:1185-90.

3. Lienard A, Merckaert I, Libert Y, Bragard I, Delvaux N, Etienne A, et al. Transfer of communication skills to the workplace during clinical rounds: impact of a program for residents. PLoS One 2010;5:e12426.

4. Hulsman L, Ros W, Winnubst J, Bensing J. Teaching clinically experienced physicians communication skills. A review of evaluation studies. Med Educ 1999;33:655-68.

5. Bosch M, van der Weijden T, Wensing M, Grol R. Tailoring quality improvement interventions to identified barriers: a multiple case analysis. J Eval Clin Pract 2007;13:161-8.

6. Greenhalgh T, Robert G, MacFarlane F, Bate P, Kyriakidou O. Diffusion of innovations in service organizations: systematic review and recommendations. Milbank $Q$ 2004;82:581-629.

7. Visser A, Wysmans M. Improving patient education by an in-service communication training for health care providers at a cancer ward: communication climate, patient satisfaction and the need of lasting implementation. Patient Educ Couns 2010;78:402-8.

8. Grol R. Successes and failures in the implementation of evidence-based guidelines for clinical practice. Med Care 2001;39:46-54.

9. Grol R, Baker R, Moss F. Quality improvement research: understanding the science of change in health care. Qual Saf Health Care 2002;11:110-1.

10. Grol R, Bosch M, Hulscher M, Eccles M, Wensing M. Planning and studying improvement in patient care: the use of theoretical perspectives. Milbank $Q$ 2007;85:93-138.

11. Grol R, Grimshaw J. From best evidence to best practice: effective implementation of change in patients' care. Lancet 2003;362:1225-30.

12. Greenhalgh T, Robert G, MacFarlane F, Bate P, Kyriakidou O. Diffusion of innovations in service organizations: systematic review and recommendations. Milbank $Q$ 2004;82:581-629.

13. Silverman J. Clinical communication training in continuing medical education:possible, do-able and done? Patient Educ Couns 2011;84:141-2.

14. Mazmanian P, Davis D. Continuing medical education and the physician as a learner. J Am Med Assoc 2002;288:1057-60.

15. Leberman S, McDonald L, Doyle S. The transfer of learning: participants' perspectives of adult education and training. Burlington: Gower Publishing Company Limited 2006.

16. Cole T, Carlin N. The suffering of physicians. Lancet 2009;374:1414-15.

17. O'Callaghan A. Emotional congruence in learning and health encounters in medicine: addressing an aspect of the hidden curriculum. Adv Health Sciences Educ 2013;18:305-17.

18. Salzman C, Fusi S. Emotion, cognition, and mental state representation in amygdala and prefrontal cortex. Annu Rev Neurosci 2010;33:173-202.

19. Mezirow J. Transformative learning as discourse. J Transform Educ 2003;1:58-63.

20. Korthagen F, \& Vasalos A. Kwaliteit van binnenuit als sleutel voor professionele ontwikkeling. Tijdschrift voor lerarenopleiders 2007;28:17-23.

21. Korthagen F. Zin en onzin van competentiegericht opleiden. VELON Tijdschrift voor lerarenopleiders 2004;25:13-23.

22. Salmon P \& Young B. Creativity in clinical communication: from communication skills to skilled communication. Med Educ 2011;45:217-26.

23. Koster. Arts heeft eenzaam beroep. Med Contact 2013;47:2450.

24. Broersen S. Verhaal gestopte longarts maakt veel los. Med Contact 2013;49:2562.

25. Karazivan P, Dumez V, Flora L, Pomey M, Del Grande C, Ghadiri D, \& Lebel P. The Patient-as-Partner Approach in Health Care: A Conceptual Framework for a Necessary Transition. Acad Med 2015;90:437-41.

26. Luken T. Zin en onzin van reflectie. Supervisie en coaching 2011;28:153-66.

27. Perron N, Cullati S, Hudelson P, Nendaz M, Dolmans D, van der Vleuten C. Impact of a faculty development program for teaching communication skills on participant's practice. BMC Med Educ 2014;14:80-6. 
28. Frank J, Snell L, Cate O, Holmboe E, Carraccio C, Swing S, \& Harris K. Competency-based medical education: theory to practice. Med Teach 2010;32:638-645. 



\section{Summary}





\section{Chapter 1: Introduction}

Chapter 1 introduces the main concepts of this dissertation, discusses its background, and presents the problem statement and two main research questions. The central concept of this dissertation is "effectiveness of medical communication learning at postgraduate level." The two research questions are: 1) What factors influence the weak transfer of medical communication skills from postgraduate training to medical practice?; and 2) What does the process of learning medical communication look like and what do residents need in order to render this learning process effective or transferable? The chapter first gives an account of why it is so important that we pay attention to communication in medical contexts. Effective communication is important because it is a direct function of increased health outcomes, patient and physician satisfaction, and reduced costs. The chapter then throws more light on the concept of effectiveness, pointing out that it can be measured or defined at different levels. One of these levels is called "transfer," which measures effectiveness in terms of a change in behavior on-the-job, based on what is learned. This definition of effectiveness as a concrete change in behavior is what our teaching and learning of communication actually aims to accomplish. Transfer, therefore, is our single most important conceptualization of effectiveness. Effective transfer, however, appears to be contingent upon several contextual factors. This dissertation goes on to identify the factors that are the most important with regard to communication learning. The chapter concludes with a short description of the theoretical orientation chosen to investigate the research questions, being transformative learning theory (based on humanism) and social constructivism. The term "communication skills" is used in the first chapters of this dissertation. However, in the course of our research we came to realize that the term "skills" does not sufficiently capture the non-verbal and hidden aspects of communication. Therefore, we gradually came to replace "communication skills learning" by "communication learning."

\section{Chapter 2: Learning in context - Identifying gaps in research on the transfer of medical communication skills to the clinical workplace}

Chapter 2 presents a narrative review. Research findings on the effectiveness of medical communication training still show inconsistencies and variability. To better understand the root cause of these inconsistencies and variability, this review identifies five main gaps in research on medical communication skills training. The chapter also presents insights from theories on learning and transfer to build the foundation for future research. Contemporary theories on learning based on a constructivist paradigm offer the following insights: acquisition of knowledge and skills should be viewed as an ongoing process of exchange between the learner and his or her environment, so-called lifelong learning; this process can neither be atomized nor separated from the context in which it occurs. Four contemporary approaches are presented as examples. The 
chapter concludes by proposing a shift in focus for future research: moving beyond isolated single-factor effectiveness studies toward constructivist, non-reductionist studies integrating the context. The practical implication arising from this narrative review is a need to explore more deeply how constructivist approaches can be used in the medical context to increase effective learning and transfer of communication skills.

\section{Chapter 3: Residents' perceived barriers to communication skills learning - Comparing two medical work contexts in postgraduate training}

Contextual factors are known to influence the acquisition and application of communication skills in clinical settings. Knowledge about how residents perceive these factors, however, is scant. This chapter therefore explores residents' perceptions of contextual factors affecting the acquisition and application of communication skills in the medical workplace. To this end, we conducted focus-group interviews with residents in two different specialties: general practice and surgery. Four factors arose as key determinants of communication learning. First, residents perceived confrontation with their communication behavior as a powerful incentive to learning. Second, repetition appeared to enhance the learning and application of communication skills. Residents repeatedly argued that communication was part of "who you are and how you develop as a person." Communication therefore merits attention and should be practiced repeatedly during the entire course of residency training. This was also called encouragement to deliberately practice personal communication behavior in their work environment. As a third factor residents subscribed to the effectiveness of systematic and continuous attention to communication within their institute or department. Finally, residents also perceived appropriate feedback from role models as a powerful learning tool.

An important factor inhibiting the acquisition of communication skills was the use of summative assessment checklists that reduce communication to behavioral components or skills. The summative character of these assessments induced residents to display unauthentic behavior just to pass the assessment. The chapter concludes with a theoretical and a practical suggestion. The findings of this study are consistent with the main principles of transformative learning theory. From a theoretical point of view, we therefore suggest that future research further explores to what extent the use of transformative learning theory as a theoretical framework can help clinical work environments incorporate the aforementioned factors. A practical suggestion is to deploy recordings of real resident-patient consultations which can greatly benefit communication learning. The strength of this method lies in its focus on authentic confrontations and in the recurrence of personalized follow-up sessions. 


\section{Chapter 4: Exploring residents' communication learning process in the workplace - A five-phase model}

Competency-based education is a resurgent paradigm and communication is regarded as a main competency in professional medical education. However, more specific knowledge is needed about how communication is learned, since it consists of complex skills and is strongly embedded in one's personality, background, character, temperament, frame of reference, etc. Chapter four therefore further explores the learning process that residents in general practice (GP) go through during workplace-based learning in order to become skilled communicators. GP residents were observed during their regular consultations and were interviewed in-depth afterwards.

Analysis of the data resulted in the construction of five phases and two overall conditions with which to describe the development towards becoming a "skilled communicator." The first phase consists of confrontation with desired or undesired behavior or clinical outcomes. Becoming conscious of one's own behavior and changing the underlying frame of reference forms the second phase. The third phase consists of the search for alternative behavior in the form of concrete suggestions to use and experiment with in real practice. After this phase, personalization of the alternative behavior ensued. This was perceived as difficult and required much time, since residents felt consciously incompetent. It was only by a process of trial and error that the new behavior could be personalized. Finally, the fifth phase concerned full internalization of the new behavior, which, by then, had become an integrated part of the residents' clinical repertoire. This final phase was typified by a sense - on the part of the resident - of being unconsciously competent. Safety and cognitive and emotional space were labeled as overall conditions that affected this learning process. Table 1 showcases the five phases and two conditions.

Table 1: The five phases and two overall conditions in residents' process of learning communication.

\begin{tabular}{lllll}
\hline \multicolumn{4}{c}{ COGNITIVE AND EMOTIONAL SPACE } \\
$\begin{array}{llll}\text { Phase 1 } \\
\begin{array}{l}\text { Confrontation with } \\
\text { the effect of certain } \\
\text { behavior }\end{array}\end{array}$ & $\begin{array}{l}\text { Phase 2 } \\
\text { Becoming conscious } \\
\text { of own behavior }\end{array}$ & $\begin{array}{l}\text { Phase 3 } \\
\text { Search for alternative } \\
\text { behavior }\end{array}$ & $\begin{array}{l}\text { Phase 4 } \\
\text { Personalization } \\
\text { of new behavior }\end{array}$ & $\begin{array}{l}\text { Internalization and } \\
\text { clinical integration }\end{array}$ \\
\hline & & SAFETY & \\
\hline
\end{tabular}

The above model demonstrates that communication learning requires more than the simple provision and receipt of feedback. The chapter concludes by suggesting that the new model can inform the adjustment of medical work and learning environments in such a way that the development of skilled medical communication can come to full fruition and its benefits are more fully reaped. 


\section{Chapter 5: Transformative learning in clinical communication - Creating the opportunity to know thyself}

To complement the previous study which targeted the work environment of residents in general practice, in this study we focused on the hospital work context. We conducted in-depth interviews with residents from ten different hospital departments or specialties. The central question was how these residents could learn and improve their communication in a more transformative, and, consequently, more effective manner in their daily medical work environment. Transformative learning is defined as learning that leads to a permanent change in behavior that feels authentic. In this sense transformative learning equals effective learning. This study identified the factors that these residents believed supported their process of transformative learning.

From an analysis of the results it transpired that learners first needed to be confronted with their personal behavior. Then, they needed to be afforded time to digest such confrontations. The results also showed that the success of such assimilation of confrontations depended on one's level of self-awareness. Hence, to bolster transformative learning, it became imperative to increase one's level of self-awareness. Residents identified five factors that helped them achieve this goal. The first four of these factors were: the receipt of more feedback, especially positive; the availability of sensitive role models and personal attention at the work floor; a learning environment in which they felt safe enough to reveal their vulnerability and to try and change existing behavior; and the availability of periodic moments of coaching or peer supervision with other residents in the department. These sessions should preferably be led by an independent coach or a person who is not part of the staff and thus is an outsider to the hierarchy. Finally, a more communication-minded workplace culture in which all members of the department subscribe to the importance of communication was reported as very helpful. An important insight arising from this transformative learning process is that communication learning should become part of learners' lifelong personal development. The findings in this chapter highlight the importance of continuous coaching or peer sessions in residency training, because this form offers a viable opportunity to support communication learning as a process of personal development.

\section{Chapter 6: Discussion}

Chapters 2 to 5 describe the empirical studies that provide more insight into the process whereby postgraduates learn medical communication and into the factors that influence its effectiveness (transfer). Chapter 6 forms the discussion chapter of this dissertation. The first part of this discussion summarizes the main findings in relation to the five gaps in existing research. Our findings help fill the first research gap, which is a lack of effectiveness studies focusing on transfer of learned skills to different clinical situations and on their retention. As to the second research gap, our studies revealed which factors inhibit or facilitate the application of skills in real, everyday prac- 
tice. In increasing effectiveness and transfer of communication training and learning, the following factors appeared crucial: encouragement to deliberately practice in the work environment, recognition of the value of communication, institutionalized support, appropriate feedback (especially positive) from sensitive role models, personal attention, a safe learning environment fostering the willingness to be vulnerable, independent coaching / supervision, and a communication-minded workplace culture. Noncontextual assessment based on checklists was an important factor that inhibited communication skills learning. With respect to the third research gap, our studies confirmed that systematic implementation at departmental level is crucial for the creation of space and a safe learning climate. In most clinical departments this continuous attention to communication issues was absent. In a similar fashion, the fourth research gap resonated with our finding that assessment of communication skills often occurs without taking proper account of the context and the non-verbal aspects of communication. Especially behavioral checklists appear to have a reductionist effect. Summative assessment also inhibits the learning process, since it encourages residents to display unauthentic communication behavior just to pass the assessment. Finally, our fivephase model also helps fill the fifth research gap, specifically the need for more clarification research and conceptual models. The model shows that the process of learning and improving communication requires more than the simple provision and receipt of feedback. To make learning really effective or transformative one must first become conscious of a blind spot and be afforded the opportunity to reflect on it in such a way that self-awareness increases, after which the newly found alternative behavior should be tried out safely in practice so as to make it personal and until it has finally become internalized.

The second part of the discussion offers suggestions as to how clinical departments can improve their internal organization. All residents in our studies concurred that they needed space and mutual support to reflect on communication issues and develop their professional identity as a doctor. Periodic peer sessions or peer consultations with colleagues at departmental level works well to provide such space and support. We recommend that communication teaching and learning be regarded as a lifelong personal development. This credo implies that there is more to communication than the mere behavioral level of skills. It implies that medical work and learning environments should be accommodated to facilitate this learning process. One viable way to do so is by introducing periodic peer sessions into the department. Effectiveness of such sessions will be maximized if they satisfy the following four important conditions: they are embedded and supported by all staff members in the department; they are based on real, authentic confrontations or clinical situations brought forward by the participants; they are not compulsory; and finally, they are facilitated by an independent person to warrant safety and/or by the presence of enough sensitive staff members who can support the learning processes. 

Samenvatting 



\section{Hoofdstuk 1: Introductie}

In hoofdstuk 1 wordt het thema van dit proefschrift geïntroduceerd, nl. "effectiviteit van het communicatieleerproces in de medische vervolgopleiding". De volgende twee centrale onderzoeksvragen lopen als rode draad door de verschillende hoofdstukken heen: "Welke factoren zijn verantwoordelijk voor de geringe transfer van medische communicatievaardigheden van training naar de dagelijkse praktijk?" en "Hoe ziet het communicatieleerproces er zelf precies uit en wat hebben artsen in opleiding tot specialist (AIOS) nodig om dit leerproces effectief te benutten?" Aan de hand van literatuur wordt eerst de relevantie geschetst van effectieve communicatie. Deze relevantie wordt duidelijk uit de relatie tussen effectieve communicatie en hogere gezondheidsuitkomsten, een grotere tevredenheid onder zowel artsen als patiënten, en lagere kosten voor de gezondheidszorg. Vervolgens wordt het begrip "effectiviteit" onder de loep genomen: effectiviteit kan gemeten worden op vier niveaus, waarvan het derde niveau ook wel "transfer" wordt genoemd; hierbij wordt effectiviteit gemeten op basis van daadwerkelijke gedragsverandering op de werkvloer naar aanleiding van het geleerde. Deze opvatting van effectiviteit is precies wat het medisch communicatieonderwijs beoogt te bewerkstelligen: daadwerkelijke bewustwording en gedragsverandering in de praktijk. In onze ogen is transfer daarom de belangrijkste belichaming van effectief communicatieonderwijs. In de totstandkoming van transfer blijken verschillende contextafhankelijke factoren een rol te spelen. Dit proefschrift ontrafelt welke van deze factoren belangrijk zijn bij de verwerving van competentie met betrekking tot adequate arts-patiëntcommunicatie.

Hoofdstuk 1 wordt afgesloten met een korte toelichting op het theoretisch kader waarop de beantwoording van de onderzoeksvragen zich stoelt, bestaande uit Transformative learning theory (gebaseerd op het Humanisme) en Sociaal constructivisme.

\section{Hoofdstuk 2: Leren in context - lacunes in onderzoek rondom transfer van medische communicatievaardigheden van training naar de klinische praktijk}

Hoofdstuk 2 presenteert een narratieve literatuurstudie. Onderzoek naar de effectiviteit van training in medische communicatievaardigheden laat veel inconsistentie en variatie tussen studies zien.

In een poging deze inconsistenties en variatie beter in kaart te brengen, identificeert deze studie vijf lacunes in onderzoek rondom training en transfer van medische communicatievaardigheden. Daarnaast reikt het hoofdstuk enkele inzichten aan uit het aanverwante vakgebied "leren en transfer van leren". Toekomstig onderzoek kan de inzichten uit dit aangrenzend vakgebied verder toetsen en inzetten binnen het domein van medisch communicatieonderwijs. Op die manier vindt kruisbestuiving tussen verschillende onderzoeksgebieden plaats. De voor dit proefschrift interessante inzichten uit dit aanverwante vakgebied zijn afkomstig van constructivistische leerparadigma's. Deze paradigma's zeggen dat leren (oftewel het verwerven van kennis, vaardigheden 
en inzicht) veel meer beschouwd moet worden als een continu proces. Dit proces is een wisselwerking tussen de lerende en zijn of haar omgeving, ook wel lifelong learning genoemd. Het heeft de voorkeur dit leerproces niet teveel op te splitsen in deelstukjes en niet te scheiden van de context waarin het leren plaatsvindt. Ter illustratie worden vier voorbeelden geschetst van constructivistische benaderingen van leren en transfer.

Het hoofdstuk wordt afgesloten met de aanbeveling om toekomstig communicatieonderzoek voortaan vanuit een andere invalshoek te benaderen: weg van geïsoleerde studies waarbij slechts één factor onderzocht wordt, naar constructivistische, nietreductionistische studies die de context integreren.

Een praktisch vervolg op deze studie zou zijn om nader te onderzoeken hoe constructivistische benaderingen van leren en transfer gebruikt kunnen worden om de effectiviteit van medisch communicatieonderwijs te vergroten.

\section{Hoofdstuk 3: Barrières in het communicatieleerproces volgens AIOS - een vergelijking van twee medische werkplekken in de vervolgopleiding}

Het is bekend dat contextuele factoren van invloed zijn op het aanleren en toepassen van communicatievaardigheden in de klinische praktijk. Er is echter weinig bekend over hoe AIOS als lerenden hier zelf tegenaan kijken. Dit hoofdstuk onderzoekt daarom welke contextfactoren volgens AIOS het communicatieleerproces op de werkplek het meest beïnvloeden. Voor dit doel namen we focusgroepinterviews af bij AIOS werkzaam in twee verschillende specialismen: huisartsgeneeskunde en chirurgie. Vijf factoren bleken in belangrijke mate het leerproces te beïnvloeden en te bepalen. Allereerst bleek confrontatie met het eigen communicatiegedrag een belangrijke factor die de wil om te leren voedde. Daarnaast bleek de mogelijkheid tot oefenen of herhaling erg belangrijk. De AIOS in onze studie gaven aan dat ze communicatie beschouwden als onderdeel van hun persoonlijke ontwikkeling. Structurele aandacht voor communicatie en de mogelijkheid om tijdens het werk nieuw gedrag uit te proberen en te oefenen was daarom essentieel. AIOS die hierin actief ondersteund werden door staf en collega's, konden door deze vorm van deliberate practice hun communicatie stapsgewijs en structureel verbeteren. Logischerwijs volgt hieruit dat het als zeer bevorderlijk werd beschouwd wanneer het communicatieonderwijs structureel ingebed was in de afdeling (factor 3). Als vierde factor gaven AIOS aan constructieve feedback van rolmodellen als een krachtig leermiddel te ervaren. Ten slotte was er een vijfde factor die het communicatieleerproces juist belemmerde: de summatieve toetsingsvorm aan de hand van scorelijsten. Bij deze vorm van toetsing wordt het communicatieproces tot gedragscomponenten gereduceerd zonder dat daarbij de context goed in acht wordt genomen. Hierdoor ervoeren AIOS deze scorelijsten als een reductionistische vorm van toetsing. Ook het summatieve karakter van de toetsing werd als negatief ervaren, doordat het de AIOS forceerde om bepaald (onecht) gedrag te vertonen enkel om de toets te behalen. 
Het hoofdstuk sluit af met een theoretische en een praktische suggestie. Onze bevindingen bleken te resoneren met de basisprincipes van transformative learning theory. Het zou daarom interessant zijn als vervolgonderzoek zich verder richtte op de vraag hoe transformative learning theory als theoretisch kader gebruikt kan worden om klinische werkomgevingen te helpen voornoemde factoren te integreren. De praktische suggestie betreft het gebruik van video-opnames van echte arts-patiënt consulten als effectieve manier om communicatieonderwijs structureel en stapsgewijs in te vullen. De kracht van deze methode ligt in het gebruik van authentieke confrontaties uit de praktijk van de lerende zelf en in het continue karakter waardoor er ruimte ontstaat voor deliberate practice.

\section{Hoofdstuk 4: Het communicatieleerproces op de werkvloer ontrafeld - een vijf-fasen model}

Competentiegericht opleiden is een actueel thema. Een van de basiscompetenties waarop de medische vervolgopleiding zich richt is communicatie. Specifieke kennis over hoe het communicatieleerproces er nu eigenlijk uitziet, is echter heel summier. Bekend is dat communicatie bestaat uit een complex samenspel van verbale en nonverbale vaardigheden en inzicht en dat zij sterk verankerd is in de persoonlijkheid, achtergrond, karakter, temperament, normen en waarden, overtuigingen, referentiekader etc. van de lerende. Het is daarom uitermate belangrijk dat we meer inzicht verkrijgen in het leerproces hierachter, opdat duidelijk wordt welke aanpassingen in het onderwijsaanbod voor een groter leerrendement kunnen zorgen. Hoofdstuk vier onderzoekt daarom specifiek hoe het communicatieleerproces van huisartsen in opleiding er uitziet in de praktijk. Voor dit doel hebben we huisartsen in opleiding geobserveerd tijdens hun consulten met patiënten en vervolgens één op één diepte-interviews bij hen afgenomen.

Analyses van de data hebben geleid tot de constructie van vijf fasen en twee overkoepelende voorwaarden die het leerproces beschrijven. Confrontatie met (on)gewenst gedrag of klinische uitkomsten vormt de eerste fase. In de tweede fase wordt de AIOS zich bewust van het eigen gedrag of aandeel. De derde fase bestaat uit het zoeken naar alternatieven in de vorm van praktische tips of soms zelfs concrete zinnen die uitgeprobeerd kunnen worden in de praktijk. In de vierde fase vindt personalisering van de alternatieven plaats. Hierbij probeert de lerende de alternatieven net zo lang uit in de praktijk totdat er een vorm overblijft die goed voelt, past bij de persoon en echt werkt. Dit personaliseren werd ervaren als moeilijkste fase omdat de AIOS zich bewust incompetent voelde en het alternatief enkel door middel van vallen en opstaan een vorm kon geven die paste bij zijn of haar persoon. De vijfde fase bestond uit internalisering van het nieuwe gedrag, zodanig dat dit volledig geïntegreerd was in het klinisch handelen. Kenmerkend voor deze laatste fase was het gevoel onbewust competent te zijn met betrekking tot de communicatie. Tabel 1 geeft de fasen verkort weer. 
Uit het onderzoek kwam verder naar voren dat het leerproces verbonden was aan twee overkoepelende voorwaarden. In de eerste plaats bleek cognitieve en emotionele ruimte vereist te zijn voor een succesvol verloop van het leerproces: AIOS gaven aan dat ze zowel in hun hoofd (cognitief) als emotioneel voldoende rust en ruimte moesten ervaren vooraleer ze actief aan de slag konden gaan met hun eigen communicatie. De tweede overkoepelende voorwaarde bleek een gevoel van veiligheid te zijn: zich veilig genoeg voelen om persoonlijke confrontaties of situaties openlijk te durven bespreken, maar ook om nieuw gedrag te durven uitproberen in de praktijk.

Tabel 1: De vijf fasen en twee overkoepelende voorwaarden in het communicatieleerproces

\begin{tabular}{lllll}
\hline \multicolumn{4}{c}{ Cognitieve en emotionele ruimte } \\
\hline $\begin{array}{l}\text { Fase 1 } \\
\text { Confrontatie }\end{array}$ & $\begin{array}{l}\text { Fase 2 } \\
\text { Bewustwording van } \\
\text { eigen gedrag en } \\
\text { aandeel in de } \\
\text { communicatie }\end{array}$ & $\begin{array}{l}\text { Foektocht naar } \\
\text { alternatief gedrag }\end{array}$ & $\begin{array}{l}\text { Fase 4 } \\
\text { Personalisering } \\
\text { van het nieuwe } \\
\text { gedrag }\end{array}$ & $\begin{array}{l}\text { Fase 5 } \\
\text { Internalisering en } \\
\text { integratie met } \\
\text { klinisch handelen }\end{array}$ \\
& & Veiligheid & \\
\hline
\end{tabular}

Deze fasen laten zien dat het communicatieleerproces meer omvat dan slechts het "geven en ontvangen van feedback". In het hoofdstuk wordt ten slotte voorgesteld dat, op basis van de nieuw verworven kennis en inzichten met betrekking tot de vijf fasen en twee voorwaarden, de leer- en werkomgeving van AIOS zodanig wordt aangepast dat de vruchten van effectieve communicatie sneller en langduriger geplukt kunnen worden.

\section{Hoofdstuk 5: Transformerend leren van communicatie in een ziekenhuiscontext - creëer de mogelijkheid voor zelfinzicht}

Terwijl het vorige hoofdstuk het communicatieleerproces van AIOS in een huisartsgeneeskundesetting onder de loep nam, richt dit hoofdstuk zich in het bijzonder op de ziekenhuissetting. Het belangrijkste verschil tussen deze twee settings ten aanzien van communicatie is de aandacht die zij expliciet hieraan besteden. Bij huisartsgeneeskunde is er structurele aandacht voor communicatieonderwijs, terwijl de ziekenhuisspecialisaties in ons onderzoek hun AIOS niet structureel communicatieonderwijs aanbieden. Om het communicatieleerproces in deze ziekenhuissetting inzichtelijk te maken hebben we diepte-interviews afgenomen bij AIOS van tien verschillende ziekenhuisspecialismen. Onze onderzoeksvraag was: "Wat helpt jou om je communicatieleerproces transformerend (effectief) te maken?" Transformerend leren werd gedefinieerd als een manier van leren die leidt tot een permanente verandering in gedrag die authentiek 
voelt. De resultaten van deze studie onthullen welke factoren de AIOS als ondersteunend ervoeren in hun proces van transformerend leren. Ook hier werd confrontatie duidelijk genoemd als belangrijkste prikkel voor de AIOS om überhaupt met de eigen communicatie aan de slag te gaan. Daarnaast bleek het van belang om regelmatig een moment van tijd en ruimte te creëren om de confrontatie te laten bezinken en na te kunnen denken over het eigen aandeel erin en wat anders kan. Deze reflectie, of beter gezegd de kwaliteit ervan, bleek af te hangen van de mate van zelfkennis van de lerende. Wanneer de reflectie leidde tot vergroting van zelfkennis/zelfinzicht, dan ervoeren de AIOS dit als transformerend leren.

Er werden vijf specifieke factoren genoemd die dit zelfinzicht hielpen vergroten. Ten eerste werd het belang genoemd van (meer) concrete communicatie-specifieke feedback. Hierbij werd ook expliciet de behoefte aan meer positieve feedback geuit, omdat dit bekrachtigend werkt voor het zelfvertrouwen. De tweede factor betrof de aanwezigheid van rolmodellen op de afdeling die feeling hadden voor en sensitief waren ten opzichte van communicatie. Wanneer zulke rolmodellen de AIOS hielpen bij hun reflectie tijdens een moment van persoonlijke en onbevooroordeelde aandacht, dan zette dit de AIOS aan tot transformerend leren. Een derde factor betrof de mate van veiligheid; deze bleek ook in de ziekenhuissetting noodzakelijk voor de AIOS om zich kwetsbaar te durven opstellen en bestaand gedrag te veranderen. Als vierde werd het belang genoemd van structurele intervisie binnen de afdeling. Twee van de tien afdelingen boden hun AIOS de mogelijkheid tot structurele intervisie. Dit werd ervaren als zeer waardevol en als leidend tot transformerend leren. Het had de voorkeur deze intervisiesessies te laten leiden door een externe persoon of coach met ervaring op het gebied van communicatie en sociaal-emotionele ontwikkeling en die onafhankelijk was van de hiërarchie op de afdeling. Tot slot werd genoemd dat de mate van communicatiebewustzijn binnen de afdeling een belangrijke factor vormde voor de AIOS om zelf wel of niet aan de slag te gaan met de eigen communicatie en zich wel of niet gesteund te voelen hierin.

Kortom, het communicatieleerproces zou veel meer beschouwd moeten worden als een vorm van persoonlijke ontwikkeling. Structurele intervisie biedt daar een praktische vorm van ondersteuning voor.

\section{Hoofdstuk 6: Discussie}

Hoofdstuk 6 vormt de discussie van dit proefschrift die voortvloeit uit de in hoofdstuk twee tot en met vijf gerapporteerde resultaten. Het eerste gedeelte van de discussie vat de hoofdresultaten samen aan de hand van de vijf lacunes in communicatieonderzoek zoals beschreven in hoofdstuk 2. De eerste twee lacunes betreffen enerzijds het gebrek aan effectiviteitsstudies die transfer en langetermijneffecten meten en anderzijds het gebrek aan inzicht in de factoren die deze transfer belemmeren en bevorderen. Uit onze studies kwam naar voren dat de volgende factoren transfer ondersteunden: herkenning en erkenning van het belang van communicatie, aanmoediging van en onder- 
steuning bij deliberate practice van communicatie in de dagelijkse werkomgeving, structurele facilitering hiervoor vanuit de afdeling, constructieve en positieve feedback van sensitieve rolmodellen, momenten van persoonlijke aandacht, een omgeving die dermate veilig is dat men zich kwetsbaar durft op te stellen, onafhankelijke intervisiemomenten binnen de afdeling, en een communicatiebewuste werkcultuur. Een belangrijke belemmerende factor bleek het summatief beoordelen aan de hand van checklists.

Gebrek aan structurele ondersteuning en inbedding van communicatie in de afdeling vormde de derde lacune. Onze bevinding was dat dit gebrek ook binnen de ziekenhuissetting bleek te bestaan; tevens vonden wij bevestiging van het belang van zulke structurele inbedding voor het waarborgen van ruimte en veiligheid en daarmee voor het vergroten van het leerrendement. De vierde lacune betrof voorts de subjectieve of onjuiste toetsing van communicatie door een te geringe inachtneming van context. In onze studies werd dit verder geconcretiseerd door de constatering dat de subjectiviteit of onjuistheid onder meer veroorzaakt werd doordat checklists de non-verbale aspecten van communicatie niet meenamen. Bijgevolg was dat het gebruik van deze zogeheten checklists een reductionistisch effect had. Daarnaast bleek ook dat het summatieve karakter van toetsing onecht gedrag in de hand werkte, i.e. gedrag dat enkel en alleen vertoond werd om de toets te halen.

Tot slot haakt dit proefschrift in op een vijfde lacune die zich kenmerkt door een behoefte aan meer verklarend onderzoek en conceptuele modellen. Ons vijf-fasen model conceptualiseert het communicatieleerproces en laat zien dat het veel genuanceerder is en om meer draait dan enkel om het geven en ontvangen van feedback. Wil men dat het leerproces zodanig effectief benut wordt dat het de beoogde gedragsveranderingen tot gevolg heeft, dan dient lerende zich bewust te worden van een blinde vlek, hierop te reflecteren opdat het zelfinzicht vergroot wordt en dient hij of zij het gevonden alternatieve gedrag in een veilige omgeving uit te proberen en te oefenen in de praktijk van alledag totdat er sprake is van personalisering en uiteindelijk internalisering.

Het tweede gedeelte van de discussie bespreekt verbetersuggesties op afdelingsniveau. Alle AIOS in onze studies waren het ermee eens dat voldoende ruimte voor en ondersteuning bij reflectie op communicatieaangelegenheden van essentieel belang was voor hun verdere persoonlijke en professionele ontwikkeling. Structurele intervisie binnen de afdeling bleek een geschikte manier om deze gewenste ruimte en ondersteuning te bieden.

Daarnaast moedigen wij onderwijsontwikkelaars aan om communicatieonderwijs meer te gaan beschouwen als vorm van levenslange persoonlijke ontwikkeling. Deze zienswijze impliceert dat communicatie meer behelst dan enkel gedragingen of vaardigheden. Dit impliceert ook dat medische werk- en leeromgevingen aangepast moeten worden om dit persoonlijk leerproces mogelijk te maken. Zoals gezegd kan structurele intervisie hulp bieden, mits de volgende vier punten daarbij in acht worden genomen: 1) Zorg dat de intervisie goedkeuring krijgt van en ondersteund wordt door alle leden van de afdeling, 2) Maak gebruik van echte, authentieke confrontaties die de deelne- 
mers zelf inbrengen, 3) Maak deze intervisiemomenten niet verplicht, en tot slot 4) Maak gebruik van een onafhankelijke, ervaren persoon die de intervisie begeleidt en daarmee het gevoel van veiligheid vergoot.

Tot slot dienen de voordelen die te verwachten zijn van structurele invoering van intervisie voor AIOS vanzelfsprekend verder onderzocht te worden. Vooralsnog kan in ieder geval gesteld worden dat de huidige aanpak niet afdoende werkt en geld inefficient wordt besteed: huidige kostbare communciatietrainingsvormen leiden niet tot gewenste permanente resultaten, en de gevolgen van slechte arts-patient communicatie zijn letterlijk en figuurlijk kostbaar. Hierdoor kunnen we ons niet veroorloven om niets te doen. 



\section{Valorisation}



This valorization chapter provides directions for creating value from the research work reported in this thesis.

The point of departure of this thesis is the global concern about poor doctorpatient communication, despite ample educational efforts. Much effort and finances are invested in communication skills training in medical schools around the world with only marginal effects on clinical communication in daily practice [1-4]. A majority of patients' complaints about health care still addresses poor communication skills [5] such as poor explanation, misunderstanding or no understanding at all, and - consequently - suboptimal cooperation by the patient in the management of their disease or their life-style [6]. In other words, poor doctor-patient communication is linked to considerable loss of well-being, decreased satisfaction and decreased adherence to treatment plans and medication [7-11], and increased financial costs [12].

The approach to this problem so far has been to increase the amount of training, despite considerable evidence that this does not solve the issue [3].

In this thesis we address the problem from an educational view-point. Do the current forms of training establish enough transfer of learned skills from training to daily practice? And if not so, can we find evidence for recommendations that would likely lead to more effective forms of training and learning? When stating "more effective", we mean leading to lasting behavioral change at the work floor.

The value of this thesis is in the answers to these questions. We claim that we have found evidence for a more effective type of education, more awareness and better integration of doctor-patient communication in the daily work of the busy physician. The knowledge presented in the four studies of this thesis can serve as the basis for the development of guidelines for medical educators and policy makers to improve learning and working climates within medical departments to better support communication learning processes.

The research value of this thesis is captured by relating our main findings to five gaps in existing research. We refer to section 2 of chapter 6 for a more detailed description of the five gaps and how our results contribute to a reduction in each of the gaps.

The innovative value of this thesis is captured in our five-phase model (see table 1) which contributes to a current central theme in the field of communication skills learning and teaching by showing what process is needed to increase effectiveness and transfer of postgraduate communication skills teaching. Effective learning (or transfer to the medical workplace) of communication does not automatically ensue from communication skills training, especially not so when training is decontextualized or offered off-site. Instead, the results in this thesis might trigger medical educators and policy makers to start realizing that the communication learning process entails these five phases and can only occur successfully if the learner experiences enough emotional and cognitive space and safety, the two main conditions for learning mentioned in our 
model. Only then will the learner feel safe enough to be confronted with his or her behaviour and allow reflection on it to become conscious of a blind spot, then try out and practice alternative behavior safely in practice, and personalize and internalize it to become fully integrated. We have found clear indications (provided by the stakeholders themselves) that such a type of 'education' is much more likely to lead to a lasting effect instead of or when combined with the current practice of isolated onetime training.

Table 1: The five phases and two overall conditions in residents' learning process of communication skills.

\begin{tabular}{lllll}
\hline \multicolumn{4}{c}{ COGNITIVE AND EMOTIONAL SPACE } \\
\hline $\begin{array}{l}\text { Phase 1 } \\
\begin{array}{l}\text { Confrontation with } \\
\text { the effect of a } \\
\text { certain behavior }\end{array}\end{array}$ & $\begin{array}{l}\text { Phase 2 } \\
\text { Becoming conscious } \\
\text { of own behavior }\end{array}$ & $\begin{array}{l}\text { Phase 3 } \\
\text { Searching for } \\
\text { alternative behavior }\end{array}$ & $\begin{array}{l}\text { Phase 4 } \\
\text { Personalization new behavior }\end{array}$ & $\begin{array}{l}\text { Internalization and } \\
\text { clinical integration }\end{array}$ \\
\hline \multicolumn{4}{c}{ SAFETY } \\
\hline
\end{tabular}

We hope that this dissertation will contribute to a shift in the way communication learning is envisioned. A shift toward viewing it more as a holistic and personal lifelong process of learning whereby medical work and learning environments can and should be adjusted accordingly to foster this learning process. The conception that learning is equivalent to lifelong personal development has important implications for practice and for the established model of competency-based education. Within hospitals and departments this paradigm shift entails a move toward a medical working culture in which it becomes normal to talk about how the profession affects you as a person and in which colleagues emotionally support each other more openly when needed. In this sense, professional medical associations and medical institutions carry the obligation to create better working conditions and provide programs that support such personal reflection and self-care.

On a practical level this support can be translated by implementing integrated peer sessions at departmental level to enable residents to pay continuous attention to their communication. These sessions offer space and support to discuss communication/emotional issues, such that doctors or residents feel less solitary and have the possibility to ask for tips or support when needed. These sessions can provide a safe and nurturing environment within a department, which is needed to truly perform all 5 phases of the communication learning process.

In other words, this thesis suggests supplementing competency-based education programs with structured time for residents to pay attention to communication issues and the deeper levels of learning as part of their personal and professional development, instead of focusing on isolated training programs and lists of rules and behaviors to capture the CanMEDS competency of communication skills. 
This thesis offers four practical points of attention to take into account when departments consider implementing such integrated peer sessions. First of all, the implementation should be embedded and supported by all staff members in the department. Only then will residents feel safe enough to open up and use confrontations as an incentive to learning.

Second, we suggest making use of real/authentic confrontations or clinical situations brought forward by the participants themselves. This allows learning of communication to become integrated with the daily medical work context, and the learning process becomes learner-centered and experiential (what does this specific resident need at this moment in time to develop into a skilled communicator). Learnercenteredness is necessary to enable personalization and internalization of new behavior. In case a resident lacks specific confrontations to initiate his or her learning process, collecting feedback from real patients (or colleagues, or nurses) can be powerful because of its authenticity. Another suggestion is to install video cameras in one or more consulting rooms within the department to be able to make recordings of real patient consultations. These video recordings are another effective form of authentic material to be used as input during the peer sessions to enhance reflective practice.

A third implementation point is to avoid making these sessions compulsory. Learning through coercion does not work as effectively as learning through intrinsic motivation [13]. We have found that intrinsic motivation is unmistaken present amongst learners in all specialties we studied. A remark frequently made by our respondents was that the obligatory (and reductionist) character of their current training actually counteracted their intrinsic motivation, especially when enforced by poor role-models.

A fourth implementation point to consider is to have the peer sessions guided by an independent person who has experience in supervising communication and socioemotional issues. A positive corollary to this solution is that such a person is not part of the hierarchical system and does not need to assess residents' general performance. This adds to the perceived safety of such peer sessions.

Another point of practical value rising from this thesis is to reconsider the use of behavioral checklists in the assessment of communication skills. When used in a strict way, these checklists are reductionist to the extent that they do not take proper account of the hidden aspects of communication and the context in which the communication occurs. We therefore suggest using these checklists not as a goal in itself, but only as a supporting tool to help assessors give words to behavioral aspects of the communication process they are assessing. On top of this, assessors should keep in mind the purpose of the consultation as well as the overall perceived feeling of usefulness of the communication within the consultation. In this way the non-visible aspects are better represented during the assessment.

A related issue of concern is the fact that when assessment is summative, then this is felt as thwarting the learning process. Passing the assessment then easily becomes a goal in itself rather than an instrument for skills improvement. Summative assessment fuels to display unauthentic communication behavior, only to pass the assessment. To 
make doctors less skeptic about communication skills training and assessment, we suggest replacing summative assessment of communication skills by formative assessment focused on concrete feedback and driven by personal learning goals. Such type of formative assessment would better emphasize the supportive character which residents in our study preferred communication learning and assessment to be.

A final added value or issue of concern raised in this thesis is the proposition that the five phases possibly also apply to the acquisition of other CanMEDS competencies, such as professional behavior or collaboration [14]. If future research indeed shows that the learning process for the other CanMeds competencies resembles the learning process we found for communication, then this might have further implications for postgraduate continuous education.

In sum, this thesis offers evidence-based guidelines for a more promising approach to addressing postgraduate doctor patient communication. Whether the promises actually come true is a matter of large-scale implementation and more research. As yet we can be certain that the current approach does not work sufficiently. In two ways money is currently wasted: the current training of doctor-patient communication in health care practice does not lead to the desired effects and the effects of current poor doctor patient communication are very costly. For these reasons we cannot afford not to act! 


\section{References}

van Dulmen A, Holl R. Effects of continuing pediatric education in interpersonal communication skills. Eur J Pediatr 2000;159:489-95.

Van Dulmen A \& van Weert J. Effects of gynaecological education on interpersonal communication skills. $\mathrm{Br} J$ Obstet Gynaecol 2001;108:485-91.

Hulsman R, Ros W, Winnubst J, Bensing J. Teaching clinically experienced physicians communication skills. A review of evaluation studies. Med Educ 1999;33:655-68.

Berkhof M, van Rijssen H, Schellart A, Anema J, van der Beek A. Effective training strategies for teaching communication skills to physicians: an overview of systematic reviews. Patient Educ Couns 2011;84:152-62).

Levinson W, Roter D, Mullooly J, Dull V, \& Frankel R. Physician-patient communication: the relationship with malpractice claims among primary care physicians and surgeons Jama 1997;277: 553-559.

Kurtz S, Silverman J, Draper J. Teaching and learning communication skills in medicine. Oxford: Radcliffe Pub.2005.

Epstein RM, Street Jr RL. Patient-centered communication in cancer care: promoting healing and reducing suffering. National Cancer Institute, NIH Publication 2007;07:6225.

Kaplan SH, Greenfield S, Ware J. Assessing the effects of physician-patient interactions on the outcomes of chronic disease. Med Care 1989;27:110-27.

Ong L, de Haes J, Hoos A, Lammes F. Doctor-patient communication: a review of the literature. Soc Sci Med 1995;40:903-18.

Stewart MA. Effective physician-patient communication and health outcomes: a review. Can Med Assoc J 1995;152:1423-33.

Street Jr R, Makoul G, Arora N, Epstein R. How does communication heal? Pathways linking clinician-patient communication to health outcomes. Patient Educ Couns 2009;74:295-301.

Thorne S, Bultz B, \& Baile W. Is there a cost to poor communication in cancer care? A critical review of the literature. Psycho Oncology 2005;14:875-884.

Ryan R, \& Deci, E. Self-determination theory and the facilitation of intrinsic motivation, social development, and well-being. American psychologist 2000;55:68.

Frank J, Snell L, Cate O, Holmboe E, Carraccio C, Swing S, \& Harris K. Competency-based medical education: theory to practice. Med Teach 2010;32:638-645. 

Dankwoord 

De keuze was gemaakt, we zouden naar Saudie Arabië gaan om daar Mohi Magzoub te helpen met het opzetten van een medisch onderwijsdepartement en invoering van probleemgestuurd onderwijs. Ik herinner me nog levendig de gesprekken met Jan, met Cees, met Erik, met Geraldine, Marijke, Alice, als voorbereiding op onze reis en het werk aldaar. Bepakt en bezakt met powerpoint presentaties over de Rationale of PBL en stapels boekjes over vaardigheidsonderwijs en een abaya vertrokken we. Tijdens ons verblijf schreef ik regelmatig berichtjes over onze ervaringen op een blog. Op deze manier hielden we contact en konden we letterlijk en figuurlijk een tipje van de Islamitische sluier oplichten. Jullie openheid en enorme bereidheid om ervaring en kennis te delen, vond en vind ik erg kenmerkend. Toen, eenmaal terug in Nederland, de mogelijkheid zich aandiende om vanuit het Skillslab mee te helpen met het opzetten en inrichten van een communicatietrainingsaanbod voor de medische vervolgopleidingen, was de beslissing gauw gemaakt en kwam ik op sollicitatiegesprek. Samen met Cees en Albert werd besloten de helft van mijn werktijd te besteden aan een promotieonderzoek. Deze kruisbestuiving tussen praktijk en wetenschap heb ik altijd ervaren als een zeer vruchtbare combinatie.

De samenwerking met eenieder van jullie voelt open, gelijkwaardig, organisch, en (meestal ;-)) constructivistisch. Zelfs de zoektocht in mijn promotietraject: ...hoe irritant ik het tegenwicht vond dat jullie in het begin boden om mijn (idealisme en wereld verbeterende) ambities te temperen om internationaal onderzoek te willen verrichten (:) ;),... terugkijkend is het promotietraject precies gelopen zoals het moest lopen en zijn de inzichten en resultaten uit onze studies heel logisch en natuurlijk tot stand gekomen. Kortom als voorstanders van constructivistisch leren was het best wel "practice what we preach". Dankjewel voor deze begeleiding en voor jullie altijd snelle reacties.

Albert, dankjewel voor je vrolijke kordaatheid, je scherpzinnigheid en je sensitiviteit om soms ook persoonlijke punten van aandacht op te merken.

Cees, dankjewel voor je "begeisterung" als het gaat om onderzoek. Onze bijeenkomsten vond ik inspirerend omdat je in een paar woorden of zinnen meestal de kern te pakken had. Ik kreeg veel zelfvertrouwen als onderzoeker door te merken dat onze gedachtegang vaak op eenzelfde lijn zat en door de vrijheid die jij en Albert me gaven. Hierdoor, en door jullie aanmoediging om te gaan voor wat mijzelf inspireerde en fascineerde, is het daadwerkelijk een spannende en mooie "onder-zoek-tocht" geworden!

Sandra, het was wel en geen toeval dat ik je tegenkwam en vervolgens vroeg om mijn onderzoeksteam te versterken met jouw enorme onderzoekservaring op het gebied van arts-patiënt communicatie. Inhoudelijk vormde jij de perfecte aanvulling die nodig was, en dat vertaalde zich altijd in gedegen commentaar en feedback waar ik veel van geleerd heb, dankjewel!

Jan, je bent een prachtexemplaar als mens en als co-promotor! Je gaf me alle ruimte, maar was er ook als ik je nodig had. Da's ook een kunst op zich $(-)$. Ik heb oprecht veel 
van je geleerd de afgelopen jaren. Ik zie ons nog zitten in je Volvo, terugrijdend van onze werkreis naar Italië, hardop samen meezingend met de radio! Je hebt me ingewerkt op het Skillslab en in de materie van communicatieonderwijs op een manier die voelt als "natuurlijk leren". Ik hoop dat de "transfer ;-)“ daarvan zijn vruchten af zal werpen als ik straks jouw taken verder mag overnemen op het Skillslab. Dankjewel voor je vertrouwen daarin!

Maarten, ik wil je allereerst bedanken voor de manier waarop jij het Skillslab leidt: veel van de uitkomsten uit mijn onderzoek naar wat nu werkelijk belangrijk is als je mensen wilt laten leren en transformeren, belichaam jij. En oh hoe kon ik jou (juist jou) nu vergeten in de acknowledgement van ons tweede artikel voor je rol als moderator??!! Je hebt me vaak genoeg impliciet en expliciet gevoed en geïnspireerd door je opmerkingen en ik vind het echt jammer dat je je pensioengerechtigde leeftijd bereikt en gaat stoppen bij het Skillslab. Ik heb me vanaf het begin gezien gevoeld door jou, dat is een groot goed, oprecht dankjewel daarvoor!

Marleen Gulikers, jij was mijn aanspreekpunt 7 jaar geleden toen de opzet van het discipline overstijgend onderwijs voor de vervolgopleiding in het AZM nog helemaal vorm moest krijgen. Er is veel gebeurd "along the way" en zeker nog een wereld te winnen, ik zal proberen daaraan te blijven bijdragen. Dankjewel voor de interesse die je toonde in Erin en Quinten. Suzanne Geuskens, tanx voor je opgewekte en stevige ondersteuning in de logistiek van alle trainingen.

Zeker ook dankjewel aan alle AIOS die hebben deelgenomen aan de verschillende studies in dit proefschrift. Jullie openheid heeft ertoe geleid dat we zulke rijke data konden verzamelen. En een duidelijke dank naar iedereen binnen HAG die qua ondersteuning hieraan heeft bijgedragen: Bas Maiburg, Jean Muris, Stijn de Vries, Kirsten Ritter, Alexandra van Lieshout,...

Heleen Staal en Lodewijk van Rhijn dankjewel voor jullie pioniersrol om communicatie structureel onder de aandacht te brengen binnen jullie afdeling Orthopedie.

Dewa Westerman, dankjewel voor je stoutMOEDIGE initiatief om intervisie voor AIOS op de kaart te zetten binnen de afdeling interne $: ;$ !

Jessica Mesman, tanx voor je visie en inspiratie met betrekking tot videoreflexiviteit en "health care improvements"!

Evelyn van Weel, dankjewel voor jouw enthousiasme en rolmodel als kartrekker van de NVMO werkgroep communicatie. Ik waardeer ons contact en neem het MIOCO-stokje met de nodige bescheidenheid (via Jan) van je over.

Ook de collega's van 0\&0, en in het bijzonder Mascha, Janneke, Jill, Herma, Mohammed en Erik,.... always a pleasure to meet and/or work with you. Lilian, dankjewel voor je 
praktische maar onmisbare hulp in de eindfase van dit proefschrift, het is altijd fijn contact hebben met jou!

Mereke en Angelique, dankje dat jullie mijn teksten zo goed konden invoelen en het Engels daardoor verbeteren.

Lieve collega's van het Skillslab, yess, mijn proefschrift is af...eindelijk meer tijd voor jullie in de koffiepauze (-)!! Dankjewel voor de kleine bemoedigingen en "ernaar informeren" in de afgelopen jaren. Ik verheug me enorm erop om na deze promotiefase weer meer/ intensiever binnen de afdeling zichtbaar te zijn door alle nieuwe taken die in het vooruitzicht liggen.

Lieve Mignon en Rina, dankjewel dat jullie altijd klaarzitten voor een luisterend oor en daardoor proberen te weten hoe het echt met iedereen gaat op onze afdeling! Ik waardeer onze gesprekjes zeer $:$.

Anke, Yvette, Emmaline en Moniek; dankjewel, omdat jullie zijn wie je bent! Jullie collegialiteit en vooral jullie vriendschap geeft superenergie! Ik geniet enorm van onze afspraakjes ook buiten werktijd om! Anke je bent voor mij meer dan de beste kamergenoot, ik word altijd blij als ik met je klets :-)! Yvette, we gaan gewoon weer op dezelfde dag werken! Emmaline, volgens mij ben jij de uitzondering op de regel die zegt dat wijsheid pas met de jaren komt ;-0! Moniek, tanx voor je stevige, veelzeggende kneepjes tussendoor :-:! Jouwert, tanx voor je "praktijkcursus" in het scheiden van zin en onzin ;-)!

Anke Smeenk, terwijl ik dit dankwoord schrijf, begin jij als de nieuwe Core-coördinator en als onze nieuwe kamergenoot...ik heb oprecht superveel zin in onze samenwerking en kijk er nu al naar uit om onze "niet lullen maar poetsen"-mentaliteit (met knipoog) in praktijk te brengen :-).

Renée Stalmeijer, (lieve Renée) jouw mix van professioneel en persoonlijke diepgang: het woord "kwalitatief" is jou eigenlijk letterlijk en figuurlijk op het lijf geschreven...tanx voor je kwalitatieve superadviezen...ik hoop dat er nog velen volgen;-).

Annelies Vossen, de kaft van dit boekje verraad hoe goed je mijn woorden en ideeën aanvoelde en invulde.

Cees Rullens en Christien Sepers, als acteur weten jullie onze trainingen als geen ander invoelbaar en authentiek te maken...tanx voor jullie acteertalent,... en voor jullie mensenkennis! Christien, een speciale tanx voor je fijne manier van sparren!

Thea, Ilse, Miem, Wendy, Simone, Marieke, jullie input tijdens de trainingen is onmisbaar. 
Mora and Astrid, you both do incredible things in Indonesia. Keep on pioneering in the field of medical health and communication. It is a pleasure and treasure for me to work with you and consider ourselves friends and colleagues.

Pal Gulbrandsen in Norway and Noel Junod Perron in Geneva... our "article-to-be" on best practices in medical communication teaching is a living example of how universal human needs in communication are! I am looking forward to work it out!

Otto Scharmer, Ben Willems, Marieke Terpstra, Marian Zuijdam, Erik Heineman, Hein Dijksterhuis en Bram Tjaden voor mij zijn jullie inspirerende professionals (of bevlogen enthousiastelingen): door jullie open blik en brede kijk op gezondheid, leren en veranderingsprocessen zijn jullie pioniers en voeding voor mijn mind. Waar een wil is, is een weg $(;$.

Bandito Espresso, tanx voor jullie versgemaakte soep...je bent wat je eet!

Sarah, Keetie, en Marian, aanzienlijke landsgrenzen tussen ons, maar uit het oog is zeker niet uit het hart!

Lieve Sherpa's, volgens mij hebben onze vele hike- en campeer-avonturen onbewust de "geef niet op"- mentaliteit gevoed. Wanneer trekken we onze bergschoenen en rugzak weer aan om "Sweet child oh mine" te zingen rond 't kampvuur?

De kleuren, ...inmiddels families zwart, bruin, rood en wit; oftewel lieve Jordi en Lotte, Jacques en Bernadette, Martijn en Elke...laten we onze oudejaarsavond-traditie nog vele jaren in ere houden!...en weer gaan picknicken met al onze kids als iedereen gesetteld is in zijn nieuwe huis $(-)$.

Leeve buren oet de Wilhelminasjtroat, danke dat ger us metein 'n toesgeveul hebt gegeven! Ut makt ut woenen extra riek.

Joyce, wie had dat ooit gedacht toen we tussen ons $12^{\mathrm{e}}$ en $17^{\mathrm{e}}$ als beste vriendinnen samen ieder dag braaf naar de middelbare school in België fietsten, dat we nu in hetzelfde dorp zouden wonen na al onze omzwervingen. Ik proost op nog heel veel koppen thee, glaasjes wijn, en etentjes samen, zeker ook met Claire erbij!

Dankjewel lieve meiden, en in het bijzonder Lenneke en Desiree, voor de onmisbare "mental and physical activity" op de dinsdagavond. Namaste!

Myrtho, weet je nog dat ik mijn Masterscriptie inleverde (samen met Charlotte) en jij op de gang stond te wachten om dat moment samen te vieren...en nu zijn we alweer 14 jaar verder,... van samenwonen op de Brusselseweg tot het doen van allebei mijn bevallingen. "Drukbezette en toegewijde moeders" dat we zijn, daardoor zien we elkaar lang 
niet zo vaak als dat we zouden willen...maar ook dat wordt vanzelf beter $(-)$.We gaan sowieso ieder half jaar voor "Porientieff";-).

Juud, wat ben ik blij dat onze husbands al zo lang best friends zijn, en wij daardoor in elkaars leven kwamen $:$...ik hoop dat je niet meer uit mijn leven gaat! Ik koester de lichtheid en vrolijkheid in onze vriendschap en voel me gezien door jou, dankjewel daarvoor! Je voelt als paranimf (met vleugels en humor) ook buiten de verdediging ;-).

Reinoek, alsof we elkaar al jaren kenden toen we voor het eerst tegen elkaar aanliepen op de trappen van het introductiecollege psychologie in Nijmegen. Een heel bijzondere tijd, vooral het samenwonen op de Ubbergse Holleweg. Het kan geen toeval zijn, hoe we ons soms verwonderen over dezelfde persoonlijke ontdekkingen die we opdoen. Hoe cool is het dat we onze bevlogenheid nu beiden kwijt kunnen in onderwijsvernieuwing! ...dus mijn paranimf, same spirit....woonden we maar wat dichter bij elkaar!!!

Jules en Veronique, Robert en Inge, ...dankjewel dat we elkaar wekelijks zien en zo elkaars leven meekrijgen en meemaken, daar zijn we (schoon)broers en schoonzussen voor... samen met ons klein grut Isa, Erin, Jorg, Quinten en Olivier als groot geluk... ...Lieve "Gulio" dankjewel voor de liedjes die je soms stuurde, al kletsen we elkaar niet de oren van het hoofd, we weten dat we er voor elkaar zijn als het nodig is $(\dot{)}$ !

Lieve Sje, leeve sjoenmam...dankje zoveel voor al je praktische hulp, de oma die je bent voor onze kinderen, je luisterende oor, en het strijken van Dominique's overhemden... ik vind je een mooi mens, love you!

Lieve Papa en Mama, jullie zijn de basis van dit alles. Door wie jullie zijn en wat jullie mij hebben meegegeven als persoon. Dankjewel voor Alles (met een grote "A"): ...voor jullie liefde, steun, bezorgdheid en medeleven, voor de opa en oma die jullie zijn. Papa door jouw levensmotto "maak van je werk je hobby", heb ik inmiddels gelukkig mijn eigen vorm daarin gevonden:"I try to put my heart in everything I do". Mama jouw zorgzaamheid is grenzeloos. Ik hou van jullie!

Dominique, lieve schat, op ons $16^{\text {de }}$ zei jij tegen me " Doe iets met je gevoel voor taal, mensen en creativiteit en ga kinderboeken schrijven!"...laten we zeggen dat dit boekje een eerste poging is ;-)! Terugblikkend op de pieken en dalen die we al hebben meegemaakt: Niet alleen "geografische" van Mesch en Eijsden via Nijmegen, Sudan, het midden Oosten, de Himalaya, en alle cols op de wielrenfiets naar ons thuis op nummertje $44 \ldots$ als we het dan toch over persoonlijke ontwikkeling hebben als een rode draad in dit proefschrift: dankjewel dat wij ervoor gekozen hebben om dit leven met elkaar te delen, en elkaar te verrijken juist door onze verscheidenheid in wie we zijn als persoon!

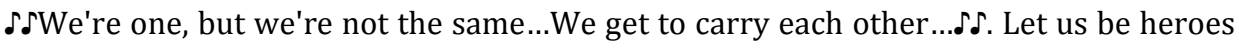
not just for 1 day $\delta \delta$ and go for big $\mathrm{L} ;-$ )! 
Erin en Quinten: mijn twee lieverds...sinds jullie er zijn ziet de wereld er nog mooier uit. Ik wens jullie vanuit m'n moederhart toe dat jullie jezelf kunnen zijn en vooral blijven. Vergeet niet dat je je dromen zelf kunt toveren als je betoverd blijft door het leven. Ik voel me rijk en immens dankbaar met jullie om me heen!!!... love you to the moon and back, voor altijd! 


\section{About the author}



Valerie van den Eertwegh was born on September 23rd 1978 in Eindhoven. She attended VWO at the Provinciale Secundaire School in Voeren, Belgium. From 1996 2001 she studied International business studies, with a master in organization and change management at Maastricht University. During her studies she lived and studied in Grenoble (France) for 9 months as an exchange student. Additionally in her final year, she was board member of Unipartners and responsible for human resource development.

After graduating (cum laude) she moved to Nijmegen to obtain a bachelor in Psychology at Radboud University and worked at the department of human resources of Lincoln Smitwelt to help set up a change process in communication among employees. In 2004 she went to Indonesia for 5 months to travel and work as a volunteer at a local primary school in Java.

From 2005 - 2006 she moved as expat to Saudi Arabia together with her partner Dominique. Their job was to train teachers in Problem-Based Learning at a newly established medical college in Riyadh. Back in the Netherlands she lived for 2 more years in Nijmegen and worked at Osmose, a training and consultancy firm specialized in education and intercultural communication.

In 2009 she started to work for the Skillslab at the Faculty of Health, Medicine and Life Science at Maastricht University. Parallel to her PhD program, Valerie works as coordinator to set up effective communication programs at postgraduate (inter- and intradepartmental) level and is involved in the undergraduate communication program. She also contributes to faculty development and chairs the NVMO taskforce on medical communication, a national taskforce connecting communication educationalists of the medical universities in the Netherlands and Belgium. She is interested in creativity and new perspectives on health and education. She likes to work across diverse cultural and disciplinary lines and collaborate with international colleagues in the field.

She is married to Dominique and they have two beautiful children Erin and Quinten. 

She Dissertations 

The SHE Dissertation Series publishes dissertations of PhD candidates from the School of Health Professions Education (SHE) who defended their PhD theses at Maastricht University. www.maastrichtuniversity.nl/she.The most recent ones are listed below.

Gingerich, A. (03-09-2015) Questioning the rater idiosyncrasy explanation for error variance, by searching for multiple signals within the noise

Goldszmidt, M. (02.09.2016) Communication and reasoning on clinical teaching teams, the genres that shape care and education

Slootweg, I. (19.06.2015) Teamwork of Clinical Teachers in Postgraduate Medical Training

Al-Eraky, M. (21.05.15) Faculty development for medical professionalism in an Arabian context

Wearne, S. (08.04.2015) Is it remotely possible? Remote supervision of general practice registrars

Embo, M. (13.03.2015) Integrating workplace learning, assessment and supervision in health care education

Zwanikken, P. (23.01.2015) Public health and international health educational programmes for low- and middle-income countries: questioning their outcomes and impact

Hill, E. (11-12-2014) A cutting culture: gender and identification in the figured world of surgery

Diemers, A. (03-10-2014) Learning from pre-clinical patient contacts

Tjiam, I. (17-09.2014) Learning in Urology. Designing simulator based skills Training \& Assessment

Berkenbosch, L. (30-06-2014) Management and leadership education for medical residents

Bergman, E.M. (30-06-2014) Dissecting anatomy education in the medical curriculum

Dijkstra, J. (25-06-2014) Guidelines for designing programmes of assessment

Van Loon, M.H. (08-05-2014) Fostering monitoring and regulation of learning

Frambach, J.M. (26-03-2014) The cultural complexity of problem-based learning across the world

Hommes, J.E. (26-02-2014) How relations, time \& size matter in medical education

Van der Zwet, J. (30-01-2014) Identity, Interaction and Power. Explaining the affordances of doctor-student interaction during clerkships

Watling, C.J. (22-01-2014) Cognition, Culture, and Credibility. Deconstructing Feedback in Medical Education

Winston, K. (12-12-2013) Remediation Theory and Practice: Transforming At-Risk Medical Students

Kamp, R.J.A. (28-11-2013) Peer Feedback to Enhance Learning in Problem-Based Tutorial Groups

Junod Perron, N. (24-10-2013) Towards a learner-centered approach to postgraduate communications skills teaching

Pratidina Susilo, A. (24-10-2013) Learning to be the Patient Advocate The Development of a Communication Skills Course to Enhance Nurses' Contribution to the Informed Consent Process

Alves de Lima, A. (23-10-2013) Assessment of clinical competence: Reliability, Validity, Feasibility and Educational Impact of the mini-CEX

Sibbald, M. (09-10-2013) Is that your final answer? How doctors should check decisions

Ladhani, Z. (05-07-2013) Competency based education and professional competencies: a study of institutional structures, perspectives and practices in Pakistan 
Jippes, M. (01-02-2013) Culture matters in medical schools: How values shape a successful curriculum change

Duvivier, R. J. (12-12-2012) Teaching and Learning Clinical Skills. Mastering the Art of Medicine

De Feijter, J.M. (09-11-2012) Learning from error to improve patient safety

Prescott, L. (09-11-2012) Ensuring the Competence of Dental Practitioners through the Development of a Workplace-Based System of Assessment

Cilliers, F.J. (05-09-2012) The Pre-assessment Learning Effects of Consequential Assessment: Modelling how the Examination Game is Played

Spanjers, I. A.E. (05-07-2012) Segmentation of Animations: Explaining the Effects on the Learning Process and Learning Outcomes

Al-Kadri, H.M.F. (28-06-2012) Does Assessment Drive Students' Learning?

Leppink, J. (20-06-2012) Propositional manipulation for conceptual understanding of statistics

Van Zundert, M.J. (04-05-2012) Conditions of Peer Assessment for Complex Learning

Claramita, M. (30-03-2012) Doctor-patient communication in a culturally hierarchical context of Southeast Asia: A partnership approach

Kleijnen, J.C.B.M. (21-03-2012) Internal quality management and organizational values in higher education

Persoon, M.C. (19-01-2012) Learning in Urology; The influence of simulators and human factors

Pawlikowska, T.R.B. (21-12-2011) Patient Enablement; A Living Dialogue

Sok Ying Liaw, (14-12-2011) Rescuing A Patient In Deteriorating Situations (RAPIDS): A programmatic approach in developing and evaluating a simulation-based educational program

Singaram, V.S. (7-12-2011) Exploring the Impact of Diversity Factors on Problem-Based Collaborative Learning

Balslev, T. (24-11-2011) Learning to diagnose using patient video cases in paediatrics: Perceptive and cognitive processes

Widyandana, D. (19-10-2011) Integrating Pre-clinical skills training in skills laboratory and primary health care centers to prepare medical students for their clerkships

Durning, S.J. (09-09-2011) Exploring the Influence of Contextual Factors of the Clinical Encounter on Clinical Reasoning Success (Unravelling context specificity)

Govaerts, M.J.B. (08-09-2011) Climbing the Pyramid;Towards Understanding Performance Assessment

Stalmeijer, R. E. (07-07-2011) Evaluating Clinical Teaching through Cognitive Apprenticeship

Malling, B.V.G. (01-07-2011) Managing word-based postgraduate medical education in clinical departments

Veldhuijzen, J.W. (17-06-2011) Challenging the patient-centred paradigm: designing feasible guidelines for doctor patient communication

Van Blankenstein, F. (18-05-2011) Elaboration during problem-based, small group discussion: A new approach to study collaborative learning

Van Mook, W. (13-05-2011) Teaching and assessment of professional behavior: Rhetoric and reality. 
